POEF-2086

ORNL/TM-11988

\section{OAK RIDGE \\ NATIONAL \\ LABORATORY}

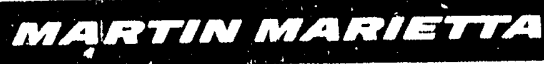

Investigation of Breached Depleted $\mathrm{UF}_{6}$ Cylinders

J. H. DeVan

J. M. Googin

M. S. Taylor

R. H. Dyer

J.R. Russell 
This report has been reproduced directly from the best avallable copy.

Avallable to DOE and DOE contractors from the Office of Scientific and Technical Irformation, P.O. Box 62, Oak Ridge, TN 37831; prices available from (615) 576-8401, FTS 626-8401.

Available to the public from the National Technical Information Service, U.S. Department of Commerce, 5285 Port Royal Rd., Springfield, VA 22161.

This report was prepared as an account of work sponsored by an agency of the United States Government. Neither the United States Government nor any agency thereof, nor any of their employees, makes any warranty, express or implied, or assumes ar f legal liability or responsibility for the accuracy, complefoness, or usefulness of any information, apparatus, product, or process disclosed, or represents that its use would not infringe privately owned rights. Reference herein to any specific commercial product, process, or service by trade name, trademark, manufacturer, or otherwise, does not necessarily constitute or imply its endorsement, recommendation, or favoring by the United States Government or any agency thereof. The views and opinions of authors expressed herein do not necessarily state or reflect those of the United States Government or any agency thereof. 
ORNL/TM- -11988

DE92 007790

\title{
INVESTIGATION OF BREACHED DEPLETED UF 6 CYLINDERS
}

\author{
E. J. Barber, T. R. Butler, J. H. DeVan, J. M. Googin, M. S. Taylor,
}

R. H. Dyer, and J. R. Russell

Date Published: September 1991

Prepared for the

DOE Office of Nuclear Energy

CD1001226

Prepared by the

OAK RIDGE NATIONAL LABORATORY

and

URANIUM ENRICHMENT

Oak Ridge, Tennessee 37831-6285

managed by

MARTIN MARIETTA ENERGY SYSTEMS, INC.

for the

U.S. DEPARTMENT OF ENERGY

under contract DE-ACO5-84OR21400 and

DE-AC05-76OR00001 


\section{CONTENTS}

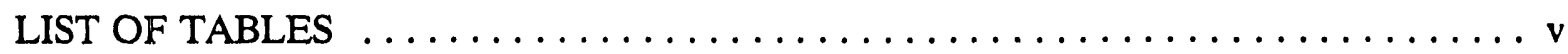

LIST OF FIGURES $\ldots \ldots \ldots \ldots \ldots \ldots \ldots \ldots \ldots \ldots \ldots \ldots \ldots \ldots \ldots \ldots$

EXECUTTVE SUMMARY $\ldots \ldots \ldots \ldots \ldots \ldots \ldots \ldots \ldots \ldots \ldots \ldots \ldots \ldots \ldots$

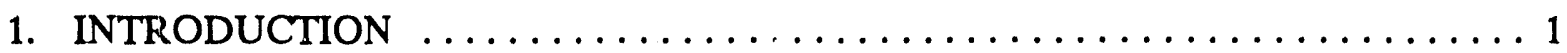

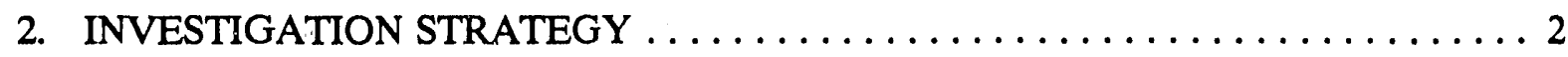

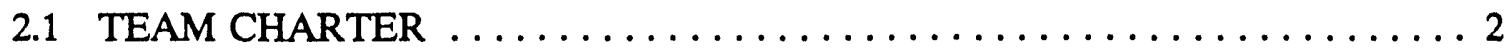

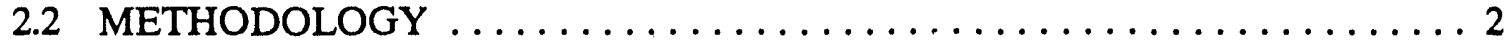

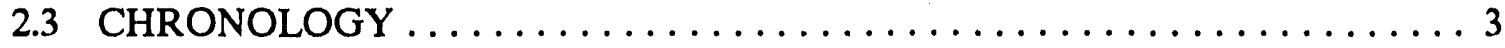

3. ANALYSIS OF FAILURE CAUSE AND CHEMICAL EFFECTS $\ldots \ldots \ldots \ldots$

3.1 LOCATIONS AND HISTORIES OF FAILED CYLINDERS $\ldots \ldots \ldots \ldots \ldots 4$

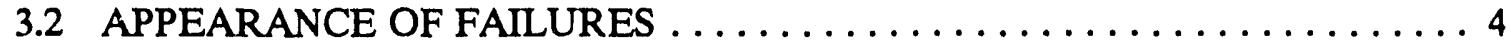

3.3 CONDITION OF NEIGHBORING CYLINDERS $\ldots \ldots \ldots \ldots \ldots \ldots \ldots \ldots 4$

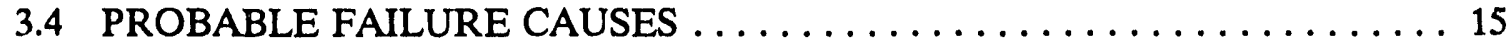

3.5 CHEMICAL PROCESSES LEADING TO GROWTH OF

HOLES AND FORMATION OF PLUG $\ldots \ldots \ldots \ldots \ldots \ldots \ldots \ldots$

4. ASSESSMENT OF ENVIRONMENTAL IMPACT $\ldots \ldots \ldots \ldots \ldots \ldots \ldots \ldots$

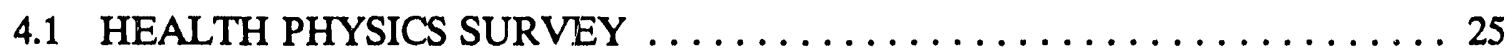

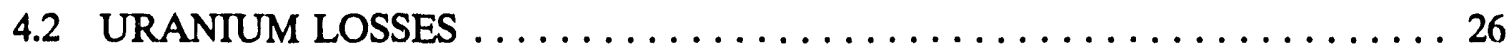

4.3 PRESENT AND FUTURE ENVIRONMENTAL IMPACT $\ldots \ldots \ldots \ldots \ldots 26$

4.4 STORAGE PAD DESIGN IMPLICATIONS $\ldots \ldots \ldots \ldots \ldots \ldots \ldots \ldots \ldots$

5. STORAGE YARDS SURVEY ..................... 27

6. IMPLICATIONS OF FAILURES ON PRESENT STORAGE POLICIES $\ldots \ldots \ldots 30$

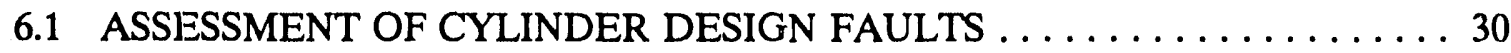

6.2 POTENTIAL EXISTENCE OF ADDITIONAL FAILED CYLINDERS $\ldots \ldots 31$

6.3 POTENTIAL EFFECTS OF FAILURES ON INTEGRITY OF

NIEIGHBORING CYLINDERS . . . . . . . . . . . . . . . 31

6.4 GENERAL ASSESSMENT OF CYLINDER INTEGRITY FOR LONG

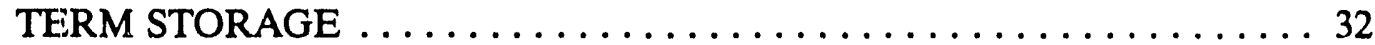

7. ADDITIONAL ACTIONS REQUIRED TO COMPLETE INVESTIGATION $\ldots 32$

8. CONCLUSIONS $\ldots \ldots \ldots \ldots \ldots \ldots \ldots \ldots \ldots \ldots \ldots \ldots \ldots \ldots \ldots \ldots \ldots \ldots$

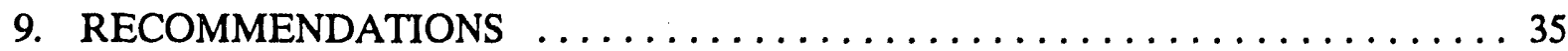




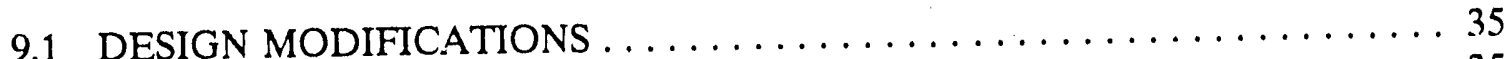

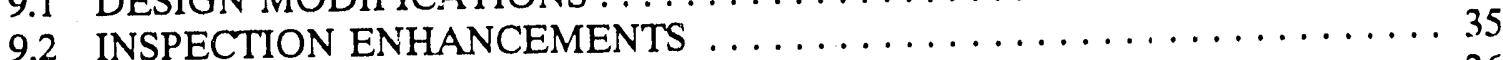

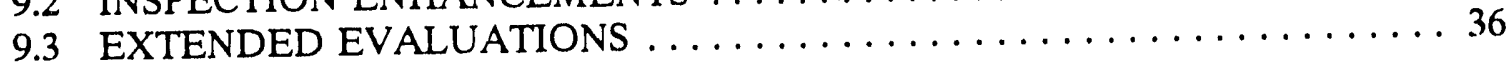

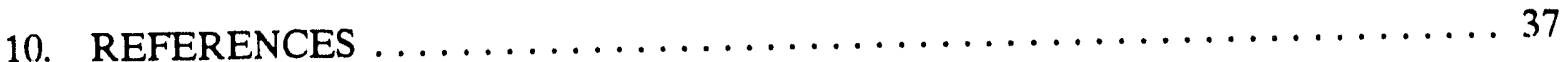

APPENDIX A: BREACHED CYLINDERS DESIGN SPECIFICATIONS, CONTENTS, AND STORAGE LOCATIONS ........... 39

APPENDIX B: DETAILED FINDINGS AND ANALYSES $\ldots \ldots \ldots \ldots \ldots \ldots \ldots 41$

PART 1: OBSERVATIONS AND ANALYSES OF THE VAPOR SPACE CONTENTS AND CORROSION DEPOSITS

PART 2: CHEMICAL ASPECTS OF CORROSION OF BREACHED $\mathrm{UF}_{6}$ CYLINDERS $\ldots \ldots \ldots \ldots \ldots \ldots \ldots \ldots \ldots$

PART 3: CHEMICAL ASPECTS OF CYLINDER CORROSION AND A SCENARIO FOR HOLE FORMATION . . . . . 95

PART 4: A LIST OF REPORTS . . . . . . . . . . . . . . . 129

APPENDIX C: ACTION PLANS $\ldots \ldots \ldots \ldots \ldots \ldots \ldots \ldots \ldots \ldots \ldots \ldots \ldots \ldots$ 


\section{LIST OF TABLES}

Table 1. Estimated uranium losses resulting from cylinder failures $\ldots \ldots \ldots \ldots$

Table 2. Additional actions to complete the breached cylinder investigation . . . . . . 33 


\section{LIST OF FIGURES}

Fig. 1. Schematic of the Portsmouth depleted $\mathrm{UF}_{6}$ storage area, C-lot, showing locations of failed cylinders and routes used to gain access $\ldots \ldots \ldots \ldots \ldots \ldots$

Fig. 2. Appearance of failure area in cylinder $4 \mathrm{G} 115688 \ldots \ldots \ldots \ldots \ldots \ldots \ldots$

Fig. 3. Area of failure in cylinder $4 \mathrm{G} 115688$ showing relative position of lifting

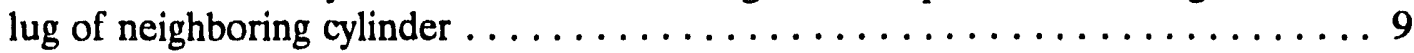

Fig. 4. Appearance of failure area on cylinder $4 \mathrm{G} 127985$ (after removal of debris covering hole) $\ldots \ldots \ldots \ldots \ldots \ldots \ldots \ldots \ldots \ldots \ldots \ldots \ldots \ldots$

Fig. 5. View of failure area after gaining access to cylinder 4 G127985 showing location of lifting lug on neighboring cylinder

Fig. 6. Appearance of wall of cylinder lying directly below cylinder $4 \mathrm{G} 115688$.

Note vein-like grooves etched into cylinder wall.

Fig. 7. Dent produced by impingement of lifting lug on cylinder 4G127985 at end opposite from failure

Fig. 8. Typical damage produced by lifting lug impingement near stiffening ring. Cylinder was located in vicinity of cylinder $4 \mathrm{G} 127985$ 


\section{EDITOR'S NOTE}

Although Oak Ridge National Laboratory has a policy of reporting its work in SI metric units, this report uses English units. The justification is that the uranium enrichment facilities at present operate completely with English units, and reporting otherwise would lose meaning to the intended readership. To assist the reader in obtaining the SI equivalents, these are listed below for the units occurring in this report.

\begin{tabular}{l|l|l}
\hline \multicolumn{1}{c|}{ Property } & Unit used & \multicolumn{1}{c}{ SI equivalent } \\
\hline Dimension & in. & $25.4 \mathrm{~mm}$ \\
Dimension & $\mathrm{ft}$ & $0.3048 \mathrm{~m}$ \\
Density & $\mathrm{lb} / \mathrm{ft}^{3}$ & $16.02 \mathrm{~kg} / \mathrm{m}^{3}$ \\
Energy & calorie & $4.184 \mathrm{~J}$ \\
Mass & $\mathrm{lb}$ & $0.4536 \mathrm{~kg}$ \\
Mass & metric ton & $1000 \mathrm{~kg}$ \\
Mass & ton & $907.2 \mathrm{~kg}$ \\
Pressure & $\mathrm{psi}$ & $6.895 \mathrm{MPa}$ \\
Pressure & torr & $133.3 \mathrm{~Pa}$ \\
Temperature & ${ }^{\circ} \mathrm{F}$ & ${ }^{\circ} \mathrm{C}=(5 / 9)\left({ }^{\circ} \mathrm{F}-32\right)$ \\
\hline
\end{tabular}




\section{INVESTIGATION OF BREACHED DEPLETED UF ${ }_{6}$ CYLINDERS}

\section{EXECUTTVE SUMMARY*}

In June 1990, during a three-site inspection of cylinders being used for long-term storage of solid depleted $\mathrm{UF}_{6}$, two 14-ton steel cylinders at Portsmouth, Ohio, were discovered with holes in the barrel section of the cylinders. Both holes, concealed by $\mathrm{UF}_{4}$ reaction products identical in color to the cylinder coating, were similarly located near the front stiffening ring. The $U_{4}$ appeared to have self-sealed the holes, thus containing nearly all of the uranium contents. Martin Marietta Energy Systems, Inc., Vice President K. W. Sommerfeld immediately formed an investigation team to: (1) identify the most likely cause of failure for the two breached cylinders, (2) determine the impact of these incidents on the three-site inventory, and (3) provide recommendations and preventive measures.

Portsmouth personnel, in association with this investigation team, made a studied effort to collect information that could be used to assess the failure mechanism and to track the effects of the failure on corrosion processes and chemical changes in the cylinder and its contents. Evidence has been gathered through the process of removing both cylinders from the storage yard, checking their internal pressure, analyzing gas and salt samples, emptying one cylinder, and sampling the internal reaction products from the other cylinder. Portsmouth Operations personnel are currently removing the contents of the second cylinder. During the investigation, considerable effort was made to estimate the uranium lost from these cylinders and the resultant environmental insult. The soil contamination was minimal (below plant-allowable limits). The unrecoverable mass of $\mathrm{UF}_{6}$ from the longer-term failure (13 years) was estimated to be between 17 and $109 \mathrm{lb}$. In the case of the shorter-term failure (4 years), the unrecovered $\mathrm{UF}_{6}$ was below measurable limits but, based on a corrosion model, possibly amounted to $4 \mathrm{lb}(1.8 \mathrm{~kg})$.

The commonality of the hole locations and the proximity of lifting lugs of adjacent cylinders suggested a similar failure initiation mode for both cylinders. From the investigation of other stacked cylinders and the evidence gathered from examinations of the failures, the team determined that the initial breach in each cylinder had resulted from a mechanical tear through the shell induced by the impingement of the upper corner of an adjacent cylinder's lifting lug. The location of the impingement point was so close to the rigid stiffening ring supporting the shell that a "guillotine" fracture resulted, rather th: $n$ a dent in the cylinder shell. Since cylinder steel types and stacking mechanisms were dissimilar, no common mode of failure could be associated with either of these factors. Following the initial mechanical failures, reaction of $\mathrm{UF}_{6}$ with air and moisture led to the formation of an acid solution containing $\mathrm{HF}$ and $\mathrm{UO}_{2} \mathrm{~F}_{2}$ and, ultimately, to a protective salt layer composed of $\mathrm{UF}_{4}$ and iron fluorides. Slow seepage of the acid solution from below the UFF layer gradually corroded and extended the hole surfaces, such that the relative sizes of the openings correlated with the total time that the respective cylinders had been exposed to the elements.

Inspections performed by qualified site personnel showed that the damaged cylinders were unusual and did not reflect a generic problem. However, circumstances contributing to the

*Research sponsored by the U.S. Department of Energy, Uranium Enrichment Program, under contract DE-AC05-76OR00001 with Martin Marietta Energy Systems, Inc. 
failures, such as insufficient spacing between adjacent cylinders and improperly oriented lifting lugs, were: common as observed during the team's three-site survey. The possibility that additional cylinders may have sustained damage by the same means, while considered quite small, cannot be completely ruled out because not all cylinders can currently be viewed in their entirety. In some yard locations at all three sites, cylinder rows are stacked too closely for a thorough visual inspection. Because of the effective plugging by the reaction products of the two exposed areas, the contamination from any unidentified cylinders damaged from the same cause should be minimal, as was the case with these two failures. Nevertheless, a concerted effort should be made to identify and empty such cylinders.

After reviewing the causes and effects of the failures, the team considers the most important remedial action to prevent similar potential failures to be improved handling and inspection. Considering the minimal environmental impact associated with the shorter-term failure (4 years), routine inspections of all stockpiled cylinders can effectively limit the impact of potential future failures by a similar cause. The team made recommendations for corrective actions in three categories: design modifications, inspection enhancements, and extended evaluations. The design modifications are intended to improve the cylinder containment integrity during the stacking operation. They include saddle, yard, and cylinder design improvements in addition to visual aids for the operator stacking the cylinders. Inspection enhancements relate to the assurance of proper stacking and continued safe storage. Supplementary mechanical testing of thin-wall storage cylinders is recommended to define their fracture characteristics near the stiffening ring weld and to guide possible design improvements. Another testing recommendation calls for a study of the long-term environmental effects of a breach occurring into the gas space within the cylinder, which may lead to different consequences from the subject failures that occurred bciow the solid $\mathrm{UF}_{6}$ level. Finally, a study is recommended to better define the environmental effects of $\mathrm{UF}_{6}$ ground spills with respect to storage pad design. 


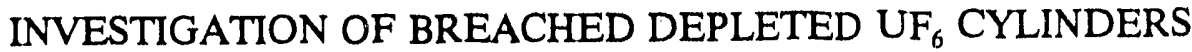

\author{
E. J. Barber, T. R. Butler, J. H. DeVan, J. M. Googin, M. S. Taylor, \\ R. H. Dyer, and J. R. Russell
}

\section{INTRODUCTION}

Depleted uranium hexafluoride $\left(\mathrm{UF}_{6}\right)$ produced at the uranium enrichment (UE) gaseous diffusion plants has been stored in steel cylinders since the diffusion plants first went into production more than 40 years ago. With no significant use relative to its current production rate, the inventory now exceeds 340,000 metric tons of depleted $U_{6}$ in approximately 40,000 cylinders. ${ }^{1}$ Once a significant invento $y$ was produced, the diffusion plants created outdoor storage facilities that evolved separately at each site and are now comprised of concrete and compacted gravel storage pads with the lowest cylinders positioned on wooden or concrete saddles. The handling equipment used to stack these cylinders in double-tiered rows has also evolved from mobile cranes hoisting the cylinders with removable bands to the Raygo Wagner loader and the Answer to Prayer (ATP) loader, specially designed tractors that grab and lift the cylinders with hydraulically actuated fingers. Paducah utilizes the ATP-designed loader, which provides improved visibility for the operator over Portsmouth's Raygo Wagner design. Although the Wagner loader allows the operator more control of the cylinder during stacking, his visual perception continues to depend on the hand signals of nearby assistants. Storage cylinder designs have also changed over the years. These design modifications vary from lifting lug shapes and stiffening ring designs to a change in the reference grade of steel. The current storage cylinder model, the $48 \mathrm{G}$, was specifically created as an economical container for $\mathrm{UF}_{6}$ storage. Although it serves as a long-term storage container, the $48 \mathrm{G}$ was designed primarily as a containment vessel to meet the pressure and temperature conditions during liquid filling.

Even though the service record of these $\mathrm{UF}_{6}$ cylinders shows a high degree of reliability, some past failures have occurred during shipping and handling. These incidents were immediately recognized, and the failed cylinders were emptied and discarded. The two recent cylinder failures at Portsmouth, addressed in this report, are unique in that they were not detected immediately. Because the surveillance methods, until recently, consisted only of an annual inventory of the cylinders, these failed cylinders escaped detection for many years. A formal corrosion monitoring program was initiated in the late 1980s; however, it focused on specific problem areas and corrosion rate indicators rather than on cylinder yaid surveillance per se. ${ }^{2}$ Back as far as the mid 1970 s, cylinder wall thickness tests were conducted on selected cylinders, and the cylinder life was projected to at least another 30 years, ${ }^{3}$ making the need for surveillance seemingly of little importance.

The inspection process that led to the discovery of the two failed cylinders at Portsmouth was initiated because numerous cylinders stored at K-25 were identified as having valves in substandard condition; ${ }^{4}$ accordingly, a three-site inspection was begun to search for faulty valves. During the valve inspection at Portsmouth, a large hole was found in cylinder $4 \mathrm{G} 115688$, which had been stacked 13 years previously. This led to a three-site visual inspection for possible holes in all cylinders being used for $\mathrm{UF}_{6}$ storage; three days later, a second breached cylinder, 
4G127985, was identified at Portsmouth. During the inspection for holes, the Energy Systems Vice President for UE formed an irvestigation team whose purpose was to determine the cause of the first and, ultimately, second failure; to predict the potential impact on the total cylinder inventory; and to recommend future actions and preventive measures. The team members consisted of Energy Systems personnel (Jack DeVan, chairman; John Barber; John Googin; Tim Butler; and Mike Taylor) and Department of Energy (DOE) representatives Bob Dyer and Joe Russell. The members were selected to provide a relevant background in the areas of safety, quality assurance, metallurgy, corrosion, enrichment operations, and UF ${ }_{6}$ chemistry.

This report records the team's investigative findings and recommendations, including those contained within the initial report issued by the team. ${ }^{5}$ This report is based on information available through January 1991. Some operations requested by the team to yield supporting evidence for their conclusions are still in progress and may take several more months to complete. Pending those findings, this report. should be considered an interim final report. When the team has assessed the latter findings, an updated report will be issued if such findings warrant a change in, or addition to, the conclusions presented herein.

This report is organized first to give a brief chronology of the investigation, including the events leading to the discovery of these breached cylinders. The failure cause and chemical effects of the breach are then discussed, followed by the perceived environmental impact from the two incidents. The findings from the team's three-site survey of the cylinder yards are presented to examine connections between the cylinder failures and present storage policies. A section outlining the actions required to conclude the investigation is given preceding the team's conclusions and recommendations. Detailed information on the chemical effects accompanying these failures is presented in appendices to the main report and has been included because it affords a first-hand look at the long-term effects that accrue when the contents of a cylinder come into contact with the ambient atmosphere.

\section{INVESTIGATION STRATEGY}

\section{TEAM CHARTER}

The assigned objectives ${ }^{6}$ of the team were to: (1) identify the most probable cause(s) of failure, (2) assess the failures in terms of their potential impact on the total three-site cylinder inventory, and (3) recommend future corrective actions and preventive measures. The team also assisted Portsmouth in developing action plans for moving and emptying these cylinders. The team's interest in formulating these action plans was to secure chemical and metallurgical evidence, giving insight into the failure and its after-effects.

\section{METHODOLOGY}

Before Operations could begin to remove these cylinders from storage and empty their contents, Energy Systems management required that action plans be formulated and approved prior to each operation. Portsmouth senior management, the investigation team chairman, and the Chairman of the $\mathrm{UF}_{6}$ Handling Committee approved each of the plans prior to implementation. The full action plans are listed in Appendix C. 


\subsection{CHRONOLOGY}

The strategy to investigate and remove the failed cylinders from inventory was decided by Portsmouth and the investigation team. The second breached cylinder, discovered the day before the investigation team arrived at the Portsmouth Plant, was investigated first because of the possible implications to currently used cylinders (identical in design). Also, because it was the least damaged cylinder, more evidence was available from which to study the initial failure cause. To access this cylinder, over 200 stacked cylinders had to be moved with the Raygo Wagner loader. Several cylinders in the vicinity of this latter cylinder were observed by the team to be dented at, or near, the location where both failures had occurred. These other cylinders were examined for cracks; however, none were found. Once access had been gained, the cylinder with the smaller hole was pressure checked and a gas sample taken for chemical analysis. As would be the case for an undamaged cylinder, the internal pressure was still less than atmospheric $\left(-4\right.$ psig at $85^{\circ} \mathrm{F}$ ), and the gas analysis showed negligible oxygen or nitrogen contamination (see Appendix B for de 2 ils). The cylinder was then patched and removed from the storage yard. The original aluminum patch applied with an epoxy did not hold, and a new aluminum patch was applied the next day using a more thorough surface preparation before applying the epoxy adhesive. This cylinder was weighed for accountability and then valved at ambient temperature into the cascade. The cylinder was evacuated in approximately $30 \mathrm{~d}$. The breached area was then $\mathrm{X}$-rayed in X-326, and the internal cylinder surface in the area of the hole was successfully imaged in the X-705 annex using a miniature video camera mounted on a flexible cable. Presently, this cylinder is in storage awaiting radioactive decay to allow removal and evaluation of the material still plugging the hole and metallographic examination of the cylinder vall.

To clear a path to the cylinder with the larger hole, a new road was constructed and 60 neighboring cylinders had to be moved. To prove that the mechanical integrity of these cylinders was sufficient for the required lifting, an action plan was approved to spot check their wall thickness prior to moving (Appendix C). Using an ultrasound thickness gage, Portsmouth identified four cylinders with abnormal wall thickness indications, and an ultrasound team from K-25 was sent to Portsmouth to more closely examine these cylinders. The suspect cylinder wall areas were determined to contain inclusions associated with imperfections in the steel produced during the manufacturing process. To establish whether these defects may have had some connection with the failure, the affected cylinders were removed from storage; they are designated for further examination under another program. Once access was gained to the failed cylinder, the gas pressure and composition were determined. The pressure in this cylinder was above atmospheric $\left(+8 \mathrm{psig}\right.$ at $\left.85^{\circ} \mathrm{F}\right)$, and it contained elevated concentrations of HF. Its internal pressure was reduced by venting into a clean, empty cylinder. The pressure was bled off several times during a one-week period. A large, two-piece aluminum patch was manufactured to fit over the breached area and was applied with epoxy and circumferential reinforcing bands. The epoxy did not completely hold during transport of the cylinder, and a small release of $\mathrm{HF} / \mathrm{H}_{2} \mathrm{O}$ fog was stopped by dry ice $\left(\mathrm{CO}_{2}\right)$. Core samples of the uranium plug were taken through two ports in the patch, and chemical analyses were performed on the samples. The cylinder was weighed for accountability and then valved into the cascade. Evacuation was begun in the same manner as for the cylinder with the smaller hole and was continuing at the time this report was prepared. 


\section{ANALYSIS OF FAILURE CAUSE AND CHEMICAL EFFECTS}

\subsection{LOCATIONS AND HISTORIES OF FAILED CYLINDERS}

On June 16, 1990, cylinder 4G115688 (the: iarge-hole cylinder) was discovered with a corroded opening near the front stiffening ring. The cylinder was located in Portsmouth storage yard X-745C, row 20, position 15, or the top (second) tier. Figure 1 illustrates the Portsmouth depleted $\mathrm{UF}_{6}$ cylinder storage area. The cylinder was manufactured in 1975 and was filled in late 1975, then moved to this location sometime in 1977 where it remained until the failure was discovered. No record was made of the exact day or month in which it was stacked. An inspection of all the Portsmouth storage yards was begun immediately after this discovery. On June 19, 1990, the small-hole cylinder was found, in whict a hole again was observed near the front stiffening ring. This latter cylinder was located in storage yard $\mathrm{X}-745 \mathrm{C}$, section 3 , row 13 , position 44, on the lower (ground-level) tier. It had been manufactured in 1982 and was filled and stacked in June 1986. Tables listing manufacturing, material, and design specifications of the cylinders and their $\mathrm{UF}_{6}$ weights are provided in Appendix $\mathrm{A}$.

\subsection{APPEARANCE OF FAIIUURES}

The large-hole cylinder is shown in Fig. 2. Viewed from the valve end, it is centered at the 9 o'clock position and runs under the nearest stiffening ring. The top section of the hole is roughly semicircular in shape, while the bottom section is in the shape of an inverted pyramid. The maximum side-to-side dimension is approximately 9 in., and the overall distance from the top of the hole to the bottom is approximately $18 \mathrm{in.}$ Approximately $30 \%$ of the hole area is on the valve-end side of the stiffening ring, and the remaining $70 \%$ is on the plug-end side. A greencolored, ged, fluoride salt layer covers the exposed hole area slightly below the original solid $\mathrm{UF}_{6}$ surtice, and similarly colored layers of salt cover areas below the hole and on the underlying cylinder. Some loose, green salt deposits were also found on the top of the underlying cylinder and on the concrete pad directly under the cylinder. The upper corner of the lifting lug of the adjacent cylinder was positioned at the approximate center of the hole (Fig. 3).

The small-hole cylinder is pictured in Fig. 4. The hole lies at the 3 o'clock position when the cylinder is viewed from the valve end. This hole is much smaller than that shown in Fig. 2 and its exact size is obscured by green salt deposits that overlaid the hole. As shown in Fig. 5, the top corner of the lifting lug of the adjacent cylinder can be seen to protrude into the hole at a point very close to the stiffening ring weld on the failed cylinder. This lug was covered by a green salt deposit, which turned to a reddish brown deposit at its outer extremities. Because the green salt deposit closely matches the color of the paint covering the cylinder, very careful inspection was required to spot the hole when viewed from the front of the cylinder. There were no salt deposits on the underside of this cylinder and only a small green spot (about the size of a dime) on the concrete pad directly under the hole.

\subsection{CONDITION OF NEIGHBORING CYLINDERS}

As noted above, the cylinder to the left and below the large-hole cylinder had a relatively thick, green salt deposit running from the 12 o'clock position to about the 5 o'clock position on the head side of the stiffening ring (as viewed from the valve end). Removal of this deposit 

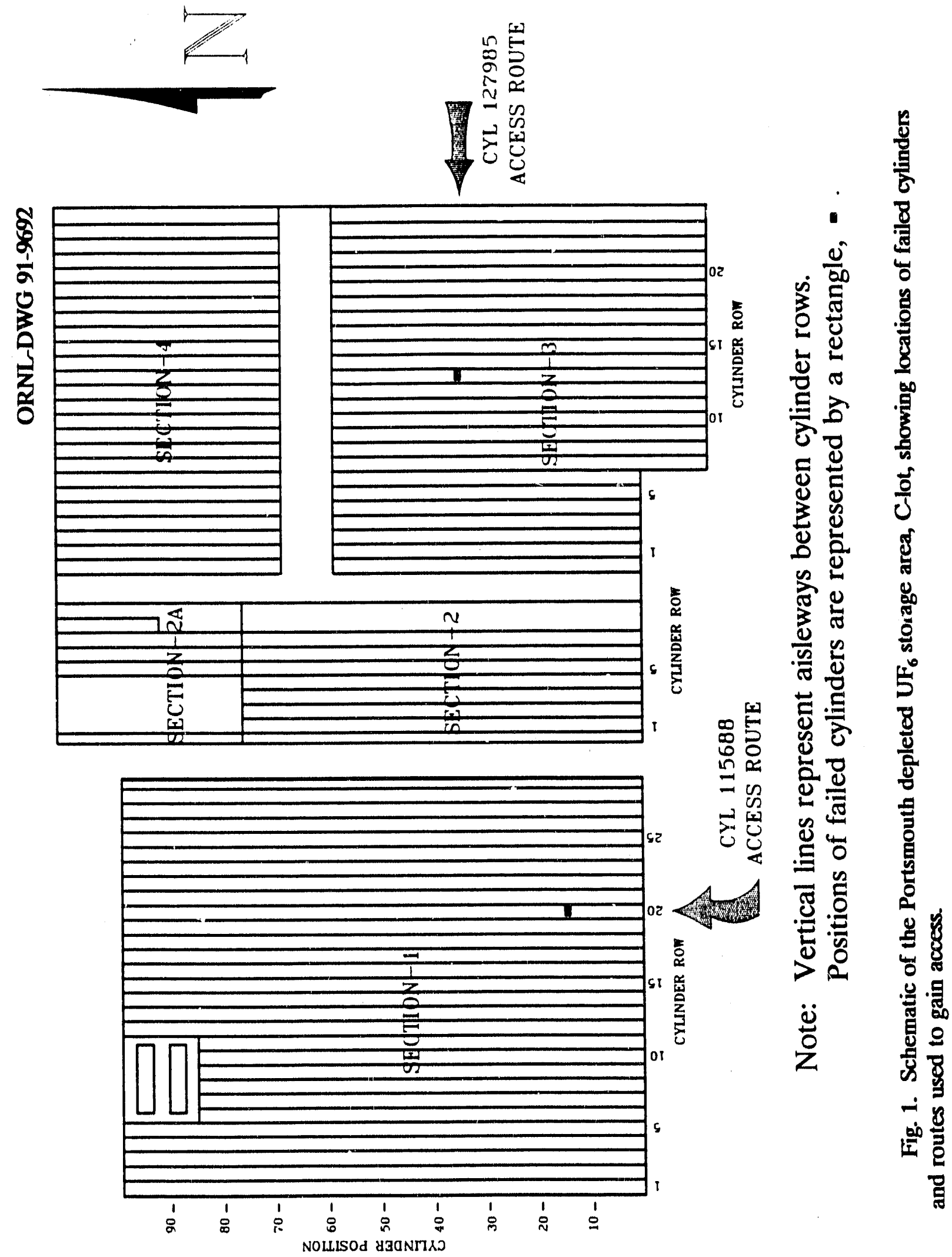
PHOTO NO. K/PH-91-3184

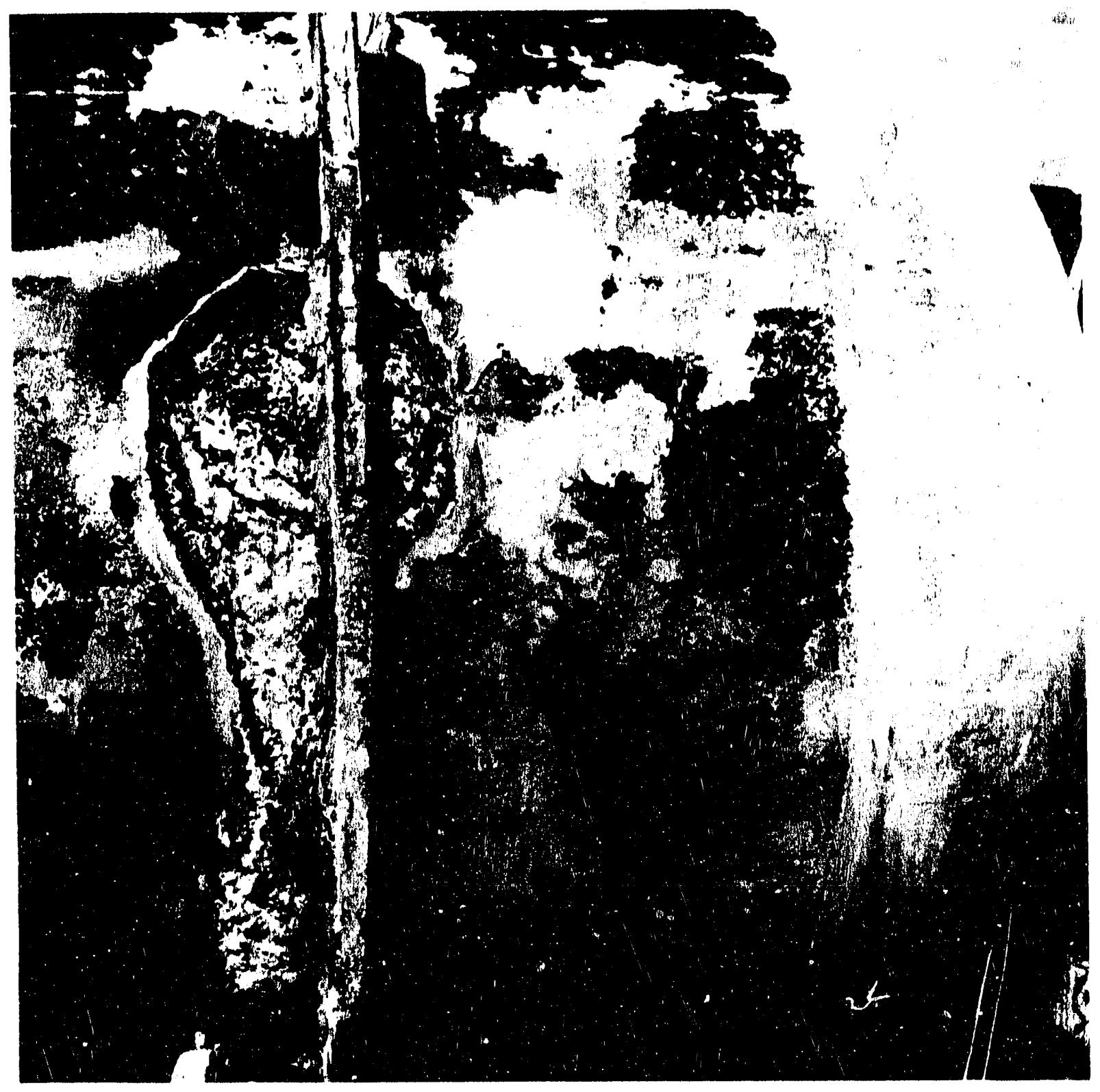

Fig. 2. Appearance of failure area in cylinder 4G115688. 


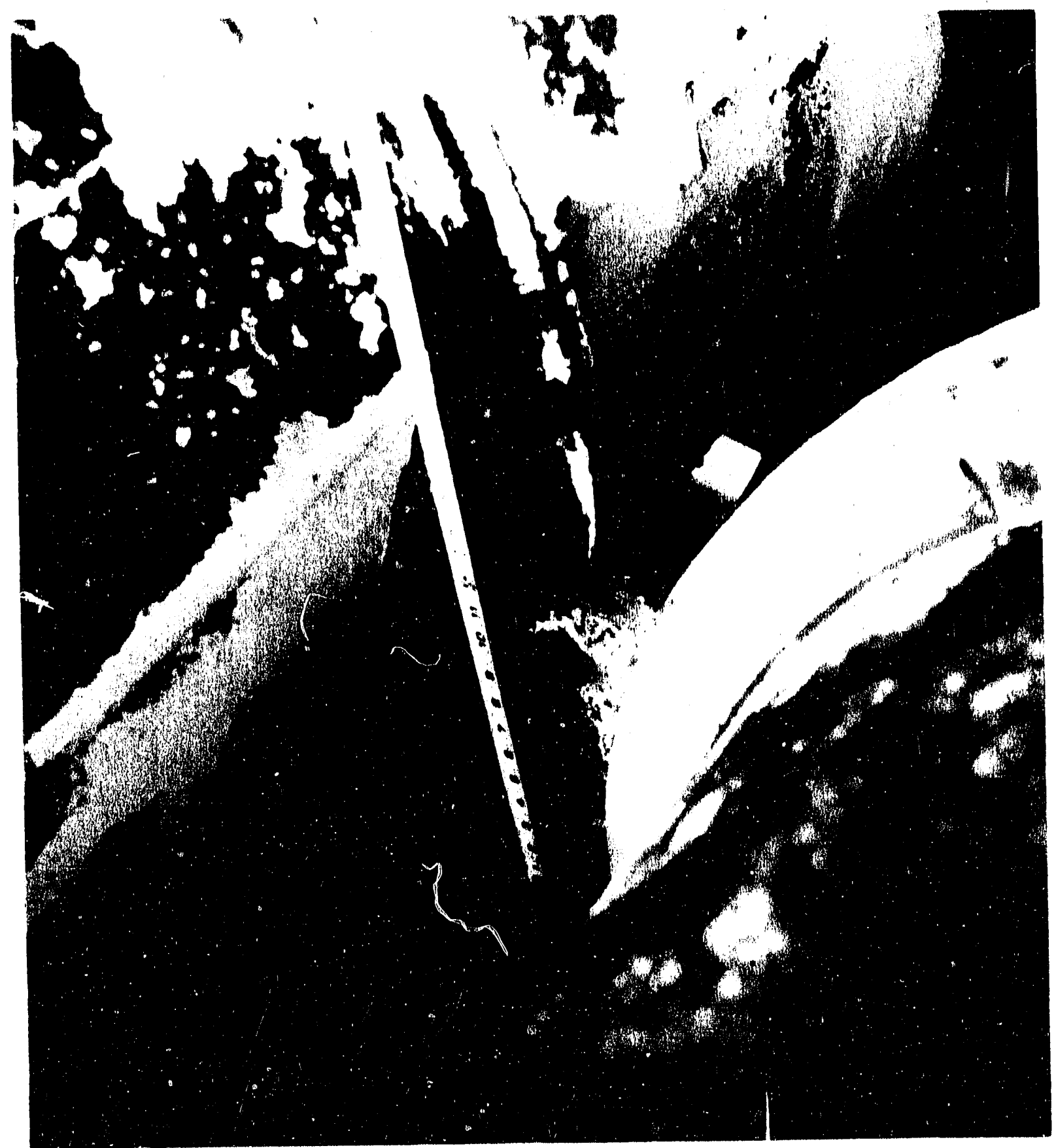

Fig. 3. Area of failure in cylinder 4G115688 showing relative position of lifting lug of neighboring cylinder. 
PHOTO NO. K/PH-91-3188

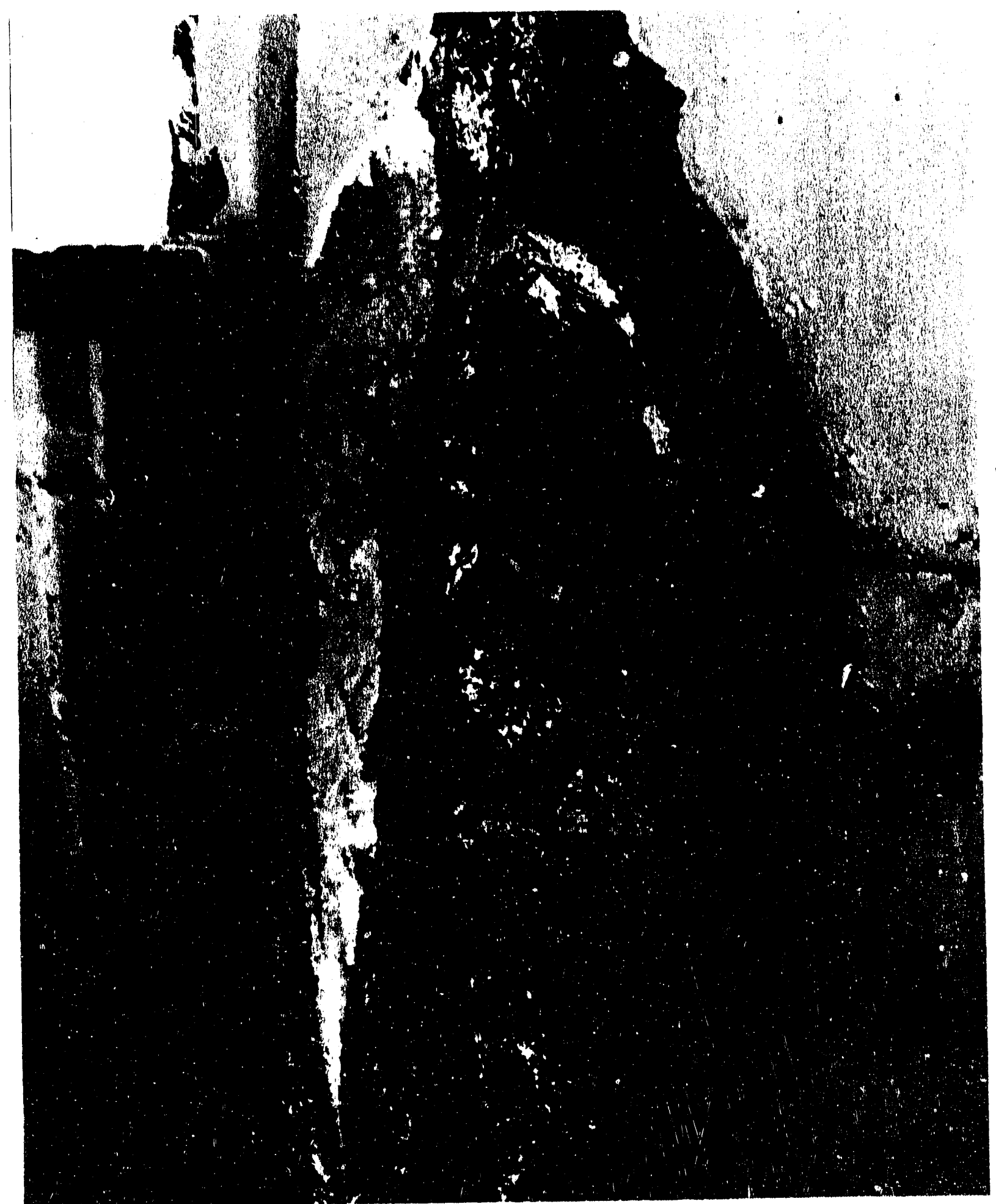

Fig. 4. Appearance of failure area on cylinder 4G127985 (after removal of debris covering hole). 
PHOTO NO. K/PH-91-3195

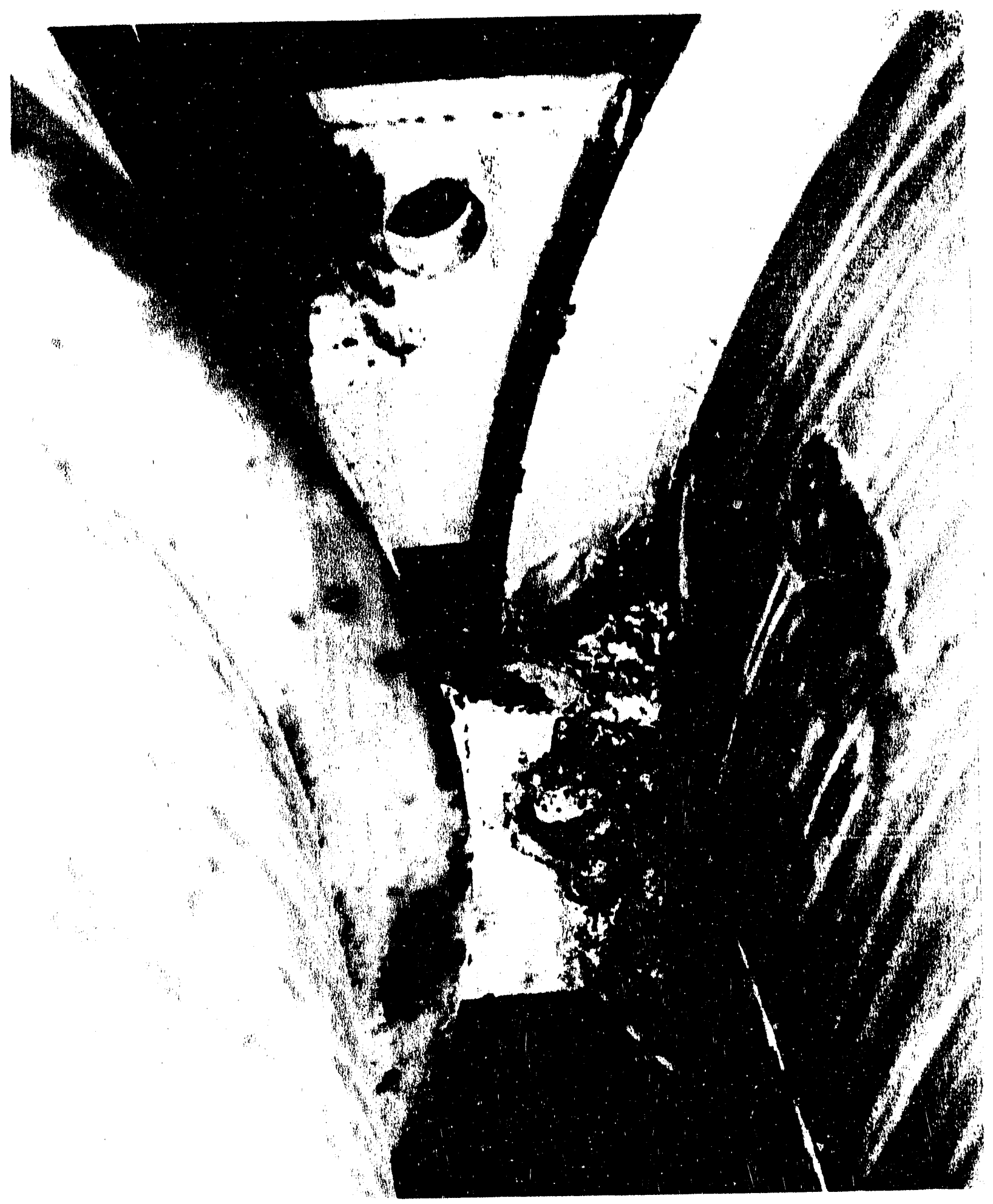

Fig. 5. View of failure area after gaining access to cylinder $4 \mathrm{G} 127985$ showing location of lifting lug on neighboring cylinder. 
revealed a series of vein-like grooves etched into the cylinder surface (Fig. 6). The grooves were relatively widely spaced and shallow near the top of the cylinder but converged into a much deeper groove over the right-hand quadrant of the cylinder, where it reached a maximum depth of .13 in. None of the other neighboring cylinders showed any evidence of corrosion.

The failure of the small-hole cylinder had no effect on adjacent cylinders. However, several cylinders in the neighborhood of the small-hole cylinder showed mechanical defects attributable to improper spacing (overcrowding) and misalignment of lifting lugs as discussed below.

\subsection{PROBABLE FAILURE CAUSES}

Evidence examined by the team indicates that the small-hole cylinder failure most likely was initiated by a through-wall crack that occurred at the time of stacking. The crack resulted from the impingement of the upper corner of the lifting lug of an adjacent cylinder, which deformed the shell of the subject cylinder in the immediate vicinity of the front stiffening ring (Fig. 5). Because of the restraint afforded by the 1-in.-thick stiffening ring, this deformation led to tearing of the shell along the fusion line of the weld joining the shell to the stiffening ring. Conditions contributing to the puncture were: (1) an insufficient separation distance between the cylinders, which resulted from too tight a spacing of the wooden saddles under the cylinders, and (2) the offending lifting lug being placed at a position of 7 o'clock rather than the desired 9 o'clock position.

The original breach has been largely obliterated by the extensive wastage of the shell associated with the exposure of $\mathrm{UF}_{6}$ to air and moisture (Fig. 4). However, evidence for the initial failure cause is afforded by examinations of neighboring cylinders, many of which show dents that were induced by the lifting lugs of adjacent cylinders. In most cases, these dents were sufficiently far away from an unyielding stiffening ring that they could be accommodated by dimpling of the shell rather than tearing. The small-hole cylinder sustained such a dent at the end opposite from where the hole occurred, as shown in Fig. 7. Although the degree of indentation here appeared to be of the same order as that which occurred at the failed end, the indent was not restrained by the stiffening ring and there was no indication of cracking in this location. In the few instances where lugs were found to have impinged much closer to the stiffening ring, the degree of indentation was insufficient to have caused failure. However, in these cases, the indents were more typical of tears as shown in Fig. 8.

Other support for the stated failure mode comes from drop tests performed on similarly designed cylinders at Paducah, Kentucky. A consistent observation in these tests has been the susceptibility of the cylinder shell to tearing when it was impacted next to the stiffening ring. The tests also showed that the 5/16-in. A516 steel plate used in the manufacture of the small-hole cylinder was particularly prone to lamellar tearing along the fusion line of the stiffening ring weld. Failures by this mode were already on record for at least two other cylinders made from this particular grade of steel. The first occurred in March 1978 when a cylinder was accidentally dropped onto a wooden saddle and the second, in March 1982, by an indeterminate cause during shipping on a railroad flatcar. It was shown by Blue ${ }^{7}$ that sulfide inclusions in this steel adversely affected its impact properties transverse to the rolling direction - a problem that is exacerbated by welding, which concentrates the inclusions along the weld fusion line. Based on these findings, the allowable sulfur content was reduced in the specifications for all cylinders subsequently built with A516 steel components. 
PHOTO NO. K/PH-91-3194

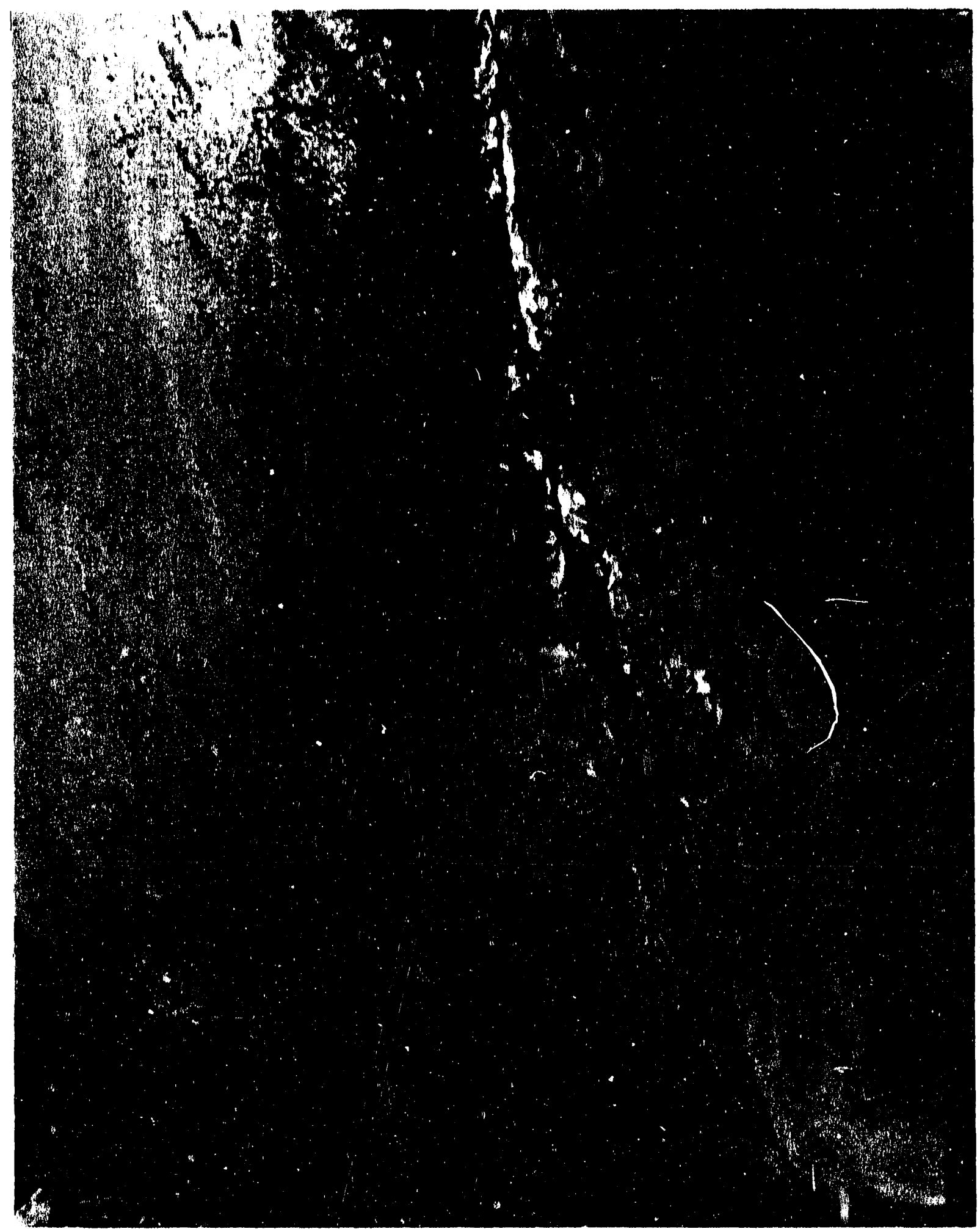

Fig. 6. Appearance of wall of cylinder lying directly below cylinder 4G115688. Note vein-like grooves etched into cylinder wall. 


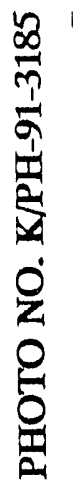
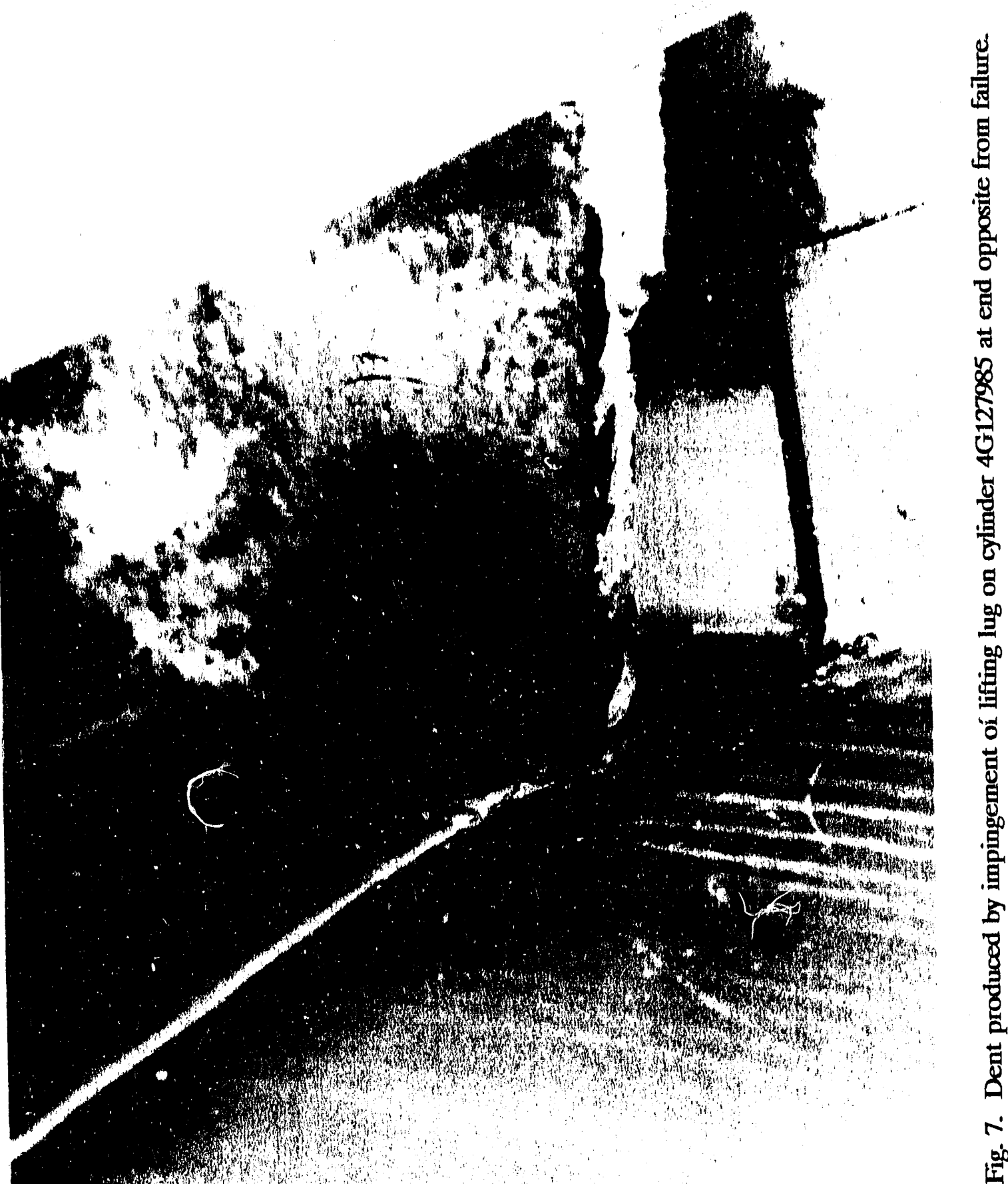


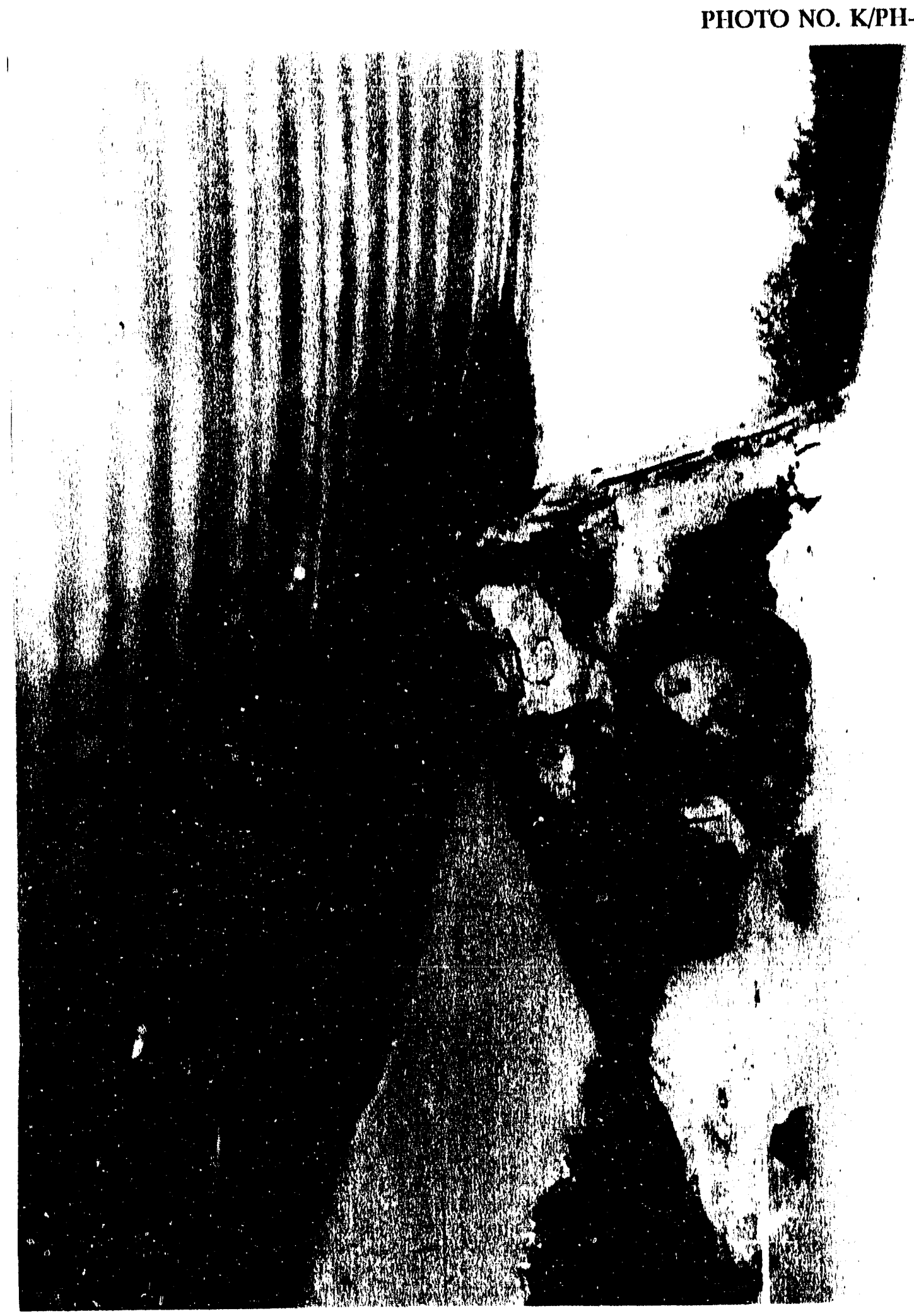

Fig. 8. Typical damage produced by lifting lug impingement near stiffening ring. Cylinder was located in vicinity of cylinder 4G127985. 
Like the small-hole cylinder, the failure of the large-hole cylinder appears to have initiated close to the stiffening ring with the corner of the lifting lug of the adjacent cylinder again positioned near the center of the hole (Fig. 3). Again, the spacing between the failed and adjacent cylinder was below the desired minimum. However, unlike the small-hole cylinder, physical measurements at the outer circumf ience of the large hole showed that a small gap had actually existed between the corner of the opposing lifting lug and the original outer circumference of this cylinder. Thus, while the positions of the two failures, with respect to the stiffening ring and lifting lugs, are quite similar and point to a common failure mechanism, any impingement of the lifting lug on the large-hole cylinder must have occurred before, not after, the cylinder reached its rest position. This caveat seems reasonable given the stacking situation for this cylinder. Unlike the small-hole cylinder, which was at ground level and supported by wooden saddles, the large-hole cylinder was in the second tier and was therefore positioned in a crease formed by two underlying cylinders. If either this cylinder or the one opposing it had been lowered and released into a position that was slightly away from the lowest point of the crease, a rolling motion would be set up as the cylinder moved to its rest point. Given the tight spacing, only a slight movement past the rest point would be required to make contact with the adjacent cylinder and, because of the relative positions of the lifting lug and stiffening ring, to initiate the type of tearing fracture discussed above. Operators at Portsmouth, who have experience in stacking these cylinders, confirm that difficulties in visual perception and in steadying the cylinders make this sequence of events entirely plausible.

The shell of the large-hole cylinder was fabricated of a different grade of steel than the small- hole cylinder. The former was made of A285, while grade A516 was being used at the time the latter cylinder was built. Grade A285 was, in fact, dropped in favor of A516 because of its poorer fracture toughness properties at low temperatures $\left(\leq 0^{\circ} \mathrm{C}\right)$. However, given the probable temperature of the cylinder and its contents at the time of stacking, the A285 cylinder should not have been any more vulnerable to fracture than one constructed of A516. In fact, based on drop tests of cylinders built with the A285 grade, this material has even butter toughness properties than the particular A516 heat used in constructing the small-nole cylinder. Nevertheless, experience during shipping and handling of these cylinders has shown that tearing near the stiffening rings can occur with even the best of these materials.

As discussed below, corrosion played a major role in these failures once the cylinders had been breached. However, the investigation team could find no evidence that corrosion might have contributed to the initial break in the wall. Wall thickness measurements were performed at numerous points around both failed cylinders, and there were no indications of wall thinning at any point other than in the immediate vicinity of the holes. Even at crevice regions, which are the most susceptible to atmospheric corrosion, there were no indications of localized attack or pitting.

\subsection{CHEMICAL PROCESSES LEADING TO GROWTH OF HOLES AND FORMATION OF PLUG}

A detailed discussion of the chemical findings relating to this failure analysis is presented in Appendices B1 and B2. Appendix B3 illustrates by schematic drawings the various proposed stages in the hole and plug development. The description given here presents a proposed scenario that summarizes these findings and explains the growth of a hole and the formation of the associated products that constitute the plug. It should be noted that the process being 
described here is for a fracture leading into solid UF . If the fracture is in the top of the cylinder, the scenario being presented is not necessarily correct over long periods of time. It probably covers what happens early with fractures but may not be valid when the fracture becomes a hole.

In both failed cylinders, the initial breaches were below the surface of the solid $\mathrm{UF}_{6}$. Breaches in this area would not have been accompanied by any audible indication of failure, such as gas entering the cylinder. However, contact of solid $\mathrm{UF}_{6}$ with air often produces a visually detectable $\mathrm{HF}-\mathrm{H}_{2} \mathrm{O}$ vapor plume. The apparent absence of such an indication here could indicate that the initial cracks were microscopic in size and air access was limited. However, weather is also a factor $h_{1}$ whether a visible plume is produced. Conditions in winter are least favorable to the fog formation since the stored $\mathrm{UF}_{6}$ will be colder, the $\mathrm{UF}_{6}$ sublimation pressure lower, and the water vapor pressure significantly reduced. Also, storing cylinders longer before stacking favors lower $U_{6}$ sublimation pressures. The rate of reaction between the $U_{F}$ and the water vapor is slower because the temperature is lower and the concentrations of the reactants are reduced. All these factors reduce the probability of producing the visible fog on cold winter days.

Whether the initial breach was microscopic or macroscopic in size, chemical attack of the steel shell would be expected to begin at, or near, the external (air-side) surface. This position is predicted because the sublimation pressure of $U F_{6}$ is approximately four times the vapor pressure of water, and two moles of water are required for each mole of $\mathrm{UF}_{6}$ converted to $\mathrm{UO}_{2} \mathrm{~F}_{2}$. This location is also confirmed by computer simulations using reasonable values for diffusion coefficients of water vapor and $\mathrm{UF}_{6}$ in air. Only at the exterior surface is sufficient water vapor available to produce $\mathrm{HF}-\mathrm{H}_{2} \mathrm{O}$ fog and some condensate on the steel surface. The $\mathrm{UO}_{2} \mathrm{~F}_{2}$ produced is largely retained in the fracture, which (with the passage of time) produces a plug that slows the diffusion of $\mathrm{UF}_{6}$ to the surface. (Anhydrous HF in the crack is not a concern because it is not an ionic acid and is actually shipped in mild steel containers.) When the diffusion of the $\mathrm{UF}_{6}$ to the surface is reduced sufficiently that water vapor is in excess at the point of mixing, aqueous HF is produced that dissolves some of the $\mathrm{UO}_{2} \mathrm{~F}_{2}$. This is a conducting acidic solution that attacks the iron, producing $\mathrm{UF}_{4}$ hydrate and an iron fluoride hydrate by a redox reaction that could be electrochemical in nature.

As attack proceeds, it can produce a very thin layer of $\mathrm{FeF}_{2}$ at the steel surface. On top of this, a layer of brick-brown $\mathrm{Fe}_{2} \mathrm{~F}_{5}$ hydrate is found. Next to this is the major iron fluoride hydrate layer of $\mathrm{FeF}_{3} \cdot 3 \mathrm{H}_{2} \mathrm{O}$. The $\mathrm{UF}_{4}$ hydrate is at the center of the fracture and is somewhat porous. The UF, hydrate contains almost no iron. Between the UF, hydrate and the solid $U_{6}$, there must exist a region of solvated $\mathrm{UO}_{2} \mathrm{~F}_{2}$ In fact, based on the earlier observations of Mallett ${ }^{8}$ and the results of the inspection of the backside of the uranium plug in the small-hole cylinder, the composition must change according to the following sequence:

$$
\begin{array}{cccc}
\mathrm{UF}_{4} 0.75 \mathrm{H}_{2} \mathrm{O}:: \mathrm{UO}_{2} \mathrm{~F}_{2} & n \mathrm{nH}_{2} \mathrm{O}::\left[\mathrm{H}_{3} \mathrm{O}\right]_{2}\left[\mathrm{U}(\mathrm{OH})_{4} \mathrm{~F}_{4}\right]:: \mathrm{UO}_{2} \mathrm{~F}_{2}:: \mathrm{U}_{2} \mathrm{O}_{3} \mathrm{~F}_{6}:: \mathrm{UOF}_{4}:: \mathrm{UF}_{6} \\
\text { green } & \text { yellow } & \text { yellow } & \text { yellow orange orange clear }
\end{array}
$$

Mallett's evidence is the existence of an orange band well below the surface of the solvated $\mathrm{UO}_{2} \mathrm{~F}_{2}$, which defined the extent to which at least partial hydrolysis had proceeded. The backside of the deposit in the small-hole cylinder was, in fact, orange, as determined by examination using a small video camera. 
The attack of the steel proceeds from the outside in and initially produces a hole with the bevel facing the outside. Once the bevel is established, the rate of attack should become nearly constant for a given set of conditions. Thus, the diameter of the hole will gradually enlarge at a relatively constant rate if viewed over a long time frame. At some time, attack of the iron cylinder wall on the inside surface near the hole becomes significant, and wall thinning from the inside occurs by the same mechanism as it initially occurred from the outside. In fact, the wall thinning extended on the inside beyond the hole by five or more inches in the case of the largehole cylinder, which may be considered to have a "mature" hole.

In addition to these solid materials, in accordance with the phase diagram of Busleav, ${ }^{9}$ an HF solution containing a small amount of an acidic, solvated uranyl fluoride, $\left[\mathrm{H}_{3} \mathrm{O}\right]_{2}\left[\mathrm{U}(\mathrm{OH})_{4} \mathrm{~F}_{4}\right]$, forms in the yellow layer and slowly oozes out of this layer through the $\mathrm{UF}_{4}$ layer, where it reacts with the steel wall to form iron tluoride hydrates and $\mathrm{UF}_{4}$ hydrate. The effects of this very strong acid solution are best seeti on the cylinder below the big hole. The salt deposits in this area were the same in appearance as those found on and between the stiffenirig ring and the lifting lug of the adjacent cylinder, immediately below the breach in the small-hole cylinder. As in that case, the iron fluoride hydrates were next to the steel and the $\mathrm{UF}_{4}$ hydrates were on top. The solution acting over 13 years has etched rivulets which, as the flow becomes faster due to the increasing slope of the cylinder surface, collect into a single groove that etches deeply into the cylinder.

\section{ASSESSMENT OF ENVIRONMENTAL IMPACT}

\subsection{HEALTH PHYSICS SURVEY}

Analysis of an air sample taken near the large hole showed approximately $1 \mathrm{ppm} \mathrm{HF}$. Contamination surveys of the concrete pad in the vicinity of the large-hole cylinder showed negligible contamination, except in the area directly under the hole and along a short track where water runoff had deposited traces of $U_{4}$. This area was successfully decontaminated without removing any of the pad surface. Contamination of cylinder surfaces in the immediate vicinity of the leaking cylinder was minor except where there were visible traces of UF. Surfaces of four neighboring cylinders (in addition to the failed cylinder) required decontamination, which again was completed using conventional swabbing techniques. Before decontaminating the area around the cylinder, a greenish salt containing approximately $7 \mathrm{lb}$ of uranium was collected from the pad under the cylinder and as loose deposits on the cylinder directly under the failed cylinder. In the case of the small-hole cylinder, contamination surveys showed negligible contamination, except in the immediate vicinity of the hole, and smears of the pad under the cylinder showed negligible alpha/beta readings.

One of the soil samples checked when preparing the roadway to access the large-hole cylinder indicated contamination above background levels. Several samples were then surveyed from soil debris left by road construction. One sample had a maximum activity of 12 picocuries/gram, and the rest were below 8 picocuries/gram. (A level of 30 picocuries/gram is permitted for landfill disposal.) The source of this activity appeared to be water runoff from the cylinder, which crossed the concrete pad and entered the ground at the edge of the pad where the new road attached. 


\subsection{URANIUM LOSSES}

An analysis of the chemical processes accompanying the formation and growth of the cylinder holes (presented in Appendix B) was used to estimate the UF 6 losses from the failed cylinders. Estimates were made of both the mass of uranium within solid reaction products that formed external to the cylinders and the total mass of $\mathrm{UF}_{6}$ that escaped the cylinders. The latter was calculated by mass balancing the weights, before and after the holes developed, against calculated losses and gains of iron, hydrogen, oxygen, and fluorine. These estimated $\mathrm{UF}_{6}$ losses are listed in Table 1. It should be noted that because of uncertainties in the calculations, values are given as upper- and lower-bound estimates. The actual losses lie somewhere between these limits.

Table 1. Estimated uranium losses resulting from cylinder failures

\begin{tabular}{lcc}
\hline \multicolumn{1}{c}{ Item } & $\begin{array}{c}\text { Cyl. 4G127985 } \\
\text { (small hole) }\end{array}$ & $\begin{array}{c}\text { Cyl. 115688 } \\
\text { (large hole) }\end{array}$ \\
\hline Initial $\mathrm{UF}_{6}$ inventory, lb & 27,517 & 27,927 \\
$\begin{array}{l}\text { Estimated mass of uranium in solid } \\
\text { deposits outside cylinder, lb }\end{array}$ & 0.5 & 7.4 \\
Estimated mass of unrecovered $\mathrm{UF}_{6}, \mathrm{lb}$ & & 17.0 \\
Lower bound & 0.0 & 109.0 \\
Upper bound & 4.0 & \\
\hline
\end{tabular}

\subsection{PRESENT AND FUTURE ENVIRONMENTAL IMPACT}

The cylinder with the larger hole has leaked several kilograms of uranium and fluoride to the environment, but the environmental insult was minimal as it existed on the site at the time of discovery. Uranium contamination was confined almost entirely to the immediate vicinity of the leak, although there was some runoff across the concrete pad into a small area of soil immediately adjacent to the pad. The maximum radioactivity in soil samples from this area was 12 picocuries/gram (an acceptable level for landfill disposal).

The real problem is the maximum credible incident $(\mathrm{MCI})$ that might be experienced within some credible time among the present 40,000 cylinders - a number that is expanding at the rate of thousands per year. The lessons learned here indicate that cylinder failures that occur below the solid-vapor interface of the cylinder do not lead to extensive or widespread contamination if detected in a reasonable time frame. The environmental effects associated with the small-hole cylinder failure (which went undetected for 4 years) were minimal, and the cylinder was moved and emptied with little difficulty. However, the MCI associated with breaches in the cylinder wall near the top of the cylinder (i.e., in the vapor space) cannot be completely assessed based on 
existing information. Scenarios have been proposed in which extreme conditions could lead to a steam-driven expulsion of contaminated liquid and HF from the cylinder, although this situation appears unlikely if the breaches are small (i.e., detected in a time span of $\leq 1$ to 2 years). In any case, the investigation team concludes that experiments should be conducted to examine the longterm effects of a hole nearer the top of the cylinder with water introduced under controlled conditions.

\subsection{STORAGE PAD DESIGN IMPLICATIONS}

There is the small chance of discharges of uranium from a few depleted UF $_{6}$ cylinders over the many years that tens of thousands of the large 14-ton containers may stay in their present storage mode. Since a substantial part of the uranium lost from cylinders will be in the hexavalent state, it can be reasonably assumed that this uranium will form compounds with substantial solubility in the naturally carbonated water of the average rain. The migration and collection of this uranium will need to be considered, along with methods of containment. One obvious solution is the use of the classical diked, water-tight, perhaps concrete, pads under the cylinders. This can aid in the detection of losses (by bringing the material to an edge of the pad) and can contain them until the uranium can be stabilized. It might be diked in total or in smaller sections. Such a system could potentially satisfy the future requirements for environmental protection.

The storage over gravel presents a potentially greater difficulty of remediation after uranium contamination. Because of washthrough to the ground water, rather extensive contamination could occur in the case of the MCI. Although this might be limited with a membrane under the gravel, the reprocessing of the gravel to remove or stabilize uranium can be expected to be required in the case of any spills of kilogram magnitude, and the collection of drainage from above an undergravel membrane is not a simple thing. The added costs of the complete removal of the contaminated gravel and subsoil from the center of an array of thousands of cylinders could offset much of the initially higher cost of the concrete pads. The added protection of the environment that can be afforded by a well-conceived pad storage system could also ease potential requirements for repackaging the cylinders.

\section{STORAGE YARDS SURVEY}

As part of the investigation charter, the team was charged with assessing the implications of these cylinder failures relative to the entire DOE inventory of depleted UF. This inventory consists of over 40,000 similar containers distributed among three sites (Paducah, Portsmouth, and $\mathrm{K}-25$ ). To complete this assessment, the team surveyed the cylinder storage yards at all three sites. The survey consisted of no less than half a day at each site viewing a representative sample of the stored cylinders. A guide, who was helpful in answering questions about the yards and in choosing a representative sample of stored cylinders, was present during each tour.

Cognizant of the two incidents at Portsmouth, the team surveyed the yards for indications of anomalous conditions (dents, lug against adjacent cylinder, uneven stacking, etc.). The frequency and severity of stacking abnormalities and the ability to visually inspect these areas were used to gage the likelihood of other breached cylinders existing in the yards. From the survey, the team was able to address faults in stacking practices that could facilitate impacting a cylinder 
or hinder the identification of problem cylinders, faults in cylinder design and yard layout, and conditions that may contribute to accelerated cylinder corrosion (another potential means for breaching a cylinder).

From the survey, the team determined that the cylinder stacking operations were not common between the facilities and appeared to have been operator controlled with no formal independent evaluation and limited documentation. Historical surveillance inspection activities associated with the stacked cylinders did not specifically address inspection for cylinder damage caused by improper handling. With respect to stacking practices, misaligned lifting lugs and improper spacing of the cylinder saddles were the two major faults observed in the yards. Numerous examples were found at all three sites where these conditions had resulted in the lifting lug of one cylinder contacting and denting an adjacent cylinder. Lifting lugs, when not in the desired horizontal orientation, project their corners toward adjacent cylinders. This increases the probability of damage if contact occurs. Numerous cases at all three sites were observed where the weight of one cylinder was partially supported by a lug corner resting on an adjacent cylinder. Improper saddle spacing, if it is too close, can cause cylinders on the same tier to impinge or, if too far apart, to cause the upper-tier cylinders to contact misaligned lifting lugs in the lower tier. It was also observed that non-uniform spacing of saddles can result in uneven loading of uppertier cylinders on lower-tier cylinders. Several cases were observed where an upper-tier cylinder had highly asymmetrical contact (support) points resulting in very uneven bearing loads on the underlying cylinder.

The team also identified obstacles in the yards that obstruct a full-surface inspection of each cylinder. In general, those surface areas that face together between cylinders stacked in doubletiered rows are difficult to inspect. The team found it difficult to visually inspect the backside of the outer stiffening ring welds (the two breach locations) because of obstruction by the lifting lugs of neighboring cylinders. Although locations near the center stiffening ring and the underside of the cylinders are not considered areas of high risk for impact failures, these areas are also difficult to visually inspect without a telescoping or periscoping mechanism. In addition to the stacking irregularities between individual cylinders, in several cases the aisleways between rows of cylinders provided insufficient space for plan viewing, and elevation viewing does not give access to lowertier cylinders. This condition was more frequently seen at Portsmouth and in the K-1066E yard at K-25 than at Paducah. The rows stacked in this manner are of particular concern to the investigation team because they cannot be fully surveyed for mechanical damage without improvising current inspection procedures or restacking these cylinders.

Throughout the survey, the team identified particular cylinder design features that could adversely affect their reliability for long-term storage. The most important concerns the sharp corners on lifting lugs, as noted above, but others include the use of channel-type stiffening rings, poorly protective cylinder coating materials (paint), and tack-welding attachment of the identification plates. As mentioned in the team's preliminary recommendations, sharp corners on the cylinders increase the potential for an impact to cause a tear that penetrates the cylinder wall. Another design oversight is the U-channel-type stiffening ring, which is specific to type-O cylinders. (Approximately 6,600 of the type-O cylinders were purchased and, presumably, are in the $\mathrm{UF}_{6}$ stockpile.) These cylinders have void areas inside the stiffening rings that cannot be visually inspected. The concern for inspection increases when a " $U$ " channel is dented or even torn, allowing water to be trapped inside the channel; several cylinders were actually seen in this condition. Denting or tearing of this type of stiffening ring tended to occur when cylinders having 
this type ring were stacked against stiffening rings of the more conventional design. An additional design fault in $\mathrm{UF}_{6}$ storage cylinders is the protective coating applied to these cylinders. The color of the paint is so similar to that of $\mathrm{UF}_{4}$ that it hinders visual identification of reaction products from a breached cylinder. When a patch of rust forms under the paint, it has the same appearance as $\mathrm{UF}_{4}$ concealing a breach. It should also be mentioned that the quality of paint is highly variable and, in many cases, it offers little long-term surface protection. Stainless steel I.D. plates do not directly relate to breached cylinder incidents; however, some I.D. plates were missing because of poor attachment welds to the cylinder. When the I.D. plate is separated from a cylinder, tracking of that cylinder through inventory and the monitoring program is hindered. These tack welds also become initiation points for crevice corrosion between the I.D. plates and the cylinder.

Another general problem recognized by the investigation team relates to the present cylinder yard designs. These yards are constructed of either concrete or compacted gravel without the ability to contain material if leaks do occur. The minor soil contamination found near the largehole cylinder runoff location might have been avoided if appropriate safeguards had been built into the cylinder yards. Depleted uranium hexafluoride is a low-level, radioactive, hazardous material and, in private industry, storage areas of hazardous materials are generally diked.

The present condition of these cylinders (with paint failing and accelerated corrosion at contact points), though not relevani to the team's charter, nevertheless requires comment. The team recognizes that a monitoring prog $\cdot \dot{m}$ is under way that focuses on cylinder life studies. The team's observations indicate that the studies should concentrate on specific accelerated corrosion cases at cylinder-to-cylinder, cylinder-to-ground, and cylinder-to-saddle contact points and corrosion within the channel-type stiffening rings. The appearance of the cylinders also has important ramifications in maintaining the depleted uranium inventory as a future resource and avoiding any implication that marks it as abandoned waste.

The findings from the investigation team's survey suggest that a small, but finite, probability existed at all the sites visited for impact-type failures such as the two that occurred at Portsmouth. The frequency of dents, misaligned lugs, and improperly spaced saddles observed at all three sites supports this assessment. Nevertheless, the three-site inspection of the yards completed by the respective site personnel has found no additional holes. As a result of the breached cylinder incidents, each site now makes a thorough examination of all $\mathrm{UF}_{6}$ storage yards every six months. At least one site (Paducah) is initiating a computerized data base tracking system of the cylinders that documents any unusual conditions a cylinder may have.

Some of the investigation team's specific findings do require action to either rectify past deficiencies or prevent future problems in $\mathrm{UF}_{6}$ storage. Remedial action should be considered where the mechanical integrity of the cylinder appears in question or a thorough inspection of the surface cannot be completed to determine the cylinder's integrity. The most pressing need for remedial action is the need to restack cylinders which are in contact with unpaved yard surfaces due to deteriorated saddles and/or saddles sinking into the ground. Cylinder rows stacked without walkways for inspection, severely dented cylinders, and cylinders with torn "U"-channel stiffening rings require remedial action. Remedial actions on the cylinder yard designs to contain spills (from whatever cause) should be carefully considered. Rusting cylinders and missing I.D. plates should be addressed. Corrective actions on cylinder design and operational practices are needed to guard against impacting cylinders in the future, to extend the service life of the cylinders, and to enhance the inspection quality of stored cylinders. Improved lug design and stringent practices for saddle and cylinder placement would help ensure cylinder safety accessibility for inspection. Improved coatings would enhance cylinder examination and extend 
the service life of the cylinders. If it is determined that operational faults (such as improper spacing of saddles and misaligned lifting lugs or minor dents) have not compromised cylinder integrity, remedial action should not be required. These conditions are only a threat to cylinder integrity during the stacking/handling operation. Restacking of these cylinders would actually open the possibility for impacting more cylinders, especially due to their present stacking configuration.

\section{IMPLICATIONS OF FAILURES ON PRESENT STORAGE POLICIES}

\subsection{ASSESSMENT OF CYLINDER DESIGN FAULTS}

Based on the overall failure statistics for the 14-ion, depleted $\mathrm{UF}_{6}$ cylinders, the mechanical design has proved generally reliable and well suited to the required filling and handling operations. However, the present failures now call into question the mechanical integrity of the cylinders for long-term storage of solid $\mathrm{UF}_{6}$, given the present stacking procedures. One obvious design change that could reduce the probability for the type of failures observed here is to reshape and possibly relocate the lifting lugs. A related change would be to add a guardrail to the stiffening ring. Both these changes are addressed in Sect. 9, "Recommendations." There is also a need for qualification testing that can assess mechanical properties of the cylinders in the context of storage requirements, where external pressures acting on the cylinders need to be addressed as well as internal pressure. Paducah personnel responsible for qualification testing of the cylin..ers have indicated that mechanical tests could be included in their test program to evaluate the effects of external loads typical of lifting lug impacts. Accordingly, the investigation tean recommending that such a test program be developed, particularly with respect to invesugating the actual forces required to penetrate the cylinders. Without such tests, there is currently no methodology for recommending design changes to the shell that would make it more resistant to handling mishaps, such as sharp impacts, or to movements induced by ground tremors or shifting between cylinders.

An issue related to cylinder design is the selection of the material to be used as the pressure boundary. The selection process for the steel for these cylinders has been very exacting, with input from a relatively long history of acceptance tests and a large service data base. The A516 grade currently specified for the 14-ton cylinders was adopted because minimum toughness properties could be included in the acceptance test requirements for this grade. It replaced the A285 grade, which had no toughness requirements as part of the purchase specification. Although both grades are considered acceptable in terms of their toughness properties at the expected cylinder service temperatures, A516 is obviously preferred for quality assurance reasons. Metallurgical tests at Paducah have indicated that the heat of A516 steel used to fabricate the small-hole cylinder probably contained segregated sulfide inclusions, which may have increased the risk for the type of damage (tearing) that ultimately occurred. However, current specifications for this steel call for a lower sulfur level to avoid the sulfur segregation problem, so this issue is not relevant to cylinders being manufactured today. Furthermore, the failure in the large-hole cylinder, which is made of A285 steel, indicates that, even without sulfide inclusions, tearing can result from an impact near the stiffening ring. Thus, the failures observed here appear endemic to the cylinder design and cannot be tied to insufficiencies in the types of steels specified. 
In summary, although the current cylinder design needs to be examined in terms of mechanical requirements for long-term storage, the more essential remedial action involves design changes that protect against handling and stacking accidents.

\subsection{POTENTIAL EXISTENCE OF ADDITIONAL FAILED CYLINDERS}

At the time the subject cylinder failures were discovered, visual inspections were immediately initiated to examine the entire stockpile of depleted uranium storage cylinders to ascertain whether other similar defects existed. No other problems of this type were found. However, a small number of cylinders were stacked such that they could not be completely accessed for viewing. Also, a few cylinders were stacked with the lifting lug of an adjacent cylinder clearly impinging at a stiffening ring weld. Paducah, at this time, initiated a record of these inspections, cataloging any mechanical or corrosion damage and potential problems with how the cylinders are supported. This record will enable an identification of cylinders that could not be physically inspected in their entirety, as well as cylinders that have mechanical defects or spacing problems that could potentially lead to problems of the type experienced here. This information will provide a basis for taking actions to verify that no other breached cylinders currently exist in the present stockpile at Paducah and that any mechanically defected, but intact, cylinders can be appropriately inspected and, if deemed necessary, fed back to the cascade. Similar information is needed for the storage yards at K-25 and Portsmouth.

The heat of A516 steel used in the manufacture of the small-hole cylinder has been shown to be more vulnerable to a tearing failure along the stiffening ring weld than steels used before or since. It is particularly important that other cylinders made from this same heat of A516 be fully inspected and kept under surveillance if evidence of mechanical damage near the stiffening ring is found. Furthermore, in the unstacking of cylinders to gain access to the subject failed cylinders at Portsmouth, cylinders were identified that have dents near the stiffening ring weld (Fig. 8). Although subsequent nondestructive examinations of these cylinders showed no detectable cracks and they, therefore, were restacked, the affected cylinders should be kept under surveillance and periodically inspected.

\subsection{POTENTIAL EFFECTS OF FAILURES ON INTEGRITY OF NEIGHBORING CYLINDERS}

The cylinder directly below the large-hole cylinder was corroded by HF-containing reaction products to a maximum depth of 0.13 in. Although the resultant loss of wall thickness posed no problems in moving the cylinder, the thickness was below that allowed for liquid feeding back to the diffusion plant, and warm feeding will have to be used to empty this cylinder. Based on the experience here, it must be accepted that failure of a neighboring cylinder could be induced by breached cylinders, provided that the neighboring cylinder is in the line of movement of HFcontaining reaction products (see Appendix B). Such an induced failure could have potentially serious consequences if: (1) the damaged area was so extensive that it precluded patching or moving the cylinder or (2) it cut a hole into the top of the cylinder where there was very little solid $\mathrm{UF}_{6}$ available to act as a plug to prevent the spread of contamination. The latter scenario reinforces the importance of early detection of failures of the type incurred here and emphasizes the need for inventorying and inaintaining surveillance on any damaged cylinders currently in storage. 


\subsection{GENERAL ASSESSMENT OF CYLINDER INTEGRITY FOR LONG-TERM STORAGE}

Until the present failures, the primary concern with the existing thin-wall cylinder design for long-term storage was corrosion. This stemmed from the assumption that, once the cylinder had been transported to the cylinder yard and stored, corrosion should be the only factor to reduce mechanical integrity. These failures indicate that mechanical factors can have an influence on cylinder lifetime even after stacking. One problem stems from mechanical damage induced at the tail end of the stacking sequence, which has remained undetected by prevailing inspection procedures. Another problem stems from damage that can occur even after the cylinders are stacked due to one cylinder resting on another or the shifting of one cylinder relative to another. Both these problems can be addressed by adding to the sequence of inspection procedures (discussed below) and ensuring proper spacing and support for the cylinders.

In the above context, the impact of the subject failures on the reliability rating of depleted uranium storage cylinders is minimal and manageable by procedural changes. However, the failures do emphasize the vulnerability of the cylinders to impact damage by projectiles and jostling from earthquakes. The team's inspections of storage yards also confirmed the need for restacking and even relocating cylinders that are improperly supported and where corrosion is suspected but cannot be verified without moving the cylinder. These needs are currently being reviewed by other committees and will not be elaborated on here. However, the team believes that these needs must be addressed if these cylinders are to be allowed to remain in their current environment. Unchecked deterioration of these cylinders will inevitably create a waste disposal problem with control passing to federal and state environmental, safety, and health agencies. Moreover, irrespective of the value of their contents as future source material, the cylinders obviously have to be in operational condition that will allow emptying or reprocessing.

\section{ADDITIONAL ACTIONS REQUIRED TO COMPLETE INVESTIGATION}

As mentioned in Sect. 1, "Introduction," this report is intended as a final report in terms of completing the team's assigned failure analysis task. However, the introduction also mentioned that additional actions are necessary to support the investigation team's conclusions and recommendations. Table 2 lists the additional actions required of Portsmouth Operations to complete the subject investigation. The investigation team requests that it be kept informed of the schedule that Portsmouth will follow in completing these actions. The team will address the findings from these actions and issue an addendum report if required.

\section{CONCLUSIONS}

Two 14-ton $\mathrm{UF}_{6}$ storage cylinders with breached walls were discovered at the Portsmouth Gaseous Diffusion Plant in June 1990. An analysis was completed to assess the failure causes and their implications for continued $\mathrm{UF}_{6}$ storage.

The investigation team's analysis showed that the failures most probably resulted from mechanical damage that occurred at the time that the cylinders had been placed in the storage 
Table 2. Additional actions to complete the breached cylinder investigation

\begin{tabular}{|c|c|c|}
\hline Cylinder & & Action \\
\hline \multirow[t]{6}{*}{$\begin{array}{l}\text { 4G127985 } \\
\text { (small hole cylinder) }\end{array}$} & 0 & $\begin{array}{l}\text { Visually inspect and weigh reaction products which } \\
\text { plugged the hole. }\end{array}$ \\
\hline & 0 & $\begin{array}{l}\text { Analyze above reaction products to determine } \mathrm{U} \text { and } \mathrm{F} \\
\text { concentrations and examine core samples by } \mathrm{X} \text {-ray } \\
\text { diffraction to identify chemical species. }\end{array}$ \\
\hline & 0 & Examine cylinder to establish distribution of heels. \\
\hline & 0 & Decontaminate cylinder. \\
\hline & 0 & $\begin{array}{l}\text { Retrieve section of stiffening weld near failure area and } \\
\text { examine metallographically to determine morphology of } \\
\text { sulfide stringers. }\end{array}$ \\
\hline & 0 & $\begin{array}{l}\text { Retrieve specimen of cylinder wall which contains dent } \\
\text { on plug-end of cylinder and examine metallographically } \\
\text { for micro-cracks. }\end{array}$ \\
\hline \multirow{5}{*}{$\begin{array}{l}\text { 4G115688 } \\
\text { (large hole cylinder) }\end{array}$} & 0 & Complete emptying of cylinder. \\
\hline & 0 & $\begin{array}{l}\text { Inspect inside surfaces of cylinder to determine nature } \\
\text { and distribution of heels. }\end{array}$ \\
\hline & 0 & $\begin{array}{l}\text { Analyze reaction products to determine } U \text { and } F \\
\text { concentrations and examine core samples by } \mathrm{X} \text {-ray } \\
\text { diffraction to identify chemical species. }\end{array}$ \\
\hline & 0 & Decontaminate cylinder. \\
\hline & o & $\begin{array}{l}\text { Retrieve metallurgical samples for microscopic } \\
\text { examination. }\end{array}$ \\
\hline \multirow{2}{*}{$\begin{array}{l}4 \mathrm{G} 113595 \\
\text { (cylinder with head inclusions) }\end{array}$} & o & Empty cylinder identified having shell/head inclusions. \\
\hline & 0 & $\begin{array}{l}\text { Remove metallurgical samples and examine micro- } \\
\text { scopically to identify morphology of inclusions. }\end{array}$ \\
\hline \multirow[t]{2}{*}{$\begin{array}{l}4 \mathrm{G} 127902 \\
\text { (cylinder with dent) }\end{array}$} & 0 & $\begin{array}{l}\text { Identify and empty a cylinder dented near stiffening ring } \\
\text { such that tearing of cylinder wall may have occurred. }\end{array}$ \\
\hline & 0 & $\begin{array}{l}\text { Remove metallurgical sample of dent for fracture and } \\
\text { microscopic analysis. }\end{array}$ \\
\hline
\end{tabular}


yard. In both cylinders evidence pointed to the impact of a lifting lug of an adjacent cylinder near the front stiffening ring, where deflection of the cylinder could occur only by tearing the cylinder wall (the exact force to fracture a thin-wall cylinder is unknown). The impacts appear to have caused tears that penetrated the cylinders and thereby set up corrosion processes that greatly extended the openings in the wall and obliterated the original crack. Fortunately, the reaction products formed by this process proved to be relatively protective and prevented any large-scale environmental insult or loss of uranium. Corrosion was associated with the formation of a strongly acidic, aqueous solution containing dissolved $\mathrm{HF}$ and $\mathrm{UO}_{2} \mathrm{~F}_{2}$. The exact composition of the hexavalent uranium-bearing ion is unknown. Reaction of this solution with steel and moist air resulted in the formation of iron fluorides and $U_{4}$, which restricted the movement of the underlying uranium.

Factors that facilitated the failures were inadequate spacing between cylinders and deviations in the orientations of lifting lugs from their intended horizontal position. In both failure cases, neighboring cylinders were crowded and lugs were misaligned to the point where dents due to impinging lugs could be found. Thus, although the current cylinder design is particularly vulnerable to punctures near the stiffening rings, the present failures stem more from handling and stacking procedures than from design inadequacies. However, design changes that could be beneficial involve rounding the lifting lug profile and modifying the present paint scheme to a color (such as white) that contrasts with that of $\mathrm{UF}_{4}$.

An assessment of the failures experienced here indicates that the associated environmental impact can be greatly reduced by a more rigorous visual inspection during the stacking operation and routine inspections thereafter. In the four years that elapsed in forming the smaller hole, there was no measurable quantity of unrecoverable uranium lost. With adequate inspection and monitoring, both of these incidents most likely would have been detected early enough to have avoided any measurable impact on the environment or loss of inventory. However, the inherent difficulty of visually inspecting stacked cylinders for dents and possible cracks will require a high level of awareness training of the personnel responsible for inspecting the cylinders.

The team's survey of the cylinder yards at the three diffusion plants showed that the factors that led to the failures were not unique to the Portsmouth site. The frequency of these factors at other sites appeared less. Yet, the possibility that a similar accident sequence could have occurred for other cylinders now in storage cannot be completely ruled out, and further efforts will be required at all three sites to examine those cylinders for which spacing has prevented a complete visual inspection. Visual inspection is also a concern for cylinders having "U"-channeltype stiffening rings, which have areas under the rings that are blocked from view.

In view of the size of the holes produced and the length of time that corrosion processes operated (13 years in one case), these failures approach the "worst-case" scenario of what can

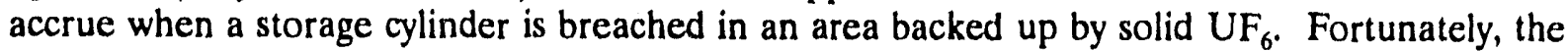
effects appear to have been minimal in terms of the inventory of uranium and fluorine lost to the environment and the overall physical damage to the cylinders. However, it is not known whether a failure closer to the top of the cylinder (i.e., in the vapor space) would have resulted in the same environmental effects, since the reaction products formed may not be as protective as those formed in the subject failures. Accordingly, a study of the effects of a break into the gas space of the cylinder will be required before the maximum credible incident associated with the mechanical failure during storage can be absolutely defined. 


\section{RECOMMENDATIONS}

Early in the investigation, preliminary recommendations wcre made concerning cylinder modifications and additional inspection and monitoring of cylinder handling, stacking, and storage operations. ${ }^{10}$ These preliminary recommendations were evaluated by the $\mathrm{UF}_{6}$ Handling Committee and others in a formal response to the investigation team, ${ }^{11}$ many of which have already been implemented or acted upon. As the investigation progressed, the team discussed other recommendations related to the findings. These fall into the categories of design modifications, inspection enhancements, and extended evaluations as listed below. They include some of the recommendations made earlier.

The team is aware that the recommendations already implemented have been funded from current budgets and that committing to any further recommendations will require additional funding. Accordingly, the full implementation of these recommendations obviously depends on budgetary considerations.

\subsection{DESIGN MODIFICATIONS}

These modifications relate to cylinder design, cylinder stacking orientation, and handling equipment improvements. They may require revision as future engineering modifications are incorporated.

1. Recommended improvements in the $\mathrm{UF}_{6}$ storage cylinder design include rounding the upper corner of the lifting lug and changing the paint color to achieve better contrast with $\mathrm{UF}_{4}$ reaction products. Design modifications that would divert impacts away from the area of the stiffening ring weld should also be considered. Possible design approaches include welding a band around the outside diameter of the stiffening ring or devising removable shields (bumpers) that can be placed on the lifting lugs during stacking.

2. Cylinder stacking procedures should be improved by standardizing the cylinder-to-cylinder spacing, the cylinder row-to-cylinder row spacing, and lifting lug alignment. The cylinder-tocylinder spacing can be controlled by standardizing the saddle length to the minimum cylinder-to-cylinder spacing requirement. Spacers can be used to correctly align the front and back saddles and the space between cylinder rows. Lug alignment could be controlled through operator training and inspection.

3. The Raygo Wagner operator's vision is hindered to the extent that hand signals (to indicate cylinder position) are required from an assistant stationed on the ground. The feasibility of mounting remote video cameras on the Wagner should be assessed as a method for improving the operator's visibility.

\subsection{INSPECTION ENHANCEMENTS}

Cylinder inspections should be instituted to detect any mechanical damage occurring during, and at the end of, the stacking operation. Cylinders should be monitored on a routine basis thereafter to ensure that any breach will be detected in a short enough time period to limit 
environmental and corrosion effects. Training, documentation, and recordkeeping are obviously essential parts of these inspection procedures and should be consistent among the three sites.

1. Cylinder inspections at the time of stacking should provide assurance that the cylinder is properly oriented, whether any defects (e.g., dents) have occurred, and establish a permanent record of the cylinder condition at the time of stacking. Routine monitoring inspections should emphasize examination of those cylinders presently in the stockpile, which are nonstandard with respect to dents or stacking clearances. These inspections should also emphasize cylinders made of the same heat of A516 steel as the small-hole cylinder and

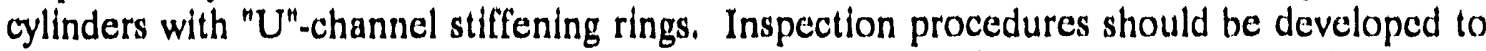
gain visual access to cylinders that, to date, have not been inspected in their entirety.

2. Documentation of the operations performed in the cylinder yards and of any potential problem areas will assist future cylinder yard surveillance and could provide a basis for reducing the frequency of routine inspections for the monitoring program.

3. Awareness training will ensure that all operators comprehend the susceptibility of weld areas to handling damage, especially damage caused by impact by a lifting lug. Training to instruct operators as to common handling and stacking requirements will also improve the quality of inspections.

\subsection{EXTENDED EVALUATIONS}

To evaluate whether design changes could improve the mechanical integrity of the cylinders for long-term storage, a better understanding of the fracture mechanics characteristics of the cylinder is required. Additional information is also required to determine the long-term effects of a breach in the cylinder wall that occurs in the gas above the level of solid $\mathrm{UF}_{6}$, since it has been postulated that such an event could lead to more serious consequences than those experienced with the subject failures. A study is also recommended to better define the environmental effects associated with ground spills of $\mathrm{UF}_{6}$ with respect to storage pad design. Specific investigations needed to obtain the additional technical data are as follows:

1. As part of the current cylinder qualification program, a mechanical testing program should be conducted to evaluate the impact loads required to puncture the cylinder from the outside as a function of distance from the stiffening rings. The information obtained should be applied to a fracture mechanics analysis to determine whether modifications in the stiffening ring welds or in the cylinder wall thickness at the ring attachment point would decrease the vulnerability of the cylinder to impact loads.

2. An experiment is needed to assess the effects of an accidental breach that penetrates into the gas space of a $U_{6}$-containing cylinder that has been in storage for several years. $A$ relatively small $\mathrm{UF}_{6}$ containment cylinder, sized to simulate the gas-to-solid volume ratio of an actual storage cylinder, should be fitted with a mechanically sealed port at the top and then filled with the designated volume fraction of $\mathrm{UF}_{6}$. After the cylinder has been repeatedly warmed and cooled to simulate diurnal atmospheric effects, the top port of the cylinder should be opened to admit a controlled amount of water, simulating rain. Chemical changes in the $\mathrm{UF}_{6}$ should be analyzed as a function of exposure time and correlated with changes observed in the current failures. 
3. With respect to design speclfications for storage yards, an assessment is needed of the environmental impact of fallures of the type experienced here in gravel-based yards as opposed to concrete-based yards.

4. To better understand the effects of corrosion damage on structural integrity, cylinder

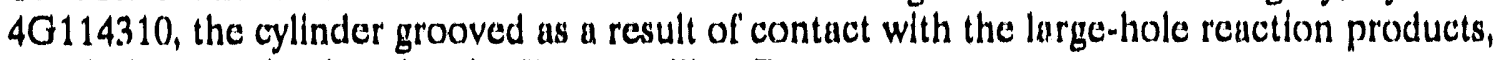
should be examined under the Rupture Test Program.

\section{REFERENCES}

1. T. R. Lemons et al., The Ultimate Disposition of Depleted Uranium, K/ETO-44, Martin Marietta Energy Systems, Inc., Oak Ridge Gaseous Diffusion Plant, December 1990.

2. H. M. Henson et al, Monitoring of Corrosion in ORGDP Cylinder Yards, CONF-89(06)1-1, Martin Marietta Energy Systems, Inc., Oak Ridge Natl. Lab., December 1989.

3. M. L. Glenn, Uranium Hexafluoride Tails Storage Cylinders, KY.657, Union Carbide Corp.Nuclcar Div., Paducah Gaseous Diffusion Plant, June 1974.

4. C. R. Barlow et al, Cylinder Yard Inspections and Corrective Actions, K/SS-546, Martin Marietta Energy Systems, Inc., Oak Ridge Gaseous Diffusion Piant, July 1990.

5. K. W. Sommerfeld, Martin Marietta Energy Systems, Inc., letter to J. W. Parks, Department of Energy, Oak Ridge, Tenn., "Activity of the Team to Investigate Tails Cylinder Breaches," dated July 23, 1991.

6. K. W. Sommerfeld, Martin Marietta Energy Systems, Inc., letter to J. W. Parks, Department of Energy, Oak Ridge, Tenn., "Tails Cylinder Integrity," June 18, 1990.

7. S. C. Blue, "Fracture Control of Steel UF, Cylinders," in Uranium Hexafluoride - Safe Handling, Processing, and Transporting-Conference Proceedings, CONF-880558, Martin Marietta Energy Systems, Inc., Oak Ridge Gaseous Diffusion Plant, May 1988.

8. A. J. Mallett, Water Immersion Tests of UF ${ }_{6}$ Cylinders With Simulated Damage, K-D-1987, Union Carbide Corp.-Nuclear Div., Oak Ridge Gaseous Diffusion Plant, November 1967.

9. Y. A. Buslaev et al., "On the Solubility and Composition of the Solid Phases in the System HF-UO ${ }_{3}-\mathrm{H}_{2} \mathrm{O}, "$ Acad. Sci. USSR 148, 832-34 (1963).

10. J. H. DeVan, Martin Marietta Energy Systems, Inc., Oak Ridge Natl. Lab., letter to

D. L. Mason, Martin Marietta Energy Systerns, Inc., Oak Ridge, Tenn., "Committee Recommendations Relating to PORTS Tails Cylinders," July 9, 1990.

11. W. E. Sykes, Martin Marietta Energy Systems, Inc., Paducah, Ky., letter to J. H. DeVan, Martin Marietta Energy Systems, Inc., Oak Ridge Natl. Lab., Oak Ridge, Tenn., "Response to Recommendations Relating to Failure of PORTS Tails Cylinders," December 21, 1990. 


\section{APPENDIX A}

\section{BREACHED CYLINDERS DESIGN SPECIFICATIONS, CONTENTS, AND STORAGE LOCATIONS}

Table A-1. Cylinder design specifications

\begin{tabular}{lcc}
\hline \multicolumn{1}{c}{ Item } & Cyl. 4G127985 & Cyl. 4G115688 \\
\hline Cylinder type & G & OM \\
Drawing No. & UCC-ND E M-1483-A, Rev. 7 & E-S-12292-A, Rev. 8 \\
Specification No. & JSP 553 R-5 & NA \\
Manufacturer & United Fabricators Inc. & Modern Welding Co. \\
Fabrication date & 1982 & 1975 \\
Steel type & A516 & A285 \\
Desigu temp, ${ }^{\circ} \mathrm{F}$ & 235 & 235 \\
Design pres., psig & 100 & 100 \\
Tare wt, lb & 2590 & 2591 \\
\hline
\end{tabular}

Table A-2. Cylinder contents

\begin{tabular}{lcc}
\hline \multicolumn{1}{c}{ Item } & Cyl. 4G127985 & Cyl. 4G115688 \\
\hline Fill date & June 21, 1986 & November 1976 \\
$\mathrm{U}_{235}$ assay, \% $\mathrm{U}_{235} / \mathrm{U}$ & 0.2514 & 0.2588 \\
$\mathrm{U}$ content, \%U & 67.61 & 67.62 \\
Initial net wt, lb & 27,517 & 27,927 \\
Present gross $w t, \mathrm{lb}$ & 30,107 & 30,507 \\
\hline
\end{tabular}


Table A-3. Cylinder storage location

\begin{tabular}{lcc}
\hline \multicolumn{1}{c}{ Item } & Cyl. 4G127985 & Cyl. 4G115688 \\
\hline Stack date & June 1986 & $197 \%$ \\
Yard & X-745C & X-745C \\
Section & 3 & 1 \\
Row & 13 & 20 \\
Shelf & A (bottom) & B (top) \\
Position & 44 & 15 \\
\hline
\end{tabular}


APPENDIX B

DETAIIED FINDINGS AND ANALYSES

\author{
PART 1 \\ Observations and Analyses of the Vapor Space \\ Contents and Corrosion Deposits
}

PART 2

Chemical Aspects of Corrosion of Breached

$\mathrm{UF}_{6}$ Cylinders

\title{
PART 3
}

Chemical Aspects of - ylinder Corrosion and a Scenario for Hole Formation

\section{PART 4}

\section{A List of Reports}

(A complete listing of all reports referenced in the document. The reference numbers in Appendix B are keyed to this listing.) 
APPENDIX B, PART 1 (B1)

OBSERVATIONS AND ANALYSES OF THE VAPOR SPACE CONTENTS AND CORROSION DEPOSITS 
This appendix documents some qualitative observations and the quantitative measurements and chemical analyses that have bearing on the development of the overall failure scenario critical to decisions relative to assessment of the risks associated with the breaching of cylinders filled to the shipping limit with solid $\mathrm{UF}_{6}$. In particular, the changes in cylinder weight, the pressure in the vapor space, the composition of the gas in the vapor space, and the composition of the various identified corrosion products developed exterior to the cylinder are reported on cylinder 4G127985, which had the small hole. In addition to these analyses, the gas pressure and composition at various times and the composition of the $\mathrm{r}$ action deposit layers within the cylinder are given for cylinder $4 \mathrm{G} 115688$, which had the large hole.

Examination of the morphology of the deposits in both cylinders cannot be completed until the $\mathrm{UF}_{6}$ is removed from the cylinders and the radioactive uranium daughter products have decayed sufficiently to permit working for a considerable period of time close to the deposits. After emptying the $\mathrm{UF}_{6}$, a video view of the interior deposit in the vicinity of the small hole in cylinder $4 \mathrm{G} 127985$ has been obtained using a fiber optics boroscope. ${ }^{12}$ An X-ray picture of the deposit in the vicinity of this hole was also obtained by an X-ray absorption technique. These suggest that the deposit has the shape of half of a crude ellipsoid and that the interior surface of the deposit, which was originally next to the $\mathrm{UF}_{6}$, was at one time coated with a thin layer of an orange-colored compound, which is believed to be $\mathrm{U}_{2} \mathrm{O}_{3} \mathrm{~F}_{6}{ }^{32}$ or perhaps $\alpha$-UOF , also orange in color. ${ }^{48}$. The minor and major diameters of the ellipsoid are perhaps of the order of those of a golf ball and a tennis ball. ${ }^{12}$ It is planned to perform similar studies on the deposits in cylinder $4 \mathrm{G} 115688$ when the $\mathrm{UF}_{6}$ has been removed.

\section{QUALTTATIVE OBSERVATIONS RELATING TO THE HOLE IN CYLINDER 4G115688}

The hole in cylinder 4G115688 and the plugging material in it were inspected up close, and materials from these deposits were removed both by grab sampling and attempted core sampling. While the identifications of the materials removed from within and around the hole are not all absolutely positive, it is obvious from their appearance that, as one might expect from the discussion in Appendix B, Parts 2 and 3, and from the work of Mallett, ${ }^{24}$ there is a large quantity of a fluorescent yellow, hexavalent uranium oxyfluoride behind the outer deposit of hydrated UF salt. ${ }^{7}$ The soft, porous, green $\mathrm{UF}_{4}$ hydrate layer over this material has only recently sloughed off the deposit at the center of the hole.

During an inspection of the hole in August 1990, the strong odor of escaping HF was evident under the canopy. With the canopy removed, the concentration of HF was measured by industrial hygiene personnel at Portsmouth Gaseous Diffusion Plant (PORTS) and found to be below the permissible exposure limit (PEL) of $2.5 \mathrm{mg} \mathrm{HF} / \mathrm{M}^{3}$. The odor of $\mathrm{HF}$ becomes detectable at a concentration of 0.1 to $1 \mathrm{ppm}$. The concentration of airborne $U$ was determined to be less than $0.001 \mathrm{mg} \mathrm{U} / \mathrm{M}^{3}$.

During the removal of the deposits from the outside surface of the cylinder, preparatory to attaching the cylinder patch, R. E. Dorning of PORTS reports that a viscous, wet-looking, acidic solution was present on the cylinder surface at the bottom of the hole and was replaced when it was removed. ${ }^{13}$ There was not a sufficient quantity of the fluid to permit sampling for analysis; however, it should be noted that the existence of such a material is consistent with the chemistry 
presented in Appendix B, Part 3. The tail or eroded channel below the hole in each cylinder is evidence for the existence of this acidic solution in both cylinders. Additional evidence for loss of this solution from the large hole is the etched grooves in the lower-level cylinder directly below the large hole and the presence of $32,000 \mathrm{ppm}$ uranium in a soil grab sample taken at the point where rainwater from the breached cylinder ran from the pad. The etched grooves in the cylinder below the large hole were initially filled and covered by the green corrosion deposits.

The attempted core sampling of the deposits within cylinder $4 \mathrm{G} 115688$ was only partially successful, since the core samplers could not be driven completely through the yellow, hexavalent uranium oxyfluoride layer to the $\mathrm{UF}_{6}(\mathrm{~s})$. The fact that the layer of $\mathrm{UF}_{4}$ hydrate is exterior to the complex, hexavalent uranium oxyfluoride materials within the plug was clearly evident and samples of the material deep within the plug were obtained. The analysis of these has not shown anything different from grab samples of similar materials taken just under the UF, layer. ${ }^{43,44}$ The outer $\mathrm{UF}_{4}$ hydrate layer is approximately 4-in. deep, and the overall plug extends more than 12 in. into the cylinder. ${ }^{6}$

Metallurgical examination of the cylinders will not be undertaken until the deposits have been removed by decontamination, so these data also will have to be reported later.

\section{WEIGHT CHANGES OF CYLINDERS 4G127985 AND 4G115688}

While there was no unaccounted-for change in the weight of cylinder 4G127985 during the 4 years in which the small hole was developing, a measurable loss in weight did occur in cylinder 4G115688 during the 13 years the hole in this cylinder was enlarging. ${ }^{5}$ The gross and net weight changes for these cylinders are given in Table B1-1. Given in Table B1-2 are the weights of $\mathrm{UF}_{6}$ and Fe needed to produce the material recovered outside these cylinders; the weight of the vapor removed before weighing, in the case of cylinder 4G115688; and the current, net, unaccounted-for weight change. For cylinder $4 \mathrm{G} 115688$, this last value should be reduced by the weight of the material removed from this cylinder and the one below it at the time of patching; however, a quantitative determination of the weight of this material is not available. Those who removed this material described it as being "light and fluffy" and estimated that the total mass was small with respect to the mass of the products previously recovered at this site $(15 \mathrm{lb})$. Thus, no corrections have been applied to account for this material. The overall stoichiometry of the reactions between $\mathrm{UF}_{6}$, water, and $\mathrm{Fe}$ occurring here is believed to be given by the following equation, as explained in Appendix B, Part 3:

$$
3 \mathrm{UF}_{6}+13.5 \mathrm{H}_{2} \mathrm{O}+2 \mathrm{Fe}=3 \mathrm{UF}_{1} * 2.5 \mathrm{H}_{2} \mathrm{O}+2 \mathrm{FeF}_{3} * 3 \mathrm{H}_{2} \mathrm{O}
$$

The residual unaccounted-for weight merely represents missing mass and does not necessarily correspond directly to the quantity of $\mathrm{UF}_{6}$ lost from the cylinder. To determine the exact quantity of $\mathrm{UF}_{6}$ lost would require a complete knowledge of the reactions undergone by the $\mathrm{UF}_{6}$ within the cylinder and the quantity that has reacted. The information available is not that complete, and one can only attempt to bound the problem based on the information available. Obviously, the lower bound on the UF $\mathrm{UF}_{6}$ lost is the missing mass. Upper bounds can be estimated using the mass of iron, which is oxidized but not found in loose deposits outside the cylinder, and the mass of $\mathrm{UF}_{6}$, which is estimated to have reacted with water inside the cylinder to produce the yellow layer. Since the plug material in the hole in cylinder 4G127985 was colored green toward the 
Table B1-1. Weight changes of cylinders 4G127985 and 4G115688

\begin{tabular}{lrr}
\hline \multicolumn{1}{c}{ Operation } & $\begin{array}{r}\text { Cyl. } \\
4 G 127985 \\
\text { (ref. 46) }\end{array}$ & $\begin{array}{r}\text { Cyl. } \\
\text { 4G115688 } \\
\text { (ref. 5) }\end{array}$ \\
\hline Gross wt of cylinder when filled in 1976, lb & 30,107 & 30,518 \\
Wt of patches, etc., lb & 1 & 26 \\
Wt to be accounted for, lb & 30,108 & 30,544 \\
Current gross wt, lb & $\underline{30,107}$ & $\underline{30,507}$ \\
Net wt change, lb & -1 & -37 \\
\hline
\end{tabular}

Table B1-2. Weight of $\mathrm{UF}_{6}$ and Fe to produce material recovered outside the cylinder plus the weight of gas withdrawn from cylinder

Operation

Cyl. 4G127985 Cyl. 4G115688

Mass of $\mathrm{UF}_{6}$ generating deposit outside cylinder, $\mathrm{lb}$

(use stoichiometry of Eq. B2-26, Appendix B, Part 2)

Mass of $\mathrm{Fe}$ in deposit outside cylinder, $\mathrm{lb}$ 0.08

(remainder of reacted $\mathrm{Fe}$ is weighed with cylinder)

Mass of HF bled from vapor space, $\mathrm{lb}^{*}$

Mass of $\mathrm{UF}_{6}$ bled from vapor space, $\mathrm{lb}^{*}$

$\mathrm{Wt}$ of materials known to be removed, $\mathrm{lb}$

0.75

11

Unaccounted-for change in cylinder wt, lb

\begin{tabular}{rr}
0 & 5 \\
0 & $\underline{3}$ \\
\hline 0.83 & 20 \\
-0.17 & -17
\end{tabular}

*An 8-lb mass of vapor from the vapor space of cylinder 4G115688 was transferred into an evacuated cylinder. This vapor was $62 \%$ HF by weight (see Appendix B, Part 2). 
atmospheric side and orange toward the $\mathrm{UF}_{6}$, the yellow layer is presumed to have been present between them in this cylinder also (see Appendix B, Part 2).

Since, as shown later in this part, this yellow layer is mostly amorphous, its structure is unknown. Analysis shows this material to be a solvated uranyl fluoride with an F-atom-to$\mathrm{U}$-atom ratio of 3.05 and a $U$ content of $67.4 \mathrm{wt} \% .^{8}$ These results suggest a mixture of the $\left[\mathrm{H}_{3} \mathrm{O}\right]_{2}\left[\mathrm{U}(\mathrm{OH})_{4} \mathrm{~F}_{4}\right]$, which Buslaev et al. ${ }^{7}$ show forms in greater than $50 \% \mathrm{HF}$ solution, and $\mathrm{UO}_{2} \mathrm{~F}_{2}$. Both of these materials yield $\mathrm{UO}_{2} \mathrm{~F}_{2} * 2 \mathrm{H}_{2} \mathrm{O}$ on exposure to additional water. A 50:50 mixture of these materials on a molar basis yields the average composition, $\mathrm{UO}_{2} \mathrm{~F}_{2} * 2 \mathrm{H}_{2} \mathrm{O} * \mathrm{HF}$, which Pickrell ${ }^{34}$ found to be formed by the vapor phase hydrolysis of $\mathrm{UF}_{6}$ at low humidities. The assumption of a material of this average composition for the yellow layer is made in the estimation of the upper bound on the loss of $\mathrm{UF}_{6}$.

The stoichiometry of this reaction of the $\mathrm{UF}_{6}$ with water vapor and the missing portion of the iron cylinder is the same reaction given above for the loose deposits found outside the cylinder, except that the $\mathrm{UF}_{4}$ product is less hydrated; i.e., about $50: 50 \mathrm{UF}_{4}^{*} 1.5 \mathrm{H}_{2} \mathrm{O}$ and $\mathrm{UF}_{4}{ }^{*} 0.75 \mathrm{H}_{2} \mathrm{O}$ as shown below:

$$
3 U F_{6}+9.375 \mathrm{H}_{2} \mathrm{O}+2 \mathrm{Fe}=2 \mathrm{FeF}_{3} * 3 \mathrm{H}_{2} \mathrm{O}+1.5 U \mathrm{~F}_{4} * 1.5 \mathrm{H}_{2} \mathrm{O}+1.5 U \mathrm{~F}_{1} * 0.75 \mathrm{H}_{2} \mathrm{O}
$$

Note that the only weight change is due to the addition of water, which would result in an increase in the weight of the cylinder contents. As shown as the second entry in Table B1-3, the gain in weight due to this reaction is about $10 \mathrm{lb}$.

In Appendix B, Part 2, it is shown that, as an approximation, the quantity of $\mathrm{UF}_{6}$ hydrolyzed within cylinder $4 \mathrm{G} 115688$ is on the order of 27 times the quantity reduced by the iron for an estimated total of $916 \mathrm{~kg}$ of $\mathrm{UF}_{6}$ hydrolyzed. For cylinder $4 \mathrm{G} 127985$, the considerations discussed in Appendix B, Part 2, led to an estimate of $13.7 \mathrm{~kg} \mathrm{(30} \mathrm{lb)} \mathrm{of} \mathrm{UF}_{6}$ hydrolyzed. It is also shown that about $15.8 \mathrm{lb}$ of $\mathrm{HF}$ is retained within cylinder $4 \mathrm{G} 115688$ and $1.8 \mathrm{lb}$ in cylinder $4 \mathrm{G} 127985$. Based on the assumption that the average composition of the yellow layer is given by $\mathrm{UO}_{2} \mathrm{~F}_{2}: 2 \mathrm{H}_{2} \mathrm{O}: \mathrm{HF}$, the gain in weight of the cylinder would be due to the water reacting, as in the following equation:

$$
U F_{6}(s)+4 \mathrm{H}_{2} \mathrm{O}(\text { aq. } \mathrm{HF})=\mathrm{UO}_{2} \mathrm{~F}_{2} * 2 \mathrm{H}_{2} \mathrm{O} * H F(s)+3 \mathrm{HF}(\mathrm{g})
$$

The weights of water added to the contents of the cylinders to produce this HF constitute the fourth quantity given in Table B1-3.

"The terms "solvated $\mathrm{UO}_{2} \mathrm{~F}_{2}$ " or " $\mathrm{UO}_{2} \mathrm{~F}_{2}$ solvate" indicate a chemical composition that can be described by the general formula, $\mathrm{UO}_{2} \mathrm{~F}_{2} * \mathrm{xH}_{2} \mathrm{O} * \mathrm{yHF}$. The water and $\mathrm{HF}$ are chemically bound but not necessarily, as such, to the uranium. If only water is bound, the material is more precisely described as "hydrated $\mathrm{UO}_{2} \mathrm{~F}_{2}$ " or " $\mathrm{UO}_{2} \mathrm{~F}_{2}$ hydrate," which specifies that the bound solvent is water. Examples of "solvated $\mathrm{UO}_{2} \mathrm{~F}_{2}$ " are $\mathrm{U}(\mathrm{OH})_{4} \mathrm{~F}_{2}$ or $\mathrm{UO}_{2} \mathrm{~F}_{2} * 2 \mathrm{H}_{2} \mathrm{O} ; \mathrm{H}\left[\mathrm{U}(\mathrm{OH})_{4} \mathrm{~F}_{3}\right]$ or $\mathrm{UO}_{2} \mathrm{~F}_{2} * 2 \mathrm{H}_{2} \mathrm{O} * \mathrm{HF}$; and $\left[\mathrm{H}_{3} \mathrm{O}\right]_{2}\left[\mathrm{U}(\mathrm{OH})_{4} \mathrm{~F}_{4}\right]$ or $\mathrm{UO}_{2} \mathrm{~F}_{2} * 4 \mathrm{H}_{2} \mathrm{O} * 2 \mathrm{HF}$. All are products of the hydrolysis of $\mathrm{UF}_{6}$. 
Table B1-3. Estimation of other weight changes accompanying reaction

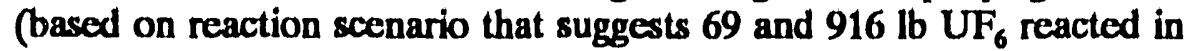
cylinders 4G127985 and 4G115688, respectively. See Appendix C.)

\begin{tabular}{|c|c|c|}
\hline Operation & Cyl. 4G127985 & Cyl. 4G115688 \\
\hline \multicolumn{3}{|c|}{ Mass gain within cylinder from reaction of $\mathrm{Fe}$ with $\mathrm{UF}_{6}$ and $\mathrm{H}_{2} \mathrm{O}$} \\
\hline Mass of Fe retained, $\mathrm{lb}$ & 0.27 & 6.8 \\
\hline $\begin{array}{l}\text { Wt of water added to cylinder by } \mathrm{Fe} \\
\text { reaction with } \mathrm{UF}_{6} \text { and } \mathrm{H}_{2} \mathrm{O}, \mathrm{lb}\end{array}$ & 1.14 & 10.0 \\
\hline \multicolumn{3}{|c|}{ Mass gain from reaction of $\mathrm{UF}_{6}$ with $\mathrm{H}_{2} \mathrm{O}$ to make retained $\mathrm{HF}$} \\
\hline Mass of $\mathrm{HF}$ retained in cylinder, $\mathrm{lb}$ & 1.80 & 15.8 \\
\hline Mass of $\mathrm{H}_{2} \mathrm{O}$ added to generate retained $\mathrm{HF}, \mathrm{lb}$ & 2.16 & 19.0 \\
\hline \multicolumn{3}{|c|}{ Mass gain from reaction of $\mathrm{UF}_{6}$ with $\mathrm{H}_{2} \mathrm{O}$ to make $\mathrm{HF}$ lost } \\
\hline Mass of $\mathrm{UF}_{6}$ so reacted, $\mathrm{lb}$ & 16.3 & 1848.0 \\
\hline Mass of $\mathrm{H}_{2} \mathrm{O}$ added to generate $\mathrm{HF}$ lost, lb & 3.3 & 378.0 \\
\hline Mass of HF lost as solution, $\mathrm{lb}$ & -2.8 & -315.0 \\
\hline Net wt gain due to reactions, $\mathrm{lb}$ & 3.8 & 92.0 \\
\hline Net wt of unaccounted-for $\mathrm{UF}_{6}, \mathrm{lb}$ (upper bound) & 4.0 & 109.0 \\
\hline
\end{tabular}

The remainder of the $\mathrm{UF}_{6}$ hydrolyzed is assumed to produce the same retained uraniumbearing material averaging $3 \mathrm{~F} / \mathrm{U}$ atom and $\mathrm{HF}$, which leaks as solution saturated with $\left[\mathrm{H}_{3} \mathrm{O}_{2}\left[\mathrm{U}(\mathrm{OH})_{4} \mathrm{~F}_{4}\right]\right.$ from the yellow layer. The quantity of water added to the cylinder to accomplish this hydrolysis is the sixth figure given in Table B1-3. The weight of the HF lost from the cylinder during the hydrolysis of this quantity of $U F_{6}$ to give the assumed yellow layer products is the seventh figure in the table. The sum of these four weights $(92 \mathrm{lb}$ for cylinder 4G115688) represents the net gain in weight of the cylinder contents due to reactions inside the cylinder. This quantity should be added to the initial gross cylinder weight corrected for the known weights of the recovered materials expressed as $\mathrm{UF}_{6}, \mathrm{Fe}$, and $\mathrm{HF}$. The difference between this weight and the final weight of the cylinder is the total weight of the unaccounted-for $\mathrm{UF}_{6}$, or $109 \mathrm{lb}$ for cylinder $4 \mathrm{G} 115688$.

There was no change in the gross weight of cylinder $4 \mathrm{G} 127985$ (ref. 46) within the weighing error of the scale of $\pm 2 \mathrm{lb}(1 \mathrm{~kg})$, which means that the difference in two weights is not known to be better than $\pm 3 \mathrm{lb}$. Given the nature of the assumptions going into the estimate of the upper bound for this cylinder, it is not possible to say with certainty that there has been any loss of uranium from the vicinity of the cylinder. Based on visual observations, only an insignificant amount of material had fallen to the concrete pad below the breach. No uranium was detectable in the soil where rainwater wetting this cylinder drained from the concrete pad. Thus, it is a reasonable conclusion that essentially all of the uranium that diffused from the cylinder over the 4-year period remains at the cylinder location. In contrast, significant losses have occurred from cylinder 4G115688 over the 13-year period. ${ }^{5}$ The actual quantity lost is not well quantified but is believed to be between 17 and $109 \mathrm{lb}$ of $\mathrm{UF}_{6}(11.5$ and $73.7 \mathrm{lb}$ of $\mathrm{U}$ ). 


\section{PRESSURES OF THE VAPOR SPACES OF CYLINDERS 4G127985 AND 4G115688} (refs. 30, 33, and 35)

The pressure of the vapor space of a cylinder at ambient temperature is usually referenced as the "cold pressure" of a cylinder. These pressures are given in Table B1-4 for the breached cylinders. For comparison, the mean and range of pressures in low-assay $\mathrm{UF}_{6}$ storage cylinders are given for each storage site.

Table B1-4. Pressure in the cylinder vapor space

\begin{tabular}{|c|c|c|}
\hline Cylinder & Gas pressure in vapor space & Ambient air temp, ${ }^{\circ} \mathrm{F}$ \\
\hline $4 G 127985$ & $\begin{array}{l}8 \mathrm{in} \text {. of } \mathrm{Hg} \text { vacuum } \\
(-4 \text { psig or } 10.7 \text { psia })\end{array}$ & 85 \\
\hline $\begin{array}{c}4 \mathrm{G} 115688 \\
\text { (no bleedoff) } \\
n n\end{array}$ & $\begin{array}{l}\text { +11 psig or } 25.7 \mathrm{psia} \\
\text { +8 psig or } 22.7 \mathrm{psia} \\
+2 \mathrm{psig} \text { or } 16.7 \mathrm{psia}\end{array}$ & $\begin{array}{l}92 \\
85 \\
47\end{array}$ \\
\hline $\begin{array}{l}4 G 115688 \\
\text { (after bleeding } 8 \mathrm{lb} \text { of } \\
\text { gaseous material) }\end{array}$ & -2.5 psig or 12.2 psia & 57 \\
\hline ORGDP $^{30}$ & $\begin{array}{l}-8 \text { psig to } 12 \text { psig }^{*} \\
\text { ca. } 7 \text { to } 26.7 \text { psia }\end{array}$ & summertime \\
\hline $\begin{array}{c}\text { PGDP }^{33} \\
\text { (undercover) }\end{array}$ & $\begin{array}{l}\text { av } 4.3 \text { psia } \\
\text { range: } 2 \text { to } 7 \text { psia }\end{array}$ & late spring \\
\hline $\begin{array}{l}\text { (outside, winter) } \\
\text { (outside, summer) }\end{array}$ & $\begin{array}{l}\text { av } 7 \text { psia } \\
\text { range: } 4 \text { to } 9 \text { psia } \\
\text { av } 8 \text { psia } \\
\text { range: } 6 \text { to } 10 \text { psia }\end{array}$ & $\begin{array}{l}\text { sunny, mid-day } \\
\text { sunny, mid-day }\end{array}$ \\
\hline $\begin{array}{c}\text { PORTS } \\
\text { (vicinity of } \\
\text { Cyl. 4G127985) }\end{array}$ & $\begin{array}{l}\text { av } 7 \text { psia } \\
\text { range: } 4 \text { to } 13 \text { psia }\end{array}$ & 85 \\
\hline $\begin{array}{l}\text { vicinity of } \\
\text { Cyl. 4G115688) }\end{array}$ & $\begin{array}{l}\text { av } 6 \text { psia } \\
\text { range: } 3 \text { to } 12 \text { psia }\end{array}$ & 85 \\
\hline $\begin{array}{l}\text { Est. Init. Pres. } \\
\text { Cyl. 4G127985 } \\
\text { Cyl. 4G115688 }\end{array}$ & $\begin{array}{l}\text { ca. } 7 \text { psia } \\
\text { ca. } 7 \text { psia }\end{array}$ & $\begin{array}{l}\text { summertime } \\
\text { summertime }\end{array}$ \\
\hline
\end{tabular}

* Only one of 316 cylinders at this pressure. Pressure above the vapor pressure of $\mathrm{UF}_{6}$ is due almost entirely to air.

The cold pressures of 316 tails cylinders at the K-25 Site, measured during the summer several years ago, ranged from -8 psig (6.7 psia) to +12 psig ( 26.7 psia). Of these, 76 cylinders were above atmospheric pressure (14.7 psia) but only one was as high as $12 \mathrm{psig}$. These cylinders were known to contain unmeasured amounts of air, which were added to the cylinder before 
filling to prevent the initial spontaneous conversion of liquid $U_{6}$ to vapor and solid, thus plugging the valves with solid and stopping the liquid flow. Analysis of the gas from the vapor space of these cylinders showed that any pressure over about 2.5 psia was due to residual air. ${ }^{30}$

The "cold pressures" of tails cylinders filled at Paducah have a significantly smaller range and, as one might expect, are functions of the ambient temperature. When measured on cold cylinders of $\mathrm{UF}_{6}$ under cover in the early morning, the cold pressure averages 4.3 psia with a range from 2 to 7 psia. Measured outside in the cooler months, the average "cold pressure" is about 7 psia with a range of 4 to 9 psia. Measured outside in the warmer months, the average "cold pressure" is 8 psia with a range of 6 to 10 psia. Ten different cylinders were measured under each condition discussed. ${ }^{33}$

Measurements of the "cold pressure" at Portsmouth were made on five cylinders in the vicinity of cylinder $4 \mathrm{G} 127985$ and four in the vicinity of cylinder $4 \mathrm{G} 115688$. The values on the five, in terms of inches of $\mathrm{Hg}$ vacuum, were $3,4,21,22$, and 22 , respectively. The values on the four cylinders expressed in the same terms were $6,14,24$, and 25 . Six of the nine cylinders sampled had vapor space pressures lower than the lower vapor space pressure of breached cylinders, and the vapor space pressures of all nine were significantly lower than the higher vapor space pressure in the breached cylinders. Thus, it is reasonable to expect that the pressure in both breached cylinders is higher than the pressure in that cylinder at the time it was placed in storage. ${ }^{35}$

Based on the gas composition given in the next section, the initial "cold pressure" of both cylinders $4 \mathrm{G} 127985$ and $4 \mathrm{G} 115688$, if measured at the same ambient temperature, would have been about 7 psia. A discussion of the partial-pressure relationships of the gases in the cylinders is presented in Appendix B, Part 2.

The most significant observation is that there is no direct path for the entry of air to the vapor space of the breached cylinders. In the cylinder with the small hole, a partial vacuum was sustained and, in the case of the cylinder with the large hole, a very significant super atmospheric pressure was sustained.

\section{COMPOSITION OF THE GAS IN THE VAPOR SPACE OF THE CYLINDERS ${ }^{25,37,38}$}

Infrared and gas chromatographic measurements of the composition of the gases in the vapor spaces of cylinders $4 \mathrm{G} 127985$ and $4 \mathrm{G} 115688$ are given in Table B1-5. It can be seen from the mole ratio of $\mathrm{O}_{2}$ to $\mathrm{N}_{2}$ in Table B1-5 that these "permanent gases" are from air. It is probable that most of these quantities of $\mathrm{O}_{2}$ and $\mathrm{N}_{2}$ were present from the initial filling.

The $\mathrm{UF}_{6}$, which is removed from the bottom of the gaseous diffusion cascades, is of high purity and should contain less $\mathrm{HF}$ than $\mathrm{UF}_{6}$, which is withdrawn as product. The typical partial pressure of the HF content of unburped product cylinders at Paducah ranges from 10 to 20 torr ( 0.2 to $0.4 \mathrm{psia}$ ). It is reasonable to assume that the partial pressure of HF in cylinders $4 \mathrm{G} 127985$ and 4G115688 did not exceed this value when placed in storage. As indicated in Appendix B, Part 2, the initial "cold pressures" of these cylinders would have been about 7 psia at the ambient temperatures for which the present measurements are reported. 
Table B1-5. Compositions of the vapor spaces in cylinders 4G127985 and 4G115688 before and after vapor phase bleeding

\begin{tabular}{cccc}
\hline & & \multicolumn{2}{c}{ Cylinder 4G115688 } \\
\cline { 3 - 4 } Component & $\begin{array}{c}\text { Cylinder 4G127985 } \\
\text { (mole \% of vapor) }\end{array}$ & $\begin{array}{c}\text { Initially, } \\
\text { mole \% of vapor }\end{array}$ & $\begin{array}{c}\text { After bleeding, } \\
\text { mole \% of vapor }\end{array}$ \\
\hline $\mathrm{UF}_{6}$ & 16.0 & 7.10 & 4.8 \\
$\mathrm{HF}$ & 36.9 & 76.6 & 66.5 \\
$\mathrm{O}_{2}$ & 9.3 & 3.40 & $5.8^{b}$ \\
$\mathrm{~N}_{2}$ & 37.8 & 12.9 & $22.9^{b}$ \\
$\mathrm{~F}_{2}$ & $<0.5$ & $<0.5$ & \\
\hline
\end{tabular}

$a_{\text {The ambient temperature at the time cylinder } 4 \mathrm{G} 127985 \text { was sampled was }}$ estimated to be about $85^{\circ} \mathrm{F}$. The ambient temperature when cylinder $4 \mathrm{G} 115688$ was initially sampled was $92^{\circ} \mathrm{F}$ and, after bleeding, was about $57^{\circ} \mathrm{F}$.

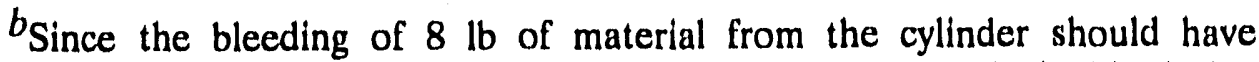
removed the air originally in the vapor space, this air must have leaked in during the moving of the cylinder, which did loosen the patch and require it to be resealed.

Samples from the Solid Corrosion Products Exterior to the Holes in Cylinders 4G127985 and 4G115688 and on Cylinder 4G127902 (refs. 14, 40, and 42)

Table B1-6 identifies, by appearance and location, the different appearing solid samples that were taken exterior to the holes in the two cylinders and that were examined for elemental composition by X-ray fluorescence elemental analysis and for compound identification by X-ray diffraction analysis. The materials on the lug of the adjacent cylinder $4 \mathrm{G} 127902$ at the breach were the same as those on the stiffening ring and exterior surface of breached cylinder 4G127985. Except for the easily explainable absence of materials containing ferrous iron, the compounds identified in the deposits on cylinder 4G127985 are also found in the deposits on the concrete pad and the external cylinder surfaces below the large hole in cylinder 4G115688. Some additional compounds associated with the location of the deposits are also found in the latter deposits.

The locations of the various materials actually associated with the deposits next to the hole in cylinder $4 \mathrm{G} 127985$, located between the stiffening ring of cylinder $4 \mathrm{G} 127985$ and the lug of adjacent cylinder 4G127902, are shown in Figs. B1.1 through B1.5. 
Table B1-6. Sample identification of materials exterior to the holes

Type A - A soft, light green powder that was found at the surface of the cylinder plug and in the core of the deposits located between the lug of the adjacent cylinder and the stiffening ring and filling the hole of the lifting lug (PORTS XRF-6). Also found in cylinder 4G115688 deposits (PORTS XRF-1).

Type B - A hard, dark green solid that coated over a portion of the corrosion deposits and appeared to have been directly exposed to the atmosphere (PORTS XRF-7). Also found in deposits from cylinder $4 \mathrm{G} 115688$.

Type C - A light tan solid located next to the iron metal where corrosion had occurred. Off-white when ground (PORTS XRF-8). (Colored yellow-brown in deposits on cylinder $4 \mathrm{G} 127985$ itself.)

Type D - A white-to-off-white solid (slightly greenish inside) in deposits from cylinder 4G115688 (PORTS XRF-2). Also found in deposits on lug and cylinder 4 G127985.

Type $\mathbf{E}-\mathbf{A}$ hard, dark brick-red (red/brown) solid formed in an elliptical ring pattern between the lifting lug and the stiffening ring. The ellipse was filled with Type A material (PORTS XRF-4).

Type F - A very hard, dark red, unidentiffed solid containing $\mathrm{Ca}$ and Fe. Relationship to corrosion process believed remote, if any (PORTS XRF-5).

Type $\mathrm{G}-$ Gray, very hard solid containing $\mathrm{CaMg}\left(\mathrm{CO}_{3}\right)_{2}$ and $\mathrm{SiO}_{2}$ from concrete. Obviously, from scooping deposits off pad.

Type $\mathrm{H}$ - Paint with adhering rust deposits (XRF-3). Cleaned paint scale is $80 \% \mathrm{TiO}_{2}$.

Type I - Red/brown scale (iron rust appearance).

\section{SAMPLES FROM TH i SOLID CORROSION PRODUCIS IN AND AROUND THE HOLE AND WITHIN THE PLUG BEHIND THE HOLE IN CYLINDER 4G115688 (refs, 43 and 44)}

Table B1-7 identifies, by appearance and location, the different appearing solid samples that were taken in and around the hole and from within the plug behind the hole in cylinder 4G115688. These were examined for elemental composition by X-ray fluorescence elemental analysis and for compound identification by X-ray diffraction analysis. It is believed that the materials in, around, and behind the hole in cylinder 4G127985 would differ only in quantity, not in kind. Additionally, during the video probing of the surface of the material forming the plug inside cylinder 4G127985, a layer of an orange material was noted to have served as an interface between the fluorescent yellow plugging material and the solid $\mathrm{UF}_{6}$ in the cylinder or, less likely, to have been formed during the removal of the $U_{6}$.

The locations from which the various materials associated with the deposits within the hole of cylinder 4G115688 were taken are shown in Fig. B1.6. 
PHO'TO NO. K/PH-91-3193

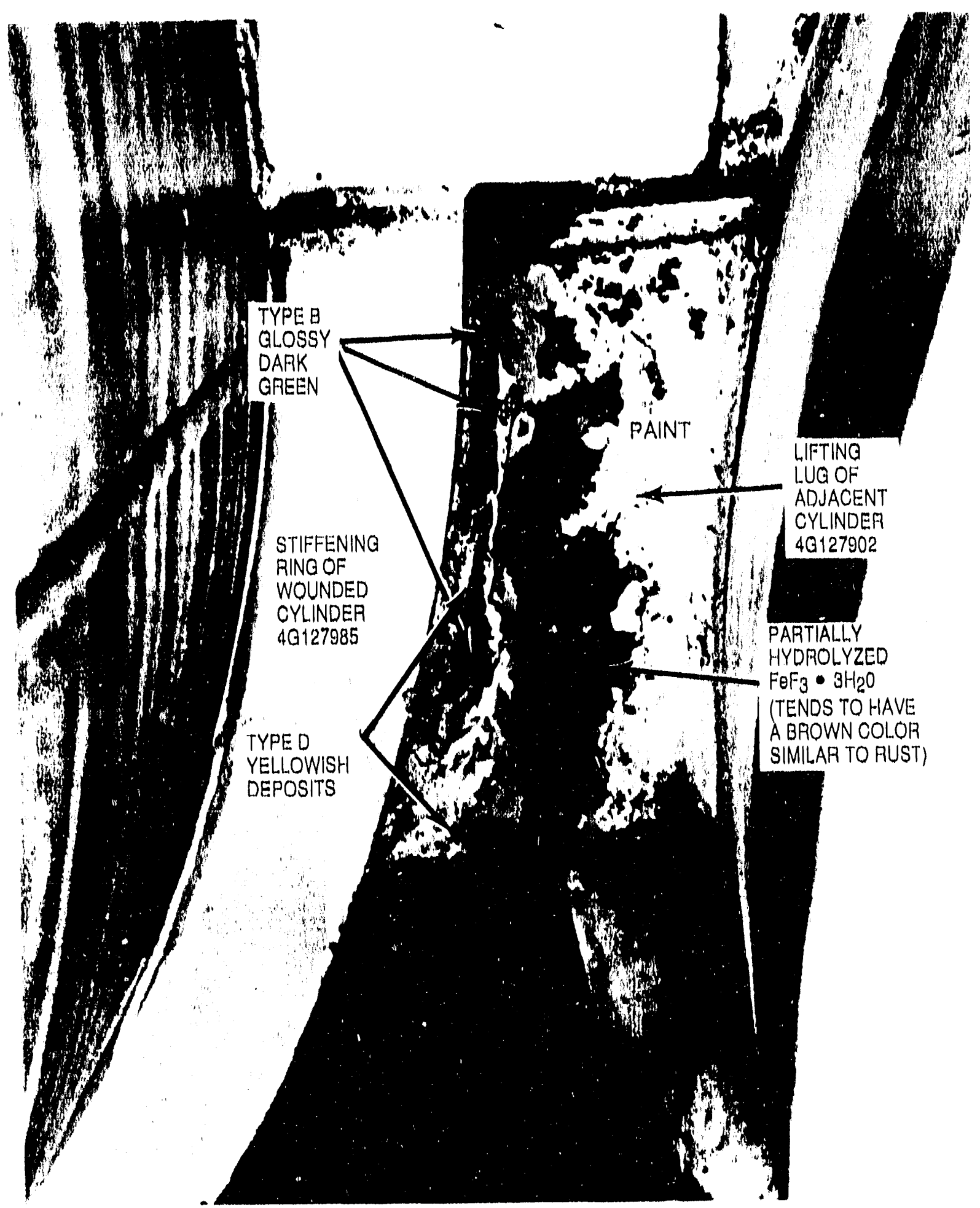

Fig. B1.1. Iocation of materials taken from surface of stiffening ring of cylinder 4G127985 and lifting lug of cylinder 4G1279(12. Photograph taken before separation of the cylinders. The hole is just above the longitudinal weld and on the other side of the stiffening ring. 
PHOTO NO. K/PH-91-3190

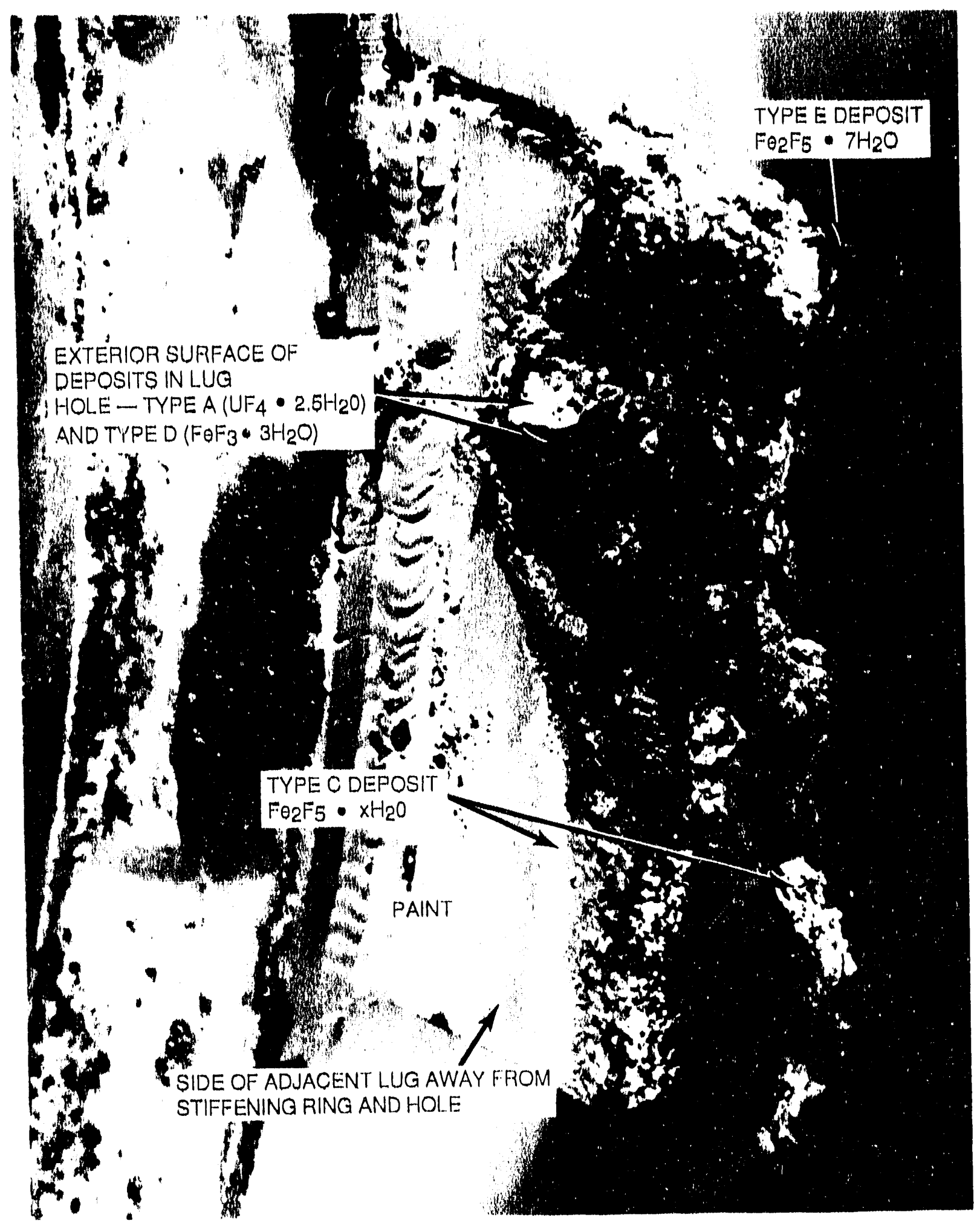

Fig. B1.2. Lexation of various materials in the lifting lug of cylinder $4 \mathrm{G} 127902$ as seen from the side away from the stiffening ring of cylinder 4G127985 after separation from cylinder $4 \mathrm{G} 127985$. 
PHO'TO NO. K/PH-91-3192

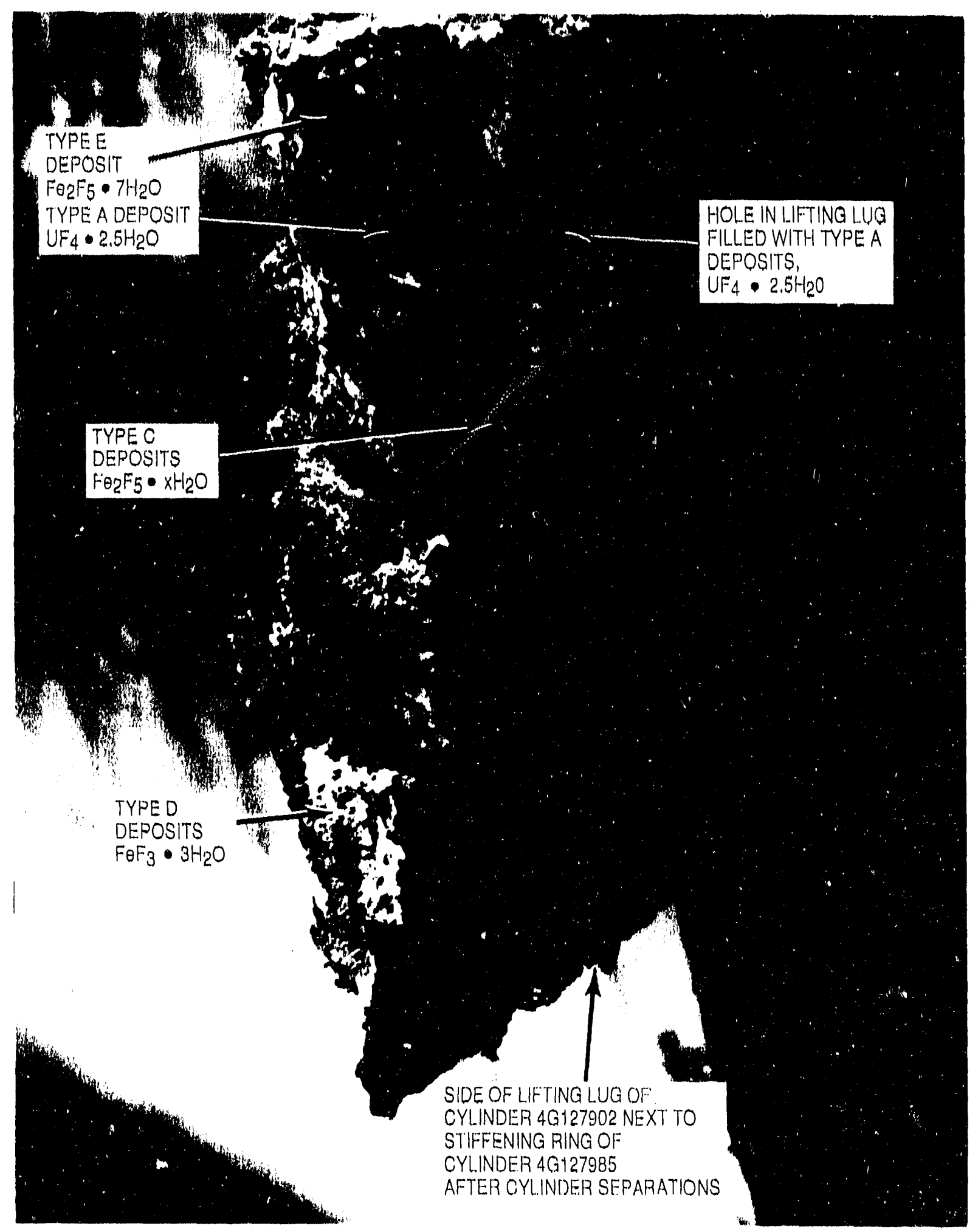

Fig. B1.3. Location of various materials on the lifting lug cylinder 4G127902 as seen from the side adjacent to the stiffening ring of cylinder 4G127985 after separation. 


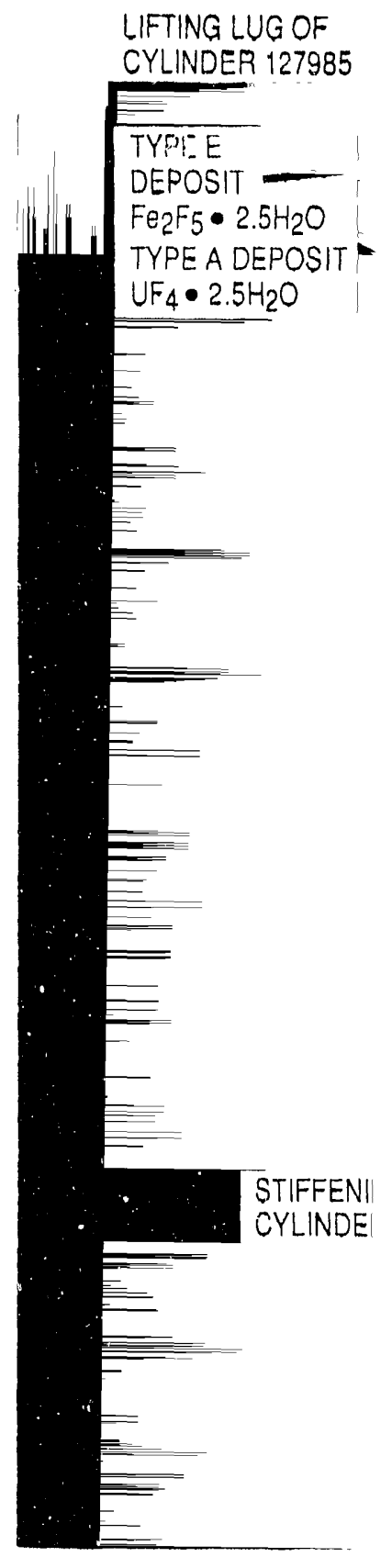

Fig. B1.4. Locat lug of cylinder 4G127\% 
PHOTO NO. K/PH-91-3187

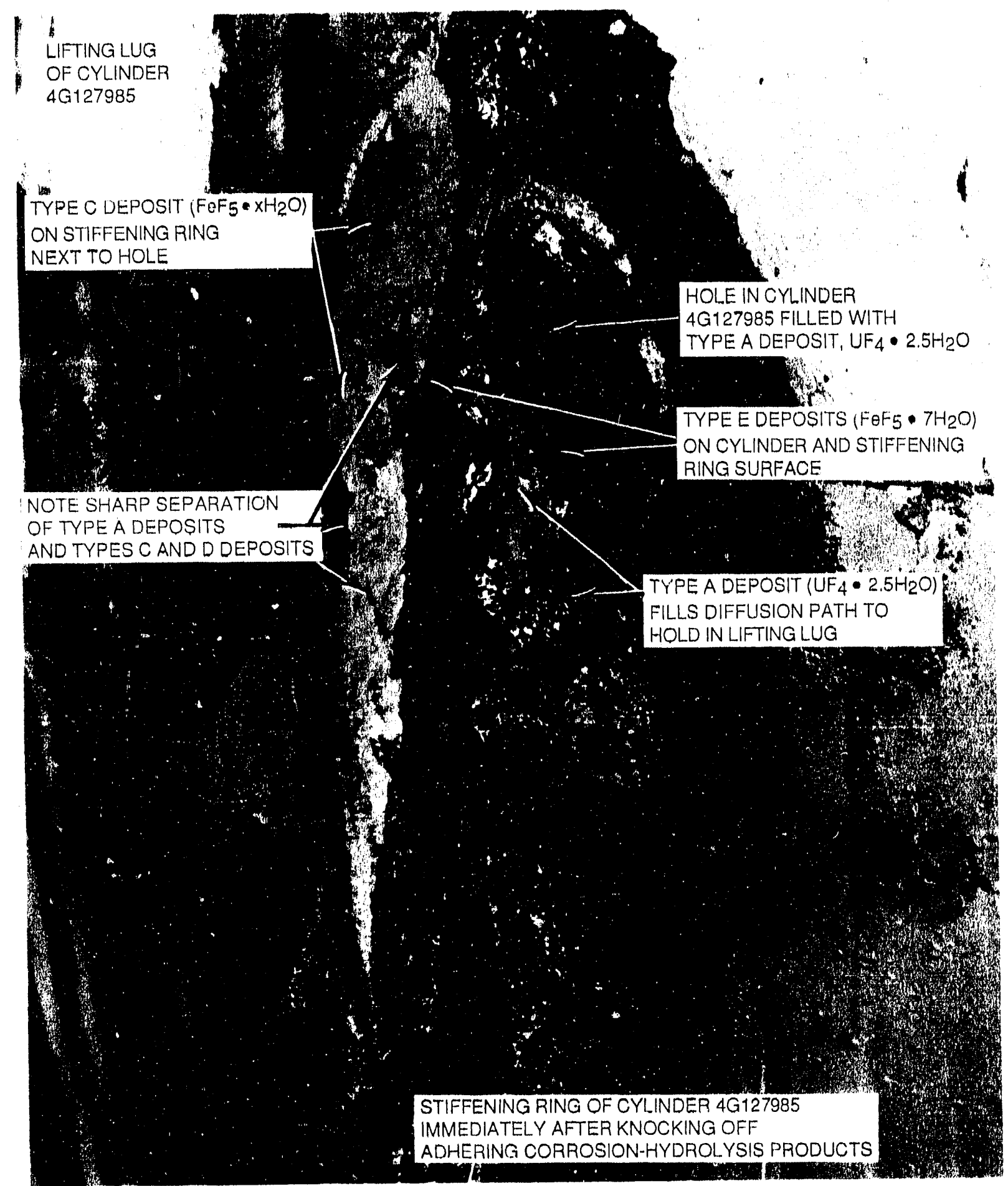

Fig. B1.5. Similar view as in Fig. B1.4 after the corrosion deposit was knocked off revealing the hole. 
Table B1-7. Sample identification of materials within the holes

Type I - A green powder very similar in appearance to Type A (Table B1-6) but slightly darker, found at the interface of the UF, material with the fluorescent yellow, hexavalent, uranium oxyfluoride solvate in the core samples. ${ }^{4}$

Type II - A fluorescent yellow solid found between the $\mathrm{UF}_{4}$ hydrates and the $\mathrm{UF}_{6}$ in the interior of cylinder $4 \mathrm{G} 115688$. The material is sticky and gummy in consistency and proved very difficult to penetrate even with hollow metal core samplers driven by a hammer. This type of material appears to be greater than 8 in. in depth in cylinder 4C115688. The degree of hydrolysis and hydration may be greater near the interface with the Type I

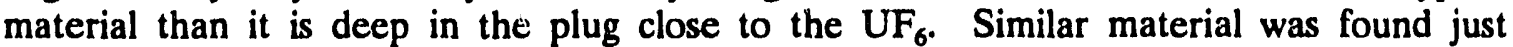
beneath the Type I layer and at the full depth of penetration of the core samplers. ${ }^{43,44}$ (Not visible in Fig. Bi .6.)

Type III - A fluorescent yellow (yellow/green) solid not significantly different in appearance from Type II but located in the center of the hole where the Type I material had sloughed off.

Type IV - A light violet- or rosy turquoise-colored solid is located between the Type A and Type $\mathrm{V}$ materials.

Type V (Type D) - A grayish material of variable color darkness located on the stiffening ring immediately over the hole in cylinder $4 \mathrm{G} 115688$. It is also found layered close to the steel around the edge of the hole.

Type VI (Type C) - A tan-colored layer of material right next to the steel surface. Very similar to Type $C$ in appearance and location.

Type VII (Type E) - A hard, dark brick-red (red/brown) solid next to the steel surface at the edge of the hole.

\section{Results of the Sample Analyses}

The elemental analysis and the results of the $\mathrm{X}$-ray diffraction analysis are given in Tables B1-8 and B1-9. It should be observed that the bulk of the UF 4 hydrate deposits contains only small amounts of iron fluorides and that most of the iron fluoride deposits lie next to the iron surfaces and contain little uranium.

The identified materials common to the deposits on or below each breached cylinder are $\mathrm{UF}_{4} * 2.5 \mathrm{H}_{2} \mathrm{O}, \mathrm{UF}_{4} * 1.5 \mathrm{H}_{2} \mathrm{O}, \mathrm{UF}_{4} * 0.75 \mathrm{H}_{2} \mathrm{O}$, and $\mathrm{FeF}_{3} * 3 \mathrm{H}_{2} \mathrm{O}$. Additional materials found in the deposits on cylinder $4 \mathrm{G} 127985$, between the stiffening ring and the lug of the adjacent cylinder $4 \mathrm{G} 127902$ at the hole, are $\mathrm{Fe}_{2} \mathrm{~F}_{5} * 7 \mathrm{H}_{2} \mathrm{O}$ and $\mathrm{FeF}_{2}$. These materials are also found on the steel surface around the edge of the large hole in cylinder $4 \mathrm{G} 115688$. The absence of these latter materials in the deposits that have fallen from the large hole is due to the atmospheric oxidation of the $\mathrm{Fe}^{+2}$ to $\mathrm{Fe}^{+3}$ in these deposits. Also found from X-ray diffraction studies of the deposits close to the active site on cylinder $4 \mathrm{G} 127985$ are unidentified, but definite, patterns for both a uranium compound and an iron compound. Further studies of the reactivity of these materials allow their tentative identification as hydrated $U F_{4}$ and $F_{2} F_{5}$. The $U F_{4}$ hydrate found most 
PHOTO NO. K/PI[-91-3184

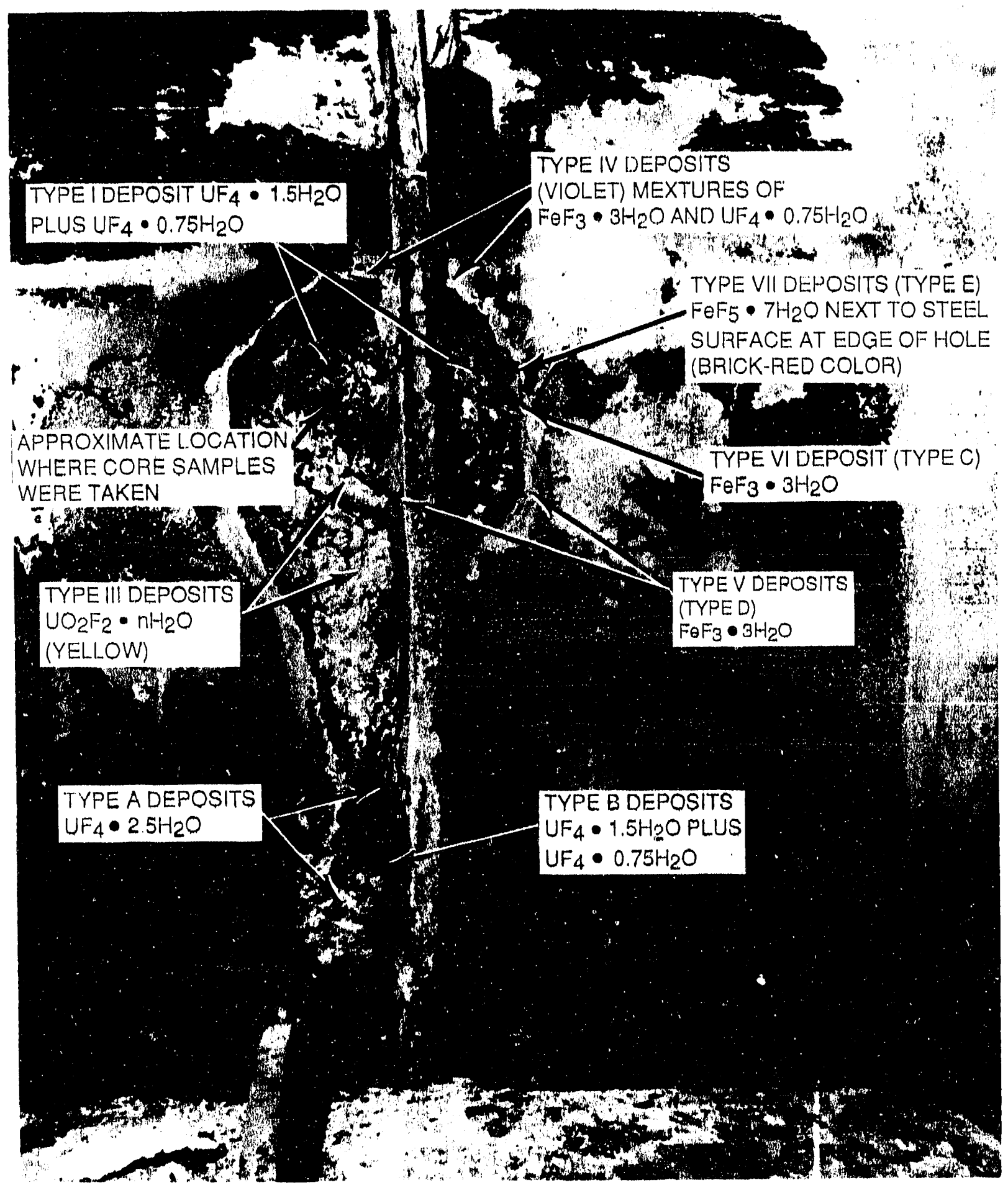

Fig. B1.6. Location of materials in and around the hole in cylinder 4G115688 like those examined by chemical analyses. 
Table B1-8. Elemental and X-ray diffraction analyses of the typical types of corrosion deposits exterior to the holes $a$

\begin{tabular}{|c|c|c|}
\hline Sample type & Elemental analysis & $\mathrm{X}$-ray analysis \\
\hline $\begin{array}{c}\mathrm{A} \\
(\mathrm{XRF}-6)\end{array}$ & $\begin{array}{l}71 \% \mathrm{U}, 2.1 \% \mathrm{Fe}, 0.5 \% \mathrm{Mn}, 0.5 \% \mathrm{Ca} \\
0.2 \% \mathrm{Cl}, 0.2 \% \mathrm{~S}, 0.4 \% \mathrm{Si}\end{array}$ & $\begin{array}{c}\text { major pattern } \mathrm{UF}_{4} * 2.5 \mathrm{H}_{2} \mathrm{O} \text {, } \\
\text { minor unidentifiable lines }\end{array}$ \\
\hline (XRF-1) & $74 \% \mathrm{U}, 1.2 \% \mathrm{Fe}, 0.07 \% \mathrm{Mn}, 0.1 \% \mathrm{Si}$ & same as above \\
\hline$\frac{B}{(X R F-7)}$ & $45 \% \mathrm{U}, 20 \% \mathrm{~F} 3,0.4 \% \mathrm{Mn}, 0.02 \% \mathrm{Ca}$ & $\begin{array}{l}\text { unidentified } \mathrm{U} \text { compound, } \\
30 \% \mathrm{FeF}_{3} * 3 \mathrm{H}_{2} \mathrm{O} \\
10 \% \mathrm{UF}_{4} * 0.75 \mathrm{H}_{2} \mathrm{O}\end{array}$ \\
\hline $\begin{array}{c}\mathrm{C} \\
(\mathrm{XRF}-8)\end{array}$ & $\begin{array}{l}0.5 \% \mathrm{U}, 49 \% \mathrm{Fe}, 0.5 \% \mathrm{Mn}, 0.02 \% \mathrm{Cr} \\
0.001 \% \mathrm{Ti}, 0.005 \% \mathrm{Ca}, 09.007 \% \mathrm{Cl} \\
0.03 \% \mathrm{~S}, 0.04 \% \mathrm{Si}\end{array}$ & $\begin{array}{l}50 \% \mathrm{Fe}_{2} \mathrm{~F}_{5} * 7 \mathrm{H}_{2} \mathrm{O} \text {, possible trace } \\
\text { FeF } \mathrm{F}_{2}, 50 \% \text { unidentified iron } \\
\text { compound } b\end{array}$ \\
\hline yellow/brown & No XRF & same as above \\
\hline dark gray & No XRF & unidentified iron compound $b$ \\
\hline$\underset{(\mathrm{XRF}-2)}{\mathrm{D}}$ & $10 \% \mathrm{U}, 43 \% \mathrm{Fe}, 0.2 \% \mathrm{Mn}$ & $\mathrm{FeF}_{3} * 3 \mathrm{H}_{2} \mathrm{O}$ \\
\hline$\frac{E}{(X R F-4)}$ & $0.3 \% \mathrm{Zn}, 49 \% \mathrm{Fe}, 0.5 \% \mathrm{Mn}$ & $\mathrm{Fe}_{2} \mathrm{~F}_{\mathrm{s}} * 7 \mathrm{H}_{2} \mathrm{O}$ \\
\hline $\begin{array}{c}F \\
(X R F-5)\end{array}$ & $\begin{array}{l}2.6 \% \mathrm{U}, 43 \% \mathrm{Fe}, 0.4 \% \mathrm{Mn}, 0.4 \% \mathrm{Ti} \\
32 \% \mathrm{Ca}, 0.5 \% \mathrm{Cl}, 3.1 \% \mathrm{~S}, 0.6 \% \mathrm{Si} \\
1 \% \mathrm{Al}\end{array}$ & $\begin{array}{l}\text { amorphous, trace unidentified } \\
\text { crystalline material }\end{array}$ \\
\hline G & No XRF & $95 \% \mathrm{CaMg}\left(\mathrm{CO}_{3}\right)_{2}, 5 \% \mathrm{SiO}_{2}$ \\
\hline $\begin{array}{c}\mathrm{H} \\
(\mathrm{XRF}-3)\end{array}$ & $\begin{array}{l}36 \% \mathrm{U}, 11 \% \mathrm{~Pb}, 0.2 \% \mathrm{Zn}, 1.2 \% \mathrm{Fe} \\
1.5 \% \mathrm{Cr}, 18 \% \mathrm{Ti}, 0.4 \% \mathrm{Ca}\end{array}$ & paint \\
\hline$I$ & No XRF & $\begin{array}{l}50 \% \mathrm{FeO}(\mathrm{OH}), 50 \% \mathrm{Fe}_{3} \mathrm{O}_{4} \\
\text { (rust) }\end{array}$ \\
\hline
\end{tabular}

${ }^{a}$ For details on every sample examined, see refs. 40 and 42.

$b_{\mathrm{X} \text {-ray powder patterns consist of a series of lines. If a material has been prepared, which has }}$ identical lines, the unknown material is identified. Where there are additional unidentified lines, only tentative identification can be made at best. The materials, which gave the unidentified patterns, were further studied by Scott. ${ }^{42}$ These studies led to the conclusion that the uranium compound was a $\mathrm{UF}_{4} * \mathrm{XH}_{2} \mathrm{O}$ and the iron compound was a $\mathrm{Fe}_{2} \mathrm{~F}_{5} * \mathrm{XH}_{2} \mathrm{O}$. 
Table B1-9. Elemental and X-ray diffraction analyses of the typical types of corrosion deposits on and inside deposits in large holes

\begin{tabular}{|c|c|c|}
\hline Sample type & Elemental analysis & $\mathrm{X}$-ray analysis \\
\hline "A" \& “B" & No XRF & $\begin{array}{l}\text { mixtures of } \mathrm{UF}_{4} * 1.5 \mathrm{H}_{2} \mathrm{O} \text { and } \\
\mathrm{UF}_{4} * 0.75 \mathrm{H}_{2} \mathrm{O}\end{array}$ \\
\hline $\begin{array}{c}\text { II } \\
(\mathrm{A}) \\
(\mathrm{C} 2 \text { hole })\end{array}$ & $\begin{array}{l}74 \% \mathrm{U}, 1.8 \% \mathrm{Fe}, 0.06 \% \mathrm{Ni} \\
0.1 \% \mathrm{Cr}, 0.06 \% \mathrm{Si} \\
74 \% \mathrm{U}, \text { ca. } 1 \% \mathrm{Fe} \text {, trace } \mathrm{Ca}\end{array}$ & $\begin{array}{l}\text { nearly amorphous, } X \text {-ray pattern } \\
\text { similar to hydrolysis product of } \\
\mathrm{U}_{2} \mathrm{O}_{3} \mathrm{~F}_{6} \text {, an orange compound }\end{array}$ \\
\hline $\begin{array}{c}\text { III } \\
(\mathrm{C} \text { hole })\end{array}$ & No XRF & mixture of $\mathrm{UO}_{2} \mathrm{~F}_{2} * n \mathrm{H}_{2} \mathrm{Os}^{b}$ \\
\hline $\begin{array}{l}\text { IV } \\
\text { (C hole) } \\
\text { ( } \mathrm{T} \text { hole })\end{array}$ & $\begin{array}{l}53 \% \mathrm{U}, 20 \% \mathrm{Fe} \text {, minor } \mathrm{Mn}, \\
\text { minor } \mathrm{Ca} \\
23 \% \mathrm{U}, 50 \% \mathrm{Fe} \text {, minor } \mathrm{Mn}, \\
\text { trace } \mathrm{Ca} \text { and } \mathrm{S}\end{array}$ & $\begin{array}{l}\mathrm{UF}_{4} * 0.75 \mathrm{H}_{2} \mathrm{O}, \text { ca. } 30 \% \mathrm{FeF}_{3} * 3 \mathrm{H}_{2} \mathrm{O} \\
\text { plus an amorphous component } \\
\mathrm{FeF}_{3} * 3 \mathrm{H}_{2} \mathrm{O} \text {, ca. } \mathrm{UF}_{4} * 0.75 \mathrm{H}_{2} \mathrm{O} \\
\text { plus an amorphous component }\end{array}$ \\
\hline $\begin{array}{c}\mathrm{V} \\
\text { (S hole) } \\
\text { (S ring) } \\
\text { (T hole) } \\
\text { (outside edge) }\end{array}$ & No $\mathrm{XRF}$ & $\mathrm{FeF}_{3} * 3 \mathrm{H}_{2} \mathrm{O}$ plus 0 to $20 \% \mathrm{Fe}_{2} \mathrm{~F}_{5} * 7 \mathrm{H}_{2} \mathrm{O}$ \\
\hline $\begin{array}{l}\text { VI } \\
\text { (outside edge) }\end{array}$ & No XRF & $\mathrm{Fe}_{2} \mathrm{~F}_{5} * 7 \mathrm{H}_{2} \mathrm{O}$ \\
\hline $\begin{array}{l}\text { VII } \\
\text { (outside edge) }\end{array}$ & $\begin{array}{l}68 \% \mathrm{Fe}, \text { minor } \mathrm{Mn} \text {, traces } \mathrm{Ti} \text {, } \\
\mathrm{Ca} \text {, and } \mathrm{S}\end{array}$ & $\begin{array}{l}\text { nearly amorphous; mixture of } \\
\mathrm{Fe}_{2} \mathrm{~F}_{5} * 7 \mathrm{H}_{2} \mathrm{O} \text { and } \mathrm{FeF}_{3} * 3 \mathrm{H}_{2} \mathrm{O}\end{array}$ \\
\hline
\end{tabular}

${ }^{a}$ For details on every sample examined, see refs. 43 and 44 .

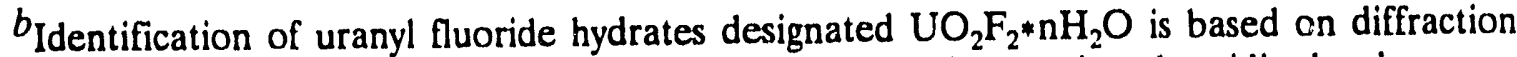
patterns of hydrates formed by exposing uranyl fluoride to air at various humidity levels.

frequently, exterior to the plug in the cylinder, is the more highly hydrated form, $\mathrm{UF}_{4} * 2.5 \mathrm{H}_{2} \mathrm{O}$, while the less hydrated forms, $U F_{4} * 1.5 \mathrm{H}_{2} \mathrm{O}$ and $\mathrm{UF}_{4} * 0.75 \mathrm{H}_{2} \mathrm{O}$, are found in the deposits within the cylinders, which serve as plugs for the holes. Although less certain, the analyses of samples taken from different positions in the hexavalent uranium oxyfluoride layer within the cylinders may suggest that water activity decreases as one penetrates this layer toward the solid $\mathrm{UF}_{6}$.

Mixtures of $\mathrm{FeF}_{3} * 3 \mathrm{H}_{2} \mathrm{O}$ and $\mathrm{UF}_{4} * 0.75 \mathrm{H}_{2} \mathrm{O}$ differ greatly in color from the pure components. In cases examined here, the material exists in the region of the $\mathrm{FeF}_{3}-\mathrm{UF}_{4}$ interface outside the hole, and the color is obtained with a variety of mixture ratios.

Other materials found in the deposits are paint from the cylinders, particles from the concrete pad from which the knocked-off deposits were scooped, and rust from the atmospheric corrosion of the cylinders. 
Quantitative chemical analysis of the yellow layer in the cylinder showed that this material contained $67.4 \mathrm{wt} \% \mathrm{U}$ and had an F-atom-to-U-atom ratio of 3.05 (ref. 8).

D. M. Manuta of PORTS made electrochemical and thermodynamic calculations, which suggest that the products found in the X-ray diffraction studies are ones that might be expected. ${ }^{20}$

\section{Identification of Lifting Lug Material ${ }^{14}$}

A sample of the lifting lug material from the cylinder adjacent to cylinder $4 \mathrm{G} 127985$ was examined. It was a typical, low-carbon steel plate containing $0.12 \%$ carbon with a grain size in the range corresponding to American Society for Testing and Materials (ASTM) size 4 to 6. Since there is apparently no specification for the lug material, any steel compatible with ASTM A516 would be acceptable.

\section{Corrosion of the Steel $\operatorname{Lug}^{14}$}

The steel lug was attacked along the top to a depth of about 0.25 in. for a distance from the corner of about $1 \mathrm{in}$. The depth of the attack decreased as one moved away from the sharp corner of the lug. The side of the lug next to the stiffening ring of cylinder 4G127985 was attacked to variable depths but none greater than about 0.125 in. The greatest penetration was at the outer edge of the lug, and penetration decreased rapidly as one moved away from the edge. The attack would not interfere with the proper functioning of the lug.

\section{Conclusions Reached From The Analyses}

A careful analysis of the data reported here indicates that the following statements may be made about the reactions occurring at the breach:

1. The reaction examined is for conditions in which no direct connection of the air exterior to the breach to the vapor space of the cylinder exists; i.e., transfer to the vapor space must occur by diffusion through solid $\mathrm{UF}_{6}$.

2. A part of the HF produced has migrated from the plug where it is generated to the vapor space of the cylinder (see Appendix B, Part 2).

3. The reduction of $U^{+6}$ to $U^{+4}$ is rapid (based on color change) suggesting surface film (solution) electron transfer processes are occurring. Most of the UF, hydrate deposits contain very little iron, which also supports this deduction. (See Appendix B, Part 3, for a discussion of the hydrolysis and corrosion chemistry.)

4. The iron fluorides seem to be concentrated near the iron surfaces, an observation also supporting the above deduction.

5. The electrochemical reduction of $\mathrm{U}^{+6}$ to form $\mathrm{UF}_{4}$ and $\mathrm{FeF}_{2}$ or $\mathrm{FeF}_{3}$ requires all the $F$-atoms associated with each $U$ in $U_{6}$, so this reaction does not contribute to the production of the HF observed to be diffusing to the cylinder vapor space and to be escaping through the hole in the cylinder. This means more $\mathrm{UF}_{6}$ must be hydrolyzed than is reduced. 
6. The $\mathrm{Fe}_{2} \mathrm{~F}_{5} * 7 \mathrm{H}_{2} \mathrm{O}$ and $\mathrm{FeF}_{3} * 3 \mathrm{H}_{2} \mathrm{O}$, with perhaps a trace of $\mathrm{FeF}_{2}$, are the identified iron products found. A definite but unidentified $\mathrm{X}$-ray diffraction pattern for yet another iron compound, which is now presumed from its reactions with water to be another hydrate of $\mathrm{Fe}_{2} \mathrm{~F}_{5}$, is also present. The presence of all these iron fluoride hydrates and tetravalent uranium fluoride hydrates is also evidence for reactions that occur in a conductive liquid film.

7. The hydrolysis and corrosion reactions produce a multilayered deposit both without and within the cylinder in which the hole is developing. The layers are distinct but there is some blending, particularly at the iron fluoride interfaces and at the ferric fluoride interface with the $U F_{4}$.

8. The nature and ordering of the reaction product layers are the keys to the stability of the plug and the extreme slowness of the reaction. The product materials exposed to rainwater tend to be unreactive and insoluble in it and those inside the cylinder tend to be insoluble in HF. Each of the layers contributes in a unique way to reduce the rate of diffusion of water to the unreacted surface of solid $\mathrm{UF}_{6}$ in the cylinder and to limit the rate of diffusion of HF out through the hole.

9. The quantitative analysis of the yellow layer inside the cylinder may be interpreted to indicate that this solid is approximately 50 mole $\%\left[\mathrm{H}_{3} \mathrm{O}_{2}\left[\mathrm{U}(\mathrm{OH})_{4} \mathrm{~F}_{4}\right]\right.$ and 50 mole \% $\mathrm{UO}_{2} \mathrm{~F}_{2}$. This interpretation has been used to estimate upper bounds on the $\mathrm{UF}_{6}$ losses from the cylinders.

10. Small breaches below the solid $\mathrm{UF}_{6}$ level are inherently self-sealing. 
APPENDIX B, PART 2 (B2)

CHEMICAL ASPECTS OF CORROSION OF BREACHED UF 6 CYLINDERS 


\section{BACKGROUND}

In the temperature range at which $\mathrm{UF}_{6}$ cylinders are stored, $\mathrm{HF}$ gas is usually associated because of hydrogen bonding. The degree of assoclation is dependent upon the partial pressure of the HF and the temperature. Jarry and Davis ${ }^{20}$ studied the association of pure HF at saturation and developed relationships for the saturated vapor while Long, Hildebrand, and Morrell ${ }^{23}$ earlier had examined the association of pure HF below saturation. The effect of diluent gases such as $\mathrm{UF}_{6}$ on the association of HF has not been studied per se; however, estimates made using these relationships may be considered to give an upper bound on the association of the $\mathrm{HF}$.

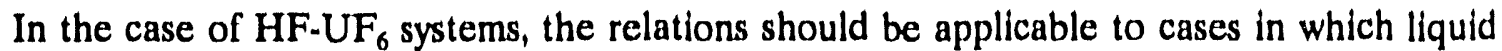
and vapor phases are in equilibrium with the solid $U F_{6}$ phase at the desublimation temperature, but the question of applicability at the significantly higher temperatures, which exist during the daylight hours in the vapor space of cylinders at some distance above the surface of the solid $U_{6}$, needs examination. The actual pressure exerted by the HF will be the same everywhere in the vapor space, but the degree of association of the $\mathrm{HF}$ will be different everywhere the temperature of the vapor space differs from the sublimation temperature of the UF 6 .

Long, Hildebrand, and Morrel1 ${ }^{23}$ and Jarry and Davis ${ }^{21}$ show that, for pure HF, the association factor, $Z$, is adequately expressed for HF by the relation

$$
\log _{10} K=\log _{10}\left[\left(5 / P_{m m}\right)^{\left.5 *(Z-1) /(6-Z)^{6}\right]}\right.
$$

where $k$ is the equilibrium constant, and $P_{m m}$ is the pressure of HF in torr.

The expression for $K$ as a function of temperature given by these sets of authors differ: slightly. Jarry and Davis ${ }^{20}$ give

$$
\log _{10} K=-42.38089+8660.4 / T
$$

and Long, Hildebrand, and Morrell ${ }^{23}$ give

$$
\log _{10} K=-43.65+8910 / T \text {. }
$$

The partial pressure of the $\mathrm{UF}_{6}$ will be the same everywhere in the vapor space and wi be equal to the sublimation pressure of the solid $U F_{6}$. The sublimation pressure of $U_{6}$ in to as given by Oliver, Milton, and Grisard ${ }^{29}$ is

$$
\ln P_{s, U F \sigma}(\text { torr })=14.69865+0.017356 t-2170.785 /(t+183.416) \text {, }
$$

where $t$ is in degrees Centigrade (Celcius).

The partial pressures of the gases like $\mathrm{O}_{2}$ and $\mathrm{N}_{2}$ are also the same everywhere, and becau :of the low solubility in solid $U_{6}$, the number of moles of these gases in the vapor space may 12 considered not to change with a change in the mean temperature of the vapor space. This mea is 
that the partial pressures of these gases are directly proportional to the mean absolute temperature in the vapor space; l.e.,

$$
\boldsymbol{P}_{1\left(\mathrm{O}_{2}\right)} V_{o}=n_{1\left(\mathrm{O}_{2}\right)} R T_{m}
$$

where $\boldsymbol{P}_{\mathrm{kO} \mathrm{O}_{2}}$ is the partial pressure of $\mathrm{O}_{2}$ at the mean absolute temperature, $T_{\mathrm{m}} ; V_{\mathrm{o}}$ is the volume of the vapor space; $n_{1\left(0_{2}\right)}$ is the number of moles of $\mathrm{O}_{2}$ in the vapor spacc, $V_{o}$; and $R$ is the gas constant in appropriate units.

Hobbs, Barber, and Jones ${ }^{19}$ employed the liquid-vapor equilibria data of Jarry et al. ${ }^{21}$ for the HF. UF $_{6}$ system to develop relations for estimating the total pressure of dilute binary solutions of $\mathrm{UF}_{6}$ in liquid $\mathrm{HF}$ as functions of composition and temperature. These relationships are accurate from 0 mole $\%{U \mathrm{UF}_{6}}_{6}$ to the saturation solubility throughout the temperature range of interest in the current study. The relationships are as follows:

$$
\ln P(\mathrm{~cm} H g)=A_{(x)}+B_{(x)} / T \text {. }
$$

Now,

$$
A_{(x)}=15.25118+13.88719 X-277.23934 X^{2}+3085.46120 X^{3}-12432.84269 X^{4}
$$

and

$$
B_{(x)}=-3203.594-2197.09576 X+70963.81576 X^{2}-1043895.379 X^{3}+4780826.925 X^{4},
$$

where $X$ is the mole fraction $\mathrm{UF}_{6}$ in the HF solution at $\mathrm{T}$ Kelvin.

Rutledge, Jarry, and Davis ${ }^{36}$ determined the solid-liquid phase equilibrium for the HF-UF 6 system from which the solubility of solid $\mathrm{UF}_{6}$ in liquid $\mathrm{HF}$ at saturation can be determined. A plot of their solid-liquid phase equilibrium data is given in Fig. B2.1 in which the logarithm of the mole fraction $U_{6}$ at the phase boundary is plotted as a function of the reciprocal of absolute temperature. With these data and Eqs. (B2-6)-(B2-8) one can obtain the pressure exerted by a solution of $\mathrm{HF}$ saturated with $\mathrm{UF}_{6}$ at any temperature of interest in the current problem. The data of Rutledge, Jarry, and Davis ${ }^{36}$ and of Jarry et al. ${ }^{21}$ show that the system is azeotropic with a partially submerged miscibility gap. This means that, for the HF-rich solutions of interest, the concentration of $\mathrm{UF}_{6}$ is enriched in the vapor over its concentration in the liquid phase at the saturation pressure and temperature. The data for this relationship are plotted in Fig. B2.2 covering the region of interest.

It should also be noted that HF has greater solubility in solid $\mathrm{UF}_{6}$ than $\mathrm{O}_{2}$ and $\mathrm{N}_{2}$. While quantitative experimental data have not been obtained on the solubility of $\mathrm{HF}$ in solid $\mathrm{UF}_{6}$, Barber $^{2}$ has estimated this using the facts that solid $\mathrm{UF}_{6}$ is a molecular solid and that the activity coefficients for the HF and the $\mathrm{UF}_{6}$ can be estimated in both the liquid and the solid phases using the methods of Scott and Hildebrand. ${ }^{18}$ The resulting phase relations are shown in Figs. B2.3 and B2.4. The solubility of $H F$ in $U_{6}$ is believed to be significant with respect to the gradual accumulation of this compound in the vapor space as reactions between the solid $\mathrm{UF}_{6}$ and moisture continue at the breach in the cylinder below the solid $\mathrm{UF}_{6}$ level in the cylinder. 


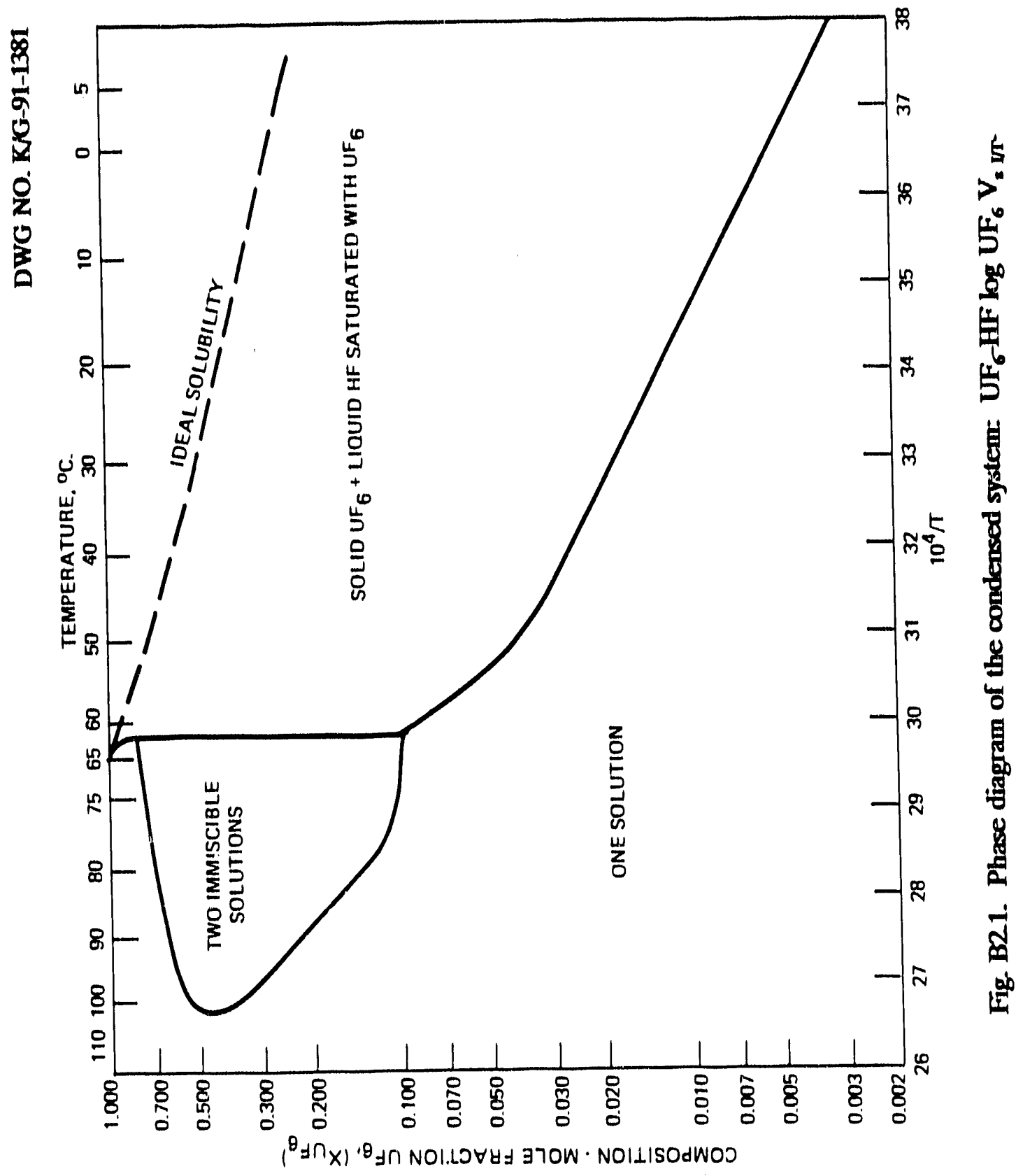


DWG NO. K/G-91-1376

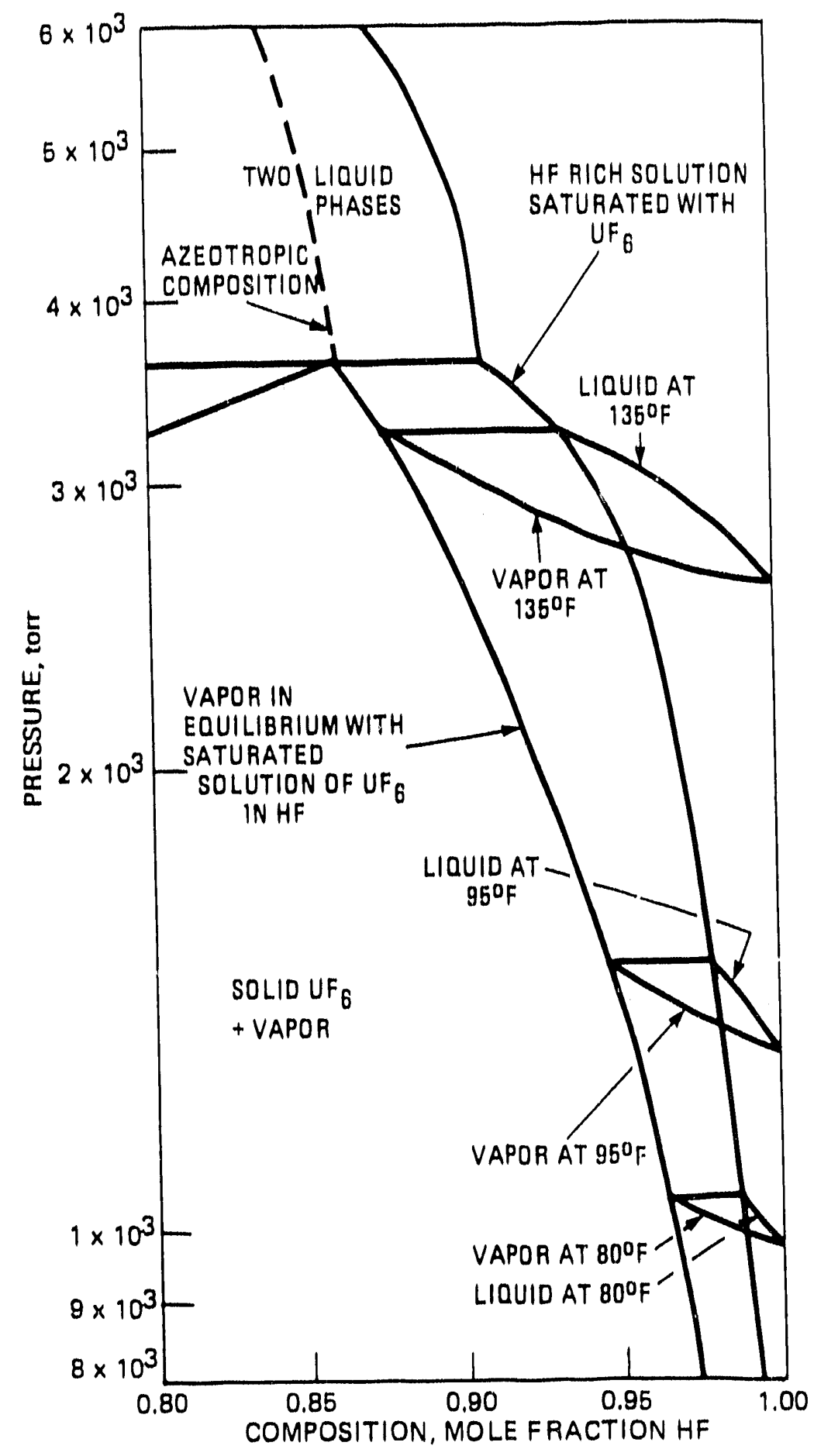

Fig. B2.2 Plot of logarithm of pressure as a function of composition. 


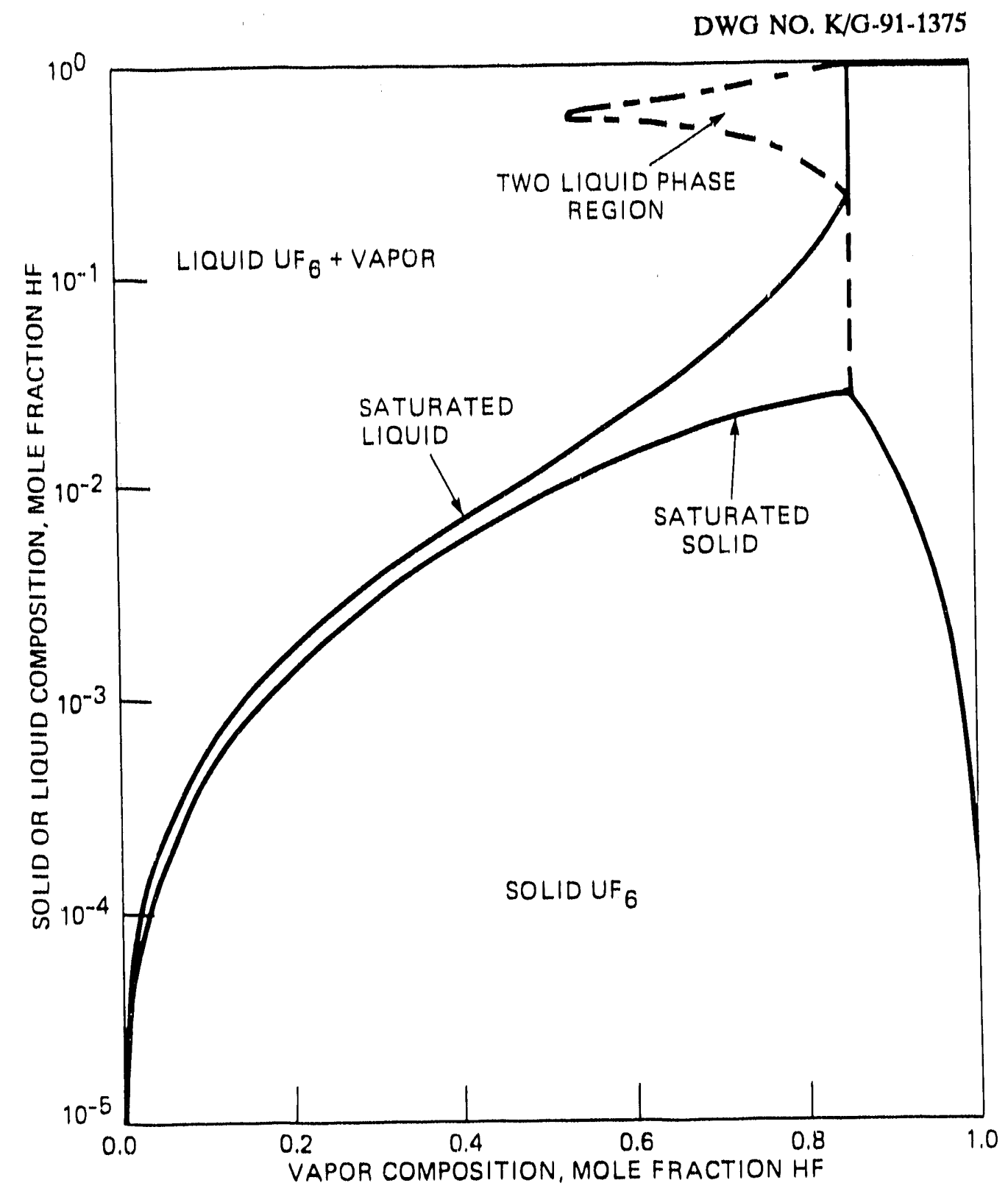

Fig. B2.3. HF solubility in condensed $\mathrm{UF}_{6}$ separating from gascous HF-UF 6 mixtures. 
DWG NO. K/G-91-1377

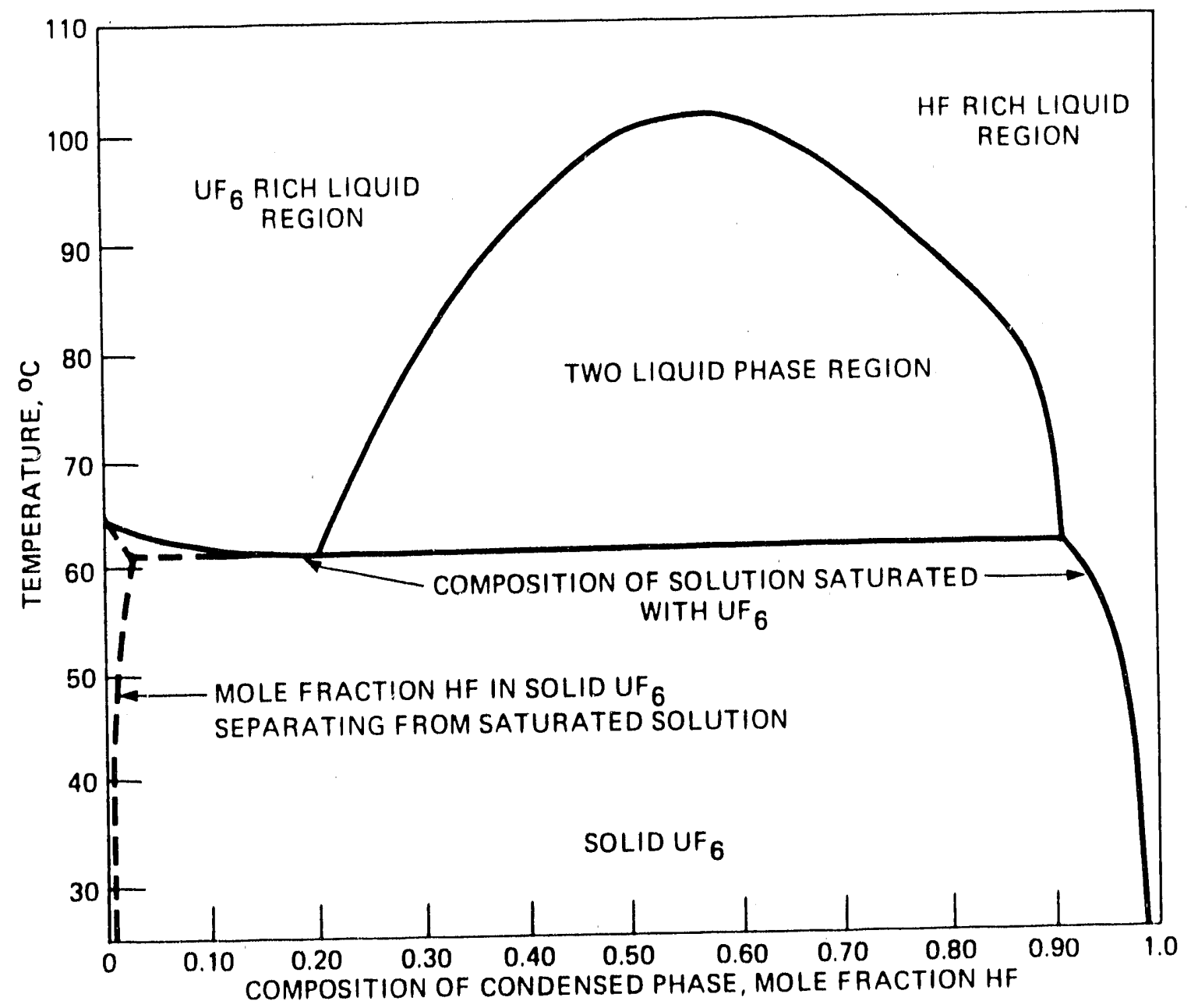

Fig. B2.4. Condensed phase diagram of HF-UF 6 showing HF content of scparating solid $\mathrm{UF}_{6}$ at saturation.

\section{ESTIMATION OF PARTIAL PRESSURES OF COMPONENTS AND UF 6 TEMPERATURES}

The quantities that are measured include the ambient air temperature, the total pressure in the vapor space of the cylinder, and the molecular composition of the vapor space obtained from samples withdrawn at the same time as the total pressure was measured. If it were not for the problem of the association of HF, the molecular composition and the total pressure would yield directly the partial pressures of the components. In any case such a calculation leads to a lower limit on the partial pressures of the $\mathrm{UF}_{6}, \mathrm{O}_{2}$, and $\mathrm{N}_{2}$ and an upper limit on the partial pressure of the HF. Since the partial pressure of the $\mathrm{UF}_{6}$ is the sublimation pressure of the solid, this estimate can be used to obtain a lower limit on the temperature of the solid UF $\mathrm{F}_{6}$. While this simple calculation does not require knowing the temperature of the vapor space, the estimation of the association factor for $\mathrm{HF}$, which is necessary to obtain the correct values of the partial 
pressures, does require this information. Estimation of the vapor space temperature is $\mathrm{p}$ rticularly difficult when the sun shines on the cylinder. This latter situation prevailed fo cylinder $4 G 127985$, but because of the low partial pressure of HF relative to its saturation pre sure, the absence of this information was not crucial. The measured pressure at the time of vapo sampling was 8 in. $\mathrm{Hg}$ vacuum, and the ambient air temperature was $85^{\circ} \mathrm{F}$ (ref. 37).

After the discovery of the breach in June 1990, cylinder 4G115688 was stored un . r a black plastic canopy. On the late August day when the vapor composition sample was :aken, the ambient air temperature was $92^{\circ} \mathrm{F}$ and the "cold pressure" was measured to be 11 psig (ref. 38). Other "cold pressure" measurements on cylinder 4G115688 were made both earlier and later. Shortly after the vapor composition samples were taken on cylinder $4 \mathrm{G} 127985$, cylinder ${ }_{\mathrm{W}} \mathrm{G} 115688$ was determined to have a "cold pressure" of 8 psig at an ambient temperature of ahout $85^{\circ} \mathrm{F}$. In November 1990, before any removal of vapor from the vapor space, the "cold pressure" of cylinder $4 \mathrm{G} 115688$ was measured to be 2 psig at an ambient temperature of $47^{\circ} \mathrm{F}$. Then, after removal of $8 \mathrm{lb}$ of vapor from the cylinder, patching the hole, placement on a low boy trailer, and resealing the patch, the vapor in the vapor space was resampled. The "cold pressure" at this time was -2.5 psig, and the ambient temperature was about $57^{\circ} \mathrm{F}$ (ref. 25 ). The composition of the vapor space of cylinder 4G127985 and the composition of the vapor space of cylinder 4G115688, before and after the removal of $8 \mathrm{lb}$ of vapor, are given in Table B1-2 of Appendix B, Part 1 .

If the HF is significantly associated, the partial pressures may be calculated if the mean association factor may be estimated or if a liquid layer of $\mathrm{HF}$ saturated with $\mathrm{UF}_{6}$ exists on the surface of the solid $\mathrm{UF}_{6}$. To begin the analysis, let the measured total pressure be given by $P_{\boldsymbol{o}}$. Then, according to Dalton's law of partial pressures,

$$
P_{U F 6}+P_{H F}+P_{O 2}+P_{N 2}=P_{0}
$$

where $\boldsymbol{P}_{i}$ is the partial pressure of component $i$.

Consider one mole of HF to have a molecular weight of 20 with association factor $Z$, and note that the partial pressure of $U F_{6}$ is the sublimation pressure; then, the mole fraction of each component in the vapor is given by Raoult's law as follows:

$$
y_{U F 6}=P_{s, U F 6}^{o} / P_{t} ; y_{H F}=Z P_{H F} / P_{t} ; y_{O 2}=P_{O 2} / P_{t} ; y_{N 2}=P_{N 2} / P_{1} \text {, }
$$

where

$$
P_{1}=P_{o}\left(y_{U F 6}+y_{O 2}+y_{N 2}+Z y_{H F}\right)
$$

and

$$
y_{U F 6}+y_{H F}+y_{O 2}+y_{N 2}=1 \text {. }
$$

Then,

$$
y_{U F \sigma} / y_{H F}=P_{s, U F \sigma}^{o} / Z P_{H F} \text { or } P_{s, U F 6}^{o}=\left[y_{U F \sigma} / y_{H F}\right] Z P_{H F} \text {. }
$$


Also,

$$
y_{O 2} / y_{H F}=P_{O 2} / Z P_{H F} \text { or } P_{O 2}=\left[y_{O 2} / y_{H F}\right] Z P_{H F}
$$

and

$$
y_{N 2} / y_{H F}=\boldsymbol{P}_{N 2} / Z P_{H F} \text { or } \boldsymbol{P}_{N 2}=\left[y_{N 2} / y_{H F}\right] Z \boldsymbol{P}_{H F} .
$$

Substituting in Eq. (B2-9),

$$
\left[y_{U F \sigma} / y_{H F}\right] Z P_{H F}+P_{H F}+\left[y_{O 2} / y_{H F}\right] Z P_{H F}+\left[y_{N 2} / y_{H F}\right] Z P_{H F}=P_{0} .
$$

Collecting terms,

$$
\left[1+Z\left(y_{U F 6}+y_{O 2}+y_{N 2}\right) / y_{H F}\right] P_{H F}=P_{0}
$$

or

$$
P_{H F}=P_{o} /\left[1+z\left(y_{U F 6}+y_{O 2}+y_{N 2}\right) / y_{H F}\right]
$$

Everything in Eq. (B2-15) is known except $Z$ and $\boldsymbol{P}_{H F}$. Equations (B2-6)-(B2-8) and the data in Fig. B2.1 permit estimation of $\boldsymbol{P}_{H F}$ as a function of temperature for saturated solutions of $\mathrm{UF}_{6}$ in liquid HF as a function of temperature, since for this condition $\boldsymbol{P}_{U F_{6}}$ is $\boldsymbol{P}_{s, U F 6}$, which may be calculated as a function of temperature by Eq. (B2-4). If one assumes that such a saturated solution exists, then the value of the first two terms in Eq. (B2-9) is the pressure in torr obtained from Eqs. (B2-6)-(B2-8) by use of the graph in Fig. B2.1, and the values of the last two terms may be evaluated at each temperature from Eqs. (B2-13) and (B2-14) or the following:

$$
\begin{aligned}
& y_{O 2} / y_{U F 6}=P_{O 2} / P_{U F 6}^{o} \text { or } P_{O 2}=\left[y_{O 2} / y_{U F 6}\right] P_{U F 6}^{o} \\
& y_{N 2} / y_{U F 6}=P_{N 2} / P_{U F 6}^{o} \text { or } P_{N 2}=\left[y_{N 2} / y_{U F 6}\right] P_{U F 6}^{o} .
\end{aligned}
$$

With these substitutions, Eq. (B2-9) can be evaluated for $P_{o}$ for each temperature and the temperature of the solid $\mathrm{UF}_{6}$ estimated by noting the temperature required for the calculated $P_{0}$ from Eq. (B2-9) to equal the measured $\mathrm{P}_{\mathrm{o}}$. If the measured value of $P_{0}$ is less than the value of $P_{0}$ calculated, assuming a saturated solution of $\mathrm{UF}_{6}$ in $\mathrm{HF}$ exists at the solid temperature estimated from the partial pressure of $\mathrm{UF}_{6}$, then there exists no liquid layer in the cylinder. Such is the case for cylinder 4G127985, the one with the small hole. Cylinder 4G115688, the one with the large hole, is predicted to have a liquid layer of HF saturated with $U_{6}$ between the vapor space and the surface of the solid $\mathrm{UF}_{6}$.

For the saturated solution case, the value of $\boldsymbol{P}_{H F}$ in the vapor space is the value obtained by subtracting the value of $P_{s, U F 6}^{0}$ from the calculated total pressure of the saturated binary HF-UF ${ }_{6}$ solution at the temperature at which the calculated value of $P_{o}$ is equal to the measured value of $P_{o}$. Substituting this value into Eq. (B2-15) gives the estimated value of $Z$ at the mean temperature of the vapor space. The value of $Z$ can also be estimated at the presumed mean temperature of the vapor space from the estimate of the partial pressure of HF determined above by using the Long, Hildebrand, and Morrell ${ }^{23}$ equations. If the assumption is made that the Long, 
Hildebrand, and Morrell equations correctly predict $Z$ for these conditions, failure of these $Z s$ to agree indicates that the mean temperature of the vapor space probably was incorrectly estimated. The value of the temperature required to produce agreement between the two estimates of $Z$ is the more likely effective mean temperature of the vapor space.

The composition of the vapor in equilibrium with the saturated solution in immediate contact with the solid $\mathrm{UF}_{6}$ at the temperature of the solid can be obtained from Fig. B2.2. As expected, this vapor will be noted to be richer in $\mathrm{UF}_{6}$ than the solution but less rich in $\mathrm{UF}_{6}$ than the average value in the vapor space. This is true because the partial pressure of $\mathrm{HF}$ is the same in this vapor next to liquid as elsewhere in the vapor space, but the temperature is lower (in summer) than the mean temperature of the vapor space (in the daytime when samples would be taken and pressure measurements made). For this reason, the degree of association of HF is greater in the colder vapor, and the number of $20-\mathrm{g}$ units (moles) of HF per unit volume is larger. The value of $Z$ required to give the determined partial pressure of $\mathrm{HF}$ at this composition can be calculated and compared to the value of $Z$ from the Jarry and Davis relations given by Eqs. (B2-1) and (B2-2) at the snlution temperature. It can be shown that these values of $Z$ agree, lending some credence to th bability that the use of the approach employed is correct for the situation existing in cylinder $4 \mathrm{G} 115688$.

\section{COMPOSITION AND PARTIAL PRESSURES OF THE COMPONENTS IN THE VAPOR SPACE OF CYLINDER 4G127985}

For determining the partial pressures of the components and the temperature of the solid $\mathrm{UF}_{6}$ in cylinder $4 \mathrm{G} 127985$, an association factor for HF consistent with the Long, Hildebrand, and Morrell ${ }^{23}$ relations at a reasonable mean vapor space temperature should be selected. If, as one might expect, the elevation of the effective vapor space temperature above ambient is the same as found for cylinder $4 \mathrm{G} 115688$, the effective mean vapor space temperature of cylinder $4 G 127985$ would be estimated to be about $106^{\circ} \mathrm{F}$ and, for the approximate value of the partial pressure of HF encountered, leads to a value of $Z$ of about 1.002 . This value of $Z$ was used with Eqs. (B2-12)-(B2-15b) to estimate the partial pressures of the components of the vapor space. Since the partial pressure of the $\mathrm{UF}_{6}$ is determined by the sublimation pressure of the solid, the temperature of the solid $\mathrm{UF}_{6}$ was estimated to be about $71^{\circ} \mathrm{F}$. If the cylinder had contained enough $\mathrm{HF}$ to reach saturation at the temperature of the solid $\mathrm{UF}_{6}$, the total pressure would have been about 1121 torr ( 21.7 psia or 7 psig). If the solid $\mathrm{UF}_{6}$ temperature were to be $79.5^{\circ} \mathrm{F}$, as is estimated in the next section for cylinder $4 \mathrm{G} 115688$, then the pressure (if liquid HF solution were present) would be about 10.5 psig.

Infrared and gas chromatographic measurements of the gas composition in the vapor space of cylinder 4G127985 ( ref. 37) are given in Table B2-1, along with the estimated partial pressures of these components in the vapor space.

The mole ratio of $\mathrm{O}_{2}$ to $\mathrm{N}_{2}$ shows that these "permanent gases" are from air. It is probable that most of these quantities of $\mathrm{O}_{2}$ and $\mathrm{N}_{2}$ were present from the initial filling.

The $\mathrm{UF}_{6}$, which is removed from the gaseous diffusion process as the low-assay stream, is of high purity and should contain much less $\mathrm{HF}$ than $\mathrm{UF}_{6}$ withdrawn as product. The typical, 
Table B2-1. Composition and partial pressures of components in cylinder 4G127985

\begin{tabular}{crr}
\hline Component & $\begin{array}{c}\text { Percent of } \\
\text { total vapor }\end{array}$ & $\begin{array}{c}\text { Partial pressure } \\
\text { of component }\end{array}$ \\
\hline $\mathrm{UF}_{6}$ & 16.0 mole \% & 88 torr $(1.7$ psia $)$ \\
$\mathrm{HF}$ & 36.9 mole \% & 204 torr $(3.9 \text { psia })^{*}$ \\
$\mathrm{O}_{2}$ & 9.3 mole \% & 51 torr $(1.0$ psia $)$ \\
$\mathrm{N}_{2}$ & 37.8 mole \% & 209 torr $(4.1$ psia $)$ \\
$\mathrm{F}_{2}$ & $<0.5$ mole \% & 0 torr $(0.0$ psia $)$ \\
\hline
\end{tabular}

*Partial pressures given are adjusted for the fact that HF gas is slightly associated at this temperature and pressure. The association factor, $Z$, is estimated to be about 1.002 .

partial pressure of the HF content of unburped product cylinders at Paducah ranges from 10 to 20 torr $(0.2$ to 0.4 psia). It is reasonable to assume that this would be an upper limit for the partial pressure of HF in cylinder 4G127985 when placed in storage, giving a "cold pressure" of about 7.3 psia for the same ambient temperature.

The $\mathrm{UF}_{6}$ partial pressure of 88 torr indicates that the temperature of the cake of solid $\mathrm{UF}_{6}$ in the cylinder is about $71^{\circ} \mathrm{F}$. That this probably is a reasonable estimate of the bulk solid temperature is confirmed by the fact that the bottoms of the cylinders are significantly cooler than the ambient air at daytime highs. The tops of these cylinders had a surface temperature of about $140^{\circ} \mathrm{F}$ after standing all morning in the sun.

\section{COMPOSITION AND PARTIAL PRESSURES OF THE VAPUR SPACE COMPONENTS OF CYLINDER 4G115688 BEFORE REMOVAL OF 8 lb OF VAPOR}

The 11 psig (1329 torr) pressure and the high HF mole fraction of $0.766\left(\mathrm{MW}_{\mathrm{HF}}=20\right.$ basis) in the vapor space of cylinder 4G115688 are suggestive of the possibility that a saturated solution of $\mathrm{UF}_{6}$ in HF exists in this cylinder. Using the equations developed earlier for this situation, one obtains the data shown in Table B2-2.

Based on this analysis, cylinder $4 \mathrm{G} 115688$ would contain an $\mathrm{HF}$ solution saturated with $\mathrm{UF}_{6}$ at a temperature of $79.5^{\circ} \mathrm{F}$. This would indicate that the temperature of the solid $\mathrm{UF}_{6}$ had risen since June 1990 when the temperature of the solid $U F_{6}$ in cylinder $4 G 127985$ is estimated to be $71^{\circ} \mathrm{F}$. Shortly after the "cold pressure" measurement on cylinder $4 \mathrm{G} 127985$ in June 1990 , the "cold pressure" of the vapor space of cylinder 4G115688 was measured to be 8 psig, and in November 1990 the "cold pressure" was 2 psig. The existence of the HF solution saturated with $\mathrm{UF}_{6}$ in the ullage of the cylinder permits ready reconciliation of both the 8 psig reading in June 1991 and the 2 psig reading in November 1990 with the 11 psig reading in August 1990. The ambient air temperature was about $85^{\circ} \mathrm{F}$ in June 1990 and $47^{\circ} \mathrm{F}$ in November 1990 , whereas it was $92^{\circ} \mathrm{F}$ in August 1990. 
Table B2-2. Predicted vapor space pressures of cylinder 4G115688 containing a saturated solution of $\mathrm{UF}_{6}$ in $\mathrm{HF}$ as a function of the temperature of the solid $\mathrm{UF}_{6}$

\begin{tabular}{ccccccc}
\hline $\begin{array}{c}\text { Temp. } \\
\text { of } \\
\mathrm{UF}_{6}(\mathrm{~s}) \\
{ }^{\circ} \mathrm{F}\end{array}$ & $\begin{array}{c}\text { Mole frac. } \\
\mathrm{UF}_{6} \text { in HF } \\
\text { solution }\end{array}$ & $\begin{array}{c}\text { Sum of partial } \\
\text { pressures of } \\
\mathrm{HF} \text { and } \mathrm{UF}_{6} \\
\text { (torr) }\end{array}$ & $\begin{array}{c}\mathrm{P}_{\mathrm{O} 2} \\
\text { (torr) }\end{array}$ & $\begin{array}{c}\mathrm{P}_{\mathrm{N} 2} \\
\text { (torr) }\end{array}$ & $\begin{array}{c}\text { Calc. total } \\
\text { P, torr }\end{array}$ & $\begin{array}{c}\text { Expt'l. } \mathrm{P}_{\circ} \\
\text { (torr) }\end{array}$ \\
\hline 79.0 & 0.150 & 1029.4 & 57.7 & 218.9 & 1306 & 1329 \\
79.5 & 0.152 & 1040.8 & 58.8 & 223.0 & 1323 & 1329 \\
80.0 & 0.155 & 1052.8 & 59.9 & 227.1 & 1340 & 1329 \\
\hline
\end{tabular}

${ }^{*}$ Computed on a binary basis; i.e., $x_{U F 6}=N_{U F 6} /\left(N_{U F 6}+N_{H F}\right)$. The values are taken from Fig. B2.1.

The relationship of the gas composition and the partial pressures of the components in the vapor space of cylinder 4G115688, at the time they were taken in August 1990, are shown in Table B2-3. The gas phase composition was obtained by infrared and gas chromatographic analysis at PORTS. ${ }^{38}$

Table B2-3. Composition and partial pressures of components in cylinder $4 \mathrm{G} 115688$ at an air ambient temperature of $92^{\circ} \mathrm{F}$

\begin{tabular}{|c|c|c|}
\hline Component & $\begin{array}{l}\text { Percent of } \\
\text { total vapor }\end{array}$ & $\begin{array}{l}\text { Partial pressure } \\
\text { of component }\end{array}$ \\
\hline $\mathrm{UF}_{6}$ & 7.0 mole $\%$ & 123 torr (2.4 psia) \\
\hline $\mathrm{HF}$ & 76.6 mole $\%$ & 918 torr $(27.7 \text { psia })^{*}$ \\
\hline $\mathrm{O}_{2}$ & 3.40 mole $\%$ & 59 torr (1.1 psia) \\
\hline $\mathrm{N}_{2}$ & 12.9 mole $\%$ & 223 torr (4.3 psia) \\
\hline $\mathrm{F}_{2}$ & $<0.5$ mole $\%$ & 0 torr (0.0 psia) \\
\hline $\begin{array}{l}\text { *Partial pre } \\
\text { significantly assoc } \\
\text { association facto } \\
\text { equations for the } \\
\text { and } 918 \text { torr is } 3 .\end{array}$ & $\begin{array}{l}\text { n are adjusted } \\
s \text { temperature and } \\
4 \text {. The value of } \\
\text { nmediate contact } \\
\text { olecular weight of }\end{array}$ & $\begin{array}{l}\text { fact that } \mathrm{H}^{-} \text {gas is } \\
\text { e. The estima : d mear } \\
\text { the Jarry an Davis } \\
\text { HF solution it } 79.5^{\circ} \mathrm{F} \\
\text { aken as } 20 \text {. }\end{array}$ \\
\hline
\end{tabular}

As before, the mole ratio of $\mathrm{O}_{2}$ to $\mathrm{N}_{2}$ suggests that most of these "permar:ent gases" remain from residual air left in the cylinder at the time of filling; however, the $\mathrm{O}_{2}$-to $\mathrm{N}_{2}$ ratio is slightly 
higher than it is in air and in cylinder 4G127985. Whether this change actually represents slightly greater diffusivity of $\mathrm{O}_{2}$ through solid $\mathrm{UF}_{6}$, or simply results from experimental error in determining the concentrations, is not known. Since it is also probable that the HF partial pressure at filling was 0.2 psia or less, the initial pressure in this cylinder would have been about 7 psia also.

The estimated $\mathrm{UF}_{6}$ partial pressure of 123 torr indicates that the temperature of the cake of solid $\mathrm{UF}_{6}$ in the cylinder is effectively $79.5^{\circ} \mathrm{F}$. The $\mathrm{UF}_{6}$ partial pressure and the HF partial pressure are consistent with the measured properties of the HF-UF 6 vapor-liquid phase system. As was the case in June 1990, the bottoms of the cylinders are definitely cooler than the ambient air during the daytime.

To reconcile the "cold pressure" measured in August 1990 of 11 psig at an ambient temperature of $92^{\circ} \mathrm{F}$ with the 8 psig measured in June 1990 at an ambient temperature of about $85^{\circ} \mathrm{F}$, one proceeds by noting that, since the temperature of the solid might well have been lower in June 1990 than in August 1990, only the number of moles of $\mathrm{O}_{2}$ and $\mathrm{N}_{2}$ in the vapor space need have been the same for both measurements. The partial pressures of these components at the time of the June 1990 measurement will be those of the August 1990 measurement reduced by the ratio of the absolute temperatures. Since it appears probable that a solution of HF saturated with $\mathrm{UF}_{6}$ was in the cylinder in August 1990, it would also have been present in June 1990. The expected difference between the observed total pressure and the sum of the partial pressures of $\mathrm{O}_{2}$ and $\mathrm{N}_{2}$ then is the pressure of the HF solution. Since the partial pressure of the $\mathrm{UF}_{6}$ and the pressure of the solution are determined simultaneously by the temperature of the solid $\mathrm{UF}_{6}$, an analysis similar to that made to obtain the data in Table B2-2 can be performed. The results of such an analysis are shown in Table B2-4.

Table B2-4. Predicted vapor space pressures of cylinder 4G115688 containing a saturated solution of $\mathrm{UF}_{6}$ in $\mathrm{HF}$ as a function of the temperature of the solid $\mathrm{UF}_{6}$ at an ambient temperature of $85^{\circ} \mathrm{F}$

\begin{tabular}{cccccccc}
\hline $\begin{array}{c}\text { Temp. of } \\
\begin{array}{c}\mathrm{UF} \\
{ }_{6}(\mathrm{~s})\end{array}\end{array}$ & $\begin{array}{c}\text { Mole } \\
\text { frac. UF } \\
\text { in HF } \\
\text { solution }\end{array}$ & $\begin{array}{c}\mathrm{P}_{\mathrm{UF} 6} \\
\text { (torr) }\end{array}$ & $\begin{array}{c}\mathrm{P}_{\mathrm{HF}} \\
\text { (torr) }\end{array}$ & $\begin{array}{c}\mathrm{P}_{\mathrm{O} 2} \\
\text { (torr) }\end{array}$ & $\begin{array}{c}\mathrm{P}_{\mathrm{N} 2} \\
\text { (torr) }\end{array}$ & $\begin{array}{c}\text { Calc. total } \\
\mathrm{P} \text {, torr }\end{array}$ & $\begin{array}{c}\text { Expt'l. } \mathrm{P}_{\mathrm{o}} \\
\text { torr }\end{array}$ \\
\hline 71.0 & 0.0126 & 89.1 & 775.1 & 58.0 & 220.2 & 1142 & 1174 \\
72.0 & 0.0130 & 92.6 & 791.0 & 58.0 & 220.2 & 1162 & 1174 \\
72.5 & $\mathbf{0 . 0 1 3 2}$ & 94.4 & 799.7 & 58.0 & 220.2 & 1172 & 1174 \\
73.0 & 0.0134 & 96.2 & 808.1 & 58.0 & 220.2 & 1182 & 1174 \\
\hline \\
"Computed on a binary basis; i.e., $\mathrm{x}_{\mathrm{UF} 6}=\mathrm{N}_{\mathrm{UP}}\left(\mathrm{N}_{\mathrm{UF} 6}+\mathrm{N}_{\mathrm{HF}}\right)$. The values are taken \\
from Fig. B2-1.
\end{tabular}


The data in Table B2-4 indicate that, by the selection of $72.5^{\circ} \mathrm{F}$ for the temperature of the solid $\mathrm{UF}_{6}$, the pressure measurement of 8 psig in June 1990 for cylinder $4 \mathrm{G} 115688$ is reconciled with the reading of $11 \mathrm{psig}$ in August 1990. Since the error in Bourdon gauges is about $\pm 0.5 \mathrm{psi}$, there is no real disagreement even if the solid $\mathrm{UF}_{6}$ is at the same temperature $\left(70.8^{\circ} \mathrm{F}\right)$ as that in cylinder 4G127985, which was sampled slightly earlier in June 1990. If there were no HF-rich solution in the cylinder, then one cannot account for the 3 psi change in the pressure of the vapor space from the small change in the ambient temperature and the change in temperature of the solid $\mathrm{UF}_{6}$.

To reconcile the "cold pressure" measured in November 1990 of 2 psig at an ambient temperature of $47^{\circ} \mathrm{F}$ with the 11 psig measured in August 1990 at an ambient temperature of about $92^{\circ} \mathrm{F}$, one proceeds by noting that, since the temperature of the solid is surely lower in November 1990 than in August 1990, again only the number of moles of $\mathrm{O}_{2}$ and $\mathrm{N}_{2}$ in the vapor space need have been the same for both measurements. The partial pressures of these components at the time of the November 1990 measurement will be those of the August 1990 measurement reduced by the ratio of the absolute temperatures. Also for the same reasons, the expected difference between the observed total pressure and the sum of the partial pressures of $\mathrm{O}_{2}$ and $\mathrm{N}_{2}$ is the pressure of the HF solution. Since the partial pressure of the $\mathrm{UF}_{6}$ and the pressure of the solution are determined simultaneously by the temperature of the solid $\mathrm{UF}_{6}$, an analysis similar to that made to obtain the data in Table B2-2 can be performed. The results of such an analysis are shown in Table B2-5.

Table B2-5. Predicted vapor space pressures of cylinder 4 G115688 containing a saturated solution of $\mathrm{UF}_{6}$ in $\mathrm{HF}$ as a function of the temperature of the solid $\mathrm{UF}_{6}$ at an ambient temperature of $47^{\circ} \mathrm{F}$

\begin{tabular}{cccccccc}
\hline $\begin{array}{c}\text { Temp. of } \\
\mathrm{UF}_{6}(\mathrm{~s}) \\
{ }^{\circ} \mathrm{F}\end{array}$ & $\begin{array}{c}\text { Mole } \\
\text { frac. UF } \\
\text { in HF }\end{array}$ & $\begin{array}{c}\mathrm{P}_{\mathrm{UF6}} \\
\text { solution }\end{array}$ & $\begin{array}{c}\mathrm{P}_{\mathrm{HF}} \\
\text { (torr) }\end{array}$ & $\begin{array}{c}\mathrm{P}_{\mathrm{O} 2} \\
\text { (torr) }\end{array}$ & $\begin{array}{c}\mathrm{P}_{\mathrm{N} 2} \\
(\text { torr) }\end{array}$ & $\begin{array}{c}\text { Calc. total } \\
\text { (torr) }\end{array}$ & $\begin{array}{c}\text { Pxpt't. } \mathrm{P}_{\mathrm{o}} \\
\text { torr }\end{array}$ \\
\hline 47.0 & 0.0072 & 33.9 & 466.6 & 54.2 & 204.8 & 759.5 & 863.4 \\
54.0 & 0.0087 & 45.4 & 539.4 & 54.2 & 204.8 & 848.8 & 863.4 \\
55.1 & 0.0088 & 47.5 & 557.0 & 54.2 & 204.8 & 863.5 & 863.4 \\
56.0 & 0.0080 & 49.3 & 567.5 & 54.2 & 204.8 & 875.8 & 863.4 \\
\hline
\end{tabular}

${ }^{*}$ Computed on a binary basis; i.e., $x_{\mathrm{UP} 6}=\mathrm{N}_{\mathrm{UF}} \mathcal{d}\left(\mathrm{N}_{\mathrm{UF} 6}+\mathrm{N}_{\mathrm{HF}}\right)$. The values are taken from Fig. B2.1.

The data in Table B2-5 indicate that, by the selection of $55.1^{\circ} \mathrm{F}$ for the temperature of the solid $\mathrm{UF}_{6}$, the pressure measurement of 2 psig in November 1990 for cylinder $4 \mathrm{G} 115688$ is reconciled with the reading of 11 psig in August 1990. The temperature of the UF $\mathrm{UF}_{6}$ solid cake is controlling, since the solution would be boiling at the cake temperature, and is refluxed by condensing at the top of the cylinder wall, which will tend to lower the UF 6 solid temperature over time. The solid temperature is indicated to have fallen from $79.5^{\circ} \mathrm{F}$ in August 1990 to 
$55.1^{\circ} \mathrm{F}$ in November 1990 . Here again, the change in total pressure is larger than would be anticipated from the change in temperature.

The molar composition of the $\mathrm{HF}$ solution saturated with $\mathrm{UF}_{6}$ at $79.5^{\circ} \mathrm{F}$ is obtained from Fig. B2-1 for the solid-liquid phase equilibrium as 0.9849 mole fraction HF. The mole fraction of $\mathrm{HF}$ in the vapor in immediate contact with the liquid phase at $79.5^{\circ} \mathrm{F}$ should be 0.962 as obtained from Fig. B2-2 for the liquid-vapor equilibrium. The mean mole fraction of HF (binary basis for $\mathrm{HF}$ and $\mathrm{UF}_{6}$ only) in the vapor space, which is at a significantly higher mean temperature, is determined from the analysis to be 0.915 when the HF partial pressure is 918 torr with $Z$ equal to 1.44 . Since the value of $Z$ at saturation for $79.5^{\circ} \mathrm{F}$ and 918 torr pressure is 3.37, the effective mole fraction of HF on a binary basis in immediate contact with the solution may be estimated as follows:

$y_{H F}=Z * P_{H F} /\left(P_{, U F \sigma}^{\circ}+Z * P_{H F}\right)=3.37(918) /((3.37)(918)+123)=0.962$ mole frac $H F$.

The agreement is excellent and attests to the excellence of the literature information, which was obtained by three independent studies, some of which did not even involve $\mathrm{UF}_{6}$.

If the effective mean temperature of the vapor space is assumed to be the ambient air temperature $\left(92^{\circ} \mathrm{F}\right)$, the association factor equ tions of Long, Hildebrand, and Morrell ${ }^{23}$ for unsaturated conditions yield a value of 2.33 , which suggests that the effective mean temperature of the cylinder is above the ambient temperature and could be as high as $113^{\circ} \mathrm{F}$. Considering that the cylinder was shielded from the direct sun with a black plastic vee-shaped canopy, it seems entirely possible :or the top of the cylinder to have been this warm. If one assumes that in June 1990 the effective temperature was also $21^{\circ} \mathrm{F}$ above the ambient air temperature, then for the value of the partial pressure of 799.7 torr (Table B2-4), one obtains a $Z$ value of 1.47, which is a quite reasonable value for a $7^{\circ} \mathrm{F}$ lower temperature, since the value of $Z$ at a given partial pressure of $\mathrm{HF}$ does increase with falling ternperatures and is 1.44 at $113^{\circ} \mathrm{F}$. Table B2-6 shows the relationships of composition and partial pressures for the components of the vapor space of cylinder $4 \mathrm{G} 115688$ at the ambient air temperatures of 92,85 , and $47^{\circ} \mathrm{F}$ measured in August, June, and November 1990, respectively.

\section{COMPOSITION AND PARTIAL PRESSURES OF THE VAPOR SPACE COMPONENTS OF CYLINDER 4G115688 AFTER REMOVAL OF 8 Ib OF VAPOR}

After the removal of $8 \mathrm{lb}$ of vapor from cylinder $4 \mathrm{G} 115688$, patching the hole, lifting the cylinder onto a low boy trailer, and resealing the patch, which had leaked as a result of the lifting, the vapor in the vapor space was resampled and the "cold pressure" was remeasured. The "cold pressure" was $-2.5 \mathrm{psig}$, and the ambient temperature was about $57^{\circ} \mathrm{F}$. Because the removal of $8 \mathrm{lb}$ of vapor from the vapor space should have removed most of the air originally present, its continued presence indicates that, when the patch leaked, it probably admitted some air to the cylinder. The composition of the vapor in the vapor space is given in Table B1-2 of Appendix B, Part 1. To determine whether or not the removal of $8 \mathrm{lb}$ of vapor was sufficient to remove the apparent liquid phase from the vapor space of the cylinder, it was assumed that the value $Z$ for $\mathrm{HF}$ was 1 . Since this value will be $>1$, the value of the vapor pressure estimated for the $\mathrm{UF}_{6}$, $\mathrm{O}_{2}$, and $\mathrm{N}_{2}$ by the use of Dalton's law with the given mole fractions is the minimum value for these substances. Since the temperature of the solid $U_{F_{6}}$ is related to this pressure, the minimum 
Table B2-6. Composition and partial pressures of components in the vapor space and mole fraction $\mathrm{UF}_{6}$ of the liquid layer in cylinder $4 \mathrm{G} 115688$

\begin{tabular}{|c|c|c|c|c|c|c|}
\hline \multirow[b]{2}{*}{ Component } & \multicolumn{2}{|c|}{$\begin{array}{l}\mathrm{P}_{\mathrm{o}}=25.7 \mathrm{psia} \\
\text { air temp, } 92^{\circ} \mathrm{F}^{a}\end{array}$} & \multicolumn{2}{|c|}{$\begin{array}{l}P_{o}=22.7 \mathrm{psia} \\
\text { air temp, } 85^{\circ} \mathrm{F}^{a}\end{array}$} & \multicolumn{2}{|c|}{$\begin{array}{c}\mathrm{P}_{\mathrm{o}}=16.7 \mathrm{psia} \\
\text { air temp, } 47^{\circ} \mathrm{F}^{a}\end{array}$} \\
\hline & $\begin{array}{c}\text { Mole } \\
\text { fraction }\end{array}$ & $\begin{array}{l}\text { Part. press. } \\
\text { (torr) }\end{array}$ & $\begin{array}{c}\text { Mole } \\
\text { fraction }\end{array}$ & $\begin{array}{l}\text { Part. press. } \\
\text { (torr) }\end{array}$ & $\begin{array}{c}\text { Mole } \\
\text { fraction }\end{array}$ & $\begin{array}{l}\text { Part. press. } \\
\text { (torr) }\end{array}$ \\
\hline $\mathrm{UF}_{6}$ & 0.071 & 123 & 0.061 & 94 & 0.021 & 48 \\
\hline $\mathrm{HF}$ & 0.766 & 918 & 0.759 & 800 & 0.867 & 557 \\
\hline $\mathrm{O}_{2}$ & 0.034 & 59 & 0.038 & 58 & 0.023 & 54 \\
\hline $\mathrm{N}_{2}$ & 0.129 & 223 & 0.142 & 220 & 0.089 & 205 \\
\hline $\begin{array}{l}\text { Liq. comp., } \\
\text { mole } \% \\
\mathrm{UF}_{6} b\end{array}$ & \multicolumn{2}{|c|}{1.51} & \multicolumn{2}{|c|}{1.29} & \multicolumn{2}{|c|}{0.88} \\
\hline
\end{tabular}

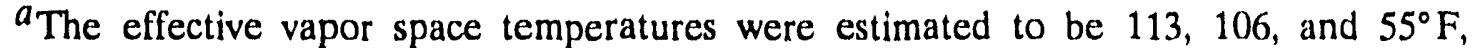
respectively. The first two values are for conditions under which HF solution reflux is not occurring. The third value is for a condition under which reflux of HF solution would be occurring. The HF solution is assumed to be present for all three conditions.

${ }^{b} \mathrm{On}$ a binary basis; i.e., as if only $\mathrm{HF}$ and $\mathrm{UF}_{6}$ were present.

temperature of the $\mathrm{UF}_{6}$ can be estimated to be $44.4^{\circ} \mathrm{F}$. At this temperature, the pressure calculated for the presence of an HF solution exceeds the measured pressure, and it may be concluded that the removal of the $8 \mathrm{lb}$ of vapor removed the solution phase.

To estimate the partial pressures of the components and the temperature of the solid cake of $\mathrm{UF}_{6}$ in the cylinder after the removal of the $8 \mathrm{lb}$ of vapor, the following approach can be used. The partial pressures of the components are related by the equations below:

$$
\begin{gathered}
P_{H F}=P_{o} /\left[1+Z\left(y_{U F 6}+y_{O 2}+y_{N 2}\right) / y_{H F}\right], \\
P_{U F 6}=P_{s 1 l F G}^{o}=\left(P_{o}-P_{H F}\right) y_{U F \sigma} /\left(y_{U F 6}+y_{O 2}+y_{N 2}\right), \\
P_{O 2}=\left(P_{o}-P_{H F}\right) y_{O 2} /\left(y_{U F 6}+y_{O 2}+y_{N 2}\right),
\end{gathered}
$$

and

$$
P_{N 2}=\left(P_{o}-P_{H F}\right) y_{N 2} /\left(y_{U F 6}+y_{O 2}+y_{N 2}\right) \text {. }
$$

Begin by assuming $Z=1$ and obtain $\boldsymbol{P}_{H F}$ and $\boldsymbol{P}_{U F G}$. Further, since the data were obtained on a sunny day in winter without reflux, assume that the effective vapor space temperature is about $10^{\circ} \mathrm{F}$ above the ambient air temperature. Using the Long, Hildebrand, and Morrell relationships, ${ }^{23}$ calculate a new value for $Z$. Using this value for $Z$, repeat the calculation to 
obtain better values for $\boldsymbol{P}_{H F}, P_{s, U F G}$ and $T_{s, U F 6}$. By repetition of the cycle, the differences obtained in $Z, P_{H F}, P_{s, U F O} P_{O Z} P_{N 2}$, and $T_{s, U F O}$ can be made arbitrarily small. When employed with the data on cylinder $4 \mathrm{G} 115688$ after the removal of $8 \mathrm{lb}$ of vapor, the data in Table B2-7 are obtained.

The temperature of the $\mathrm{UF}_{6}$ solid is estimated to be $51.6^{\circ} \mathrm{F}$ and the sum of the partial pressures of $\mathrm{HF}$ and $\mathrm{UF}_{6}$ is estimated as 385 torr, which is well below the saturation pressure of $\mathrm{HF}$ solution saturated with $\mathrm{UF}_{6}$ at $51.6^{\circ} \mathrm{F}$ of 557 torr.

Table B2-7. Estimation of the association factor for HF, the partial pressures of the components, and the temperature of the solid in cylinder $4 \mathrm{G} 115688$ after removal of $8 \mathrm{lb}$ of vapor

\begin{tabular}{|c|c|c|c|c|c|}
\hline \multirow[b]{2}{*}{ Trial $Z$} & \multicolumn{4}{|c|}{ Partial pressure of components as listed, torr } & \multirow{2}{*}{$\begin{array}{c}\text { Temp. of } \\
\mathrm{UF}_{6} \\
{ }^{\circ} \mathrm{F}\end{array}$} \\
\hline & $\mathrm{UF}_{6}$ & $\mathrm{O}_{2}$ & $\mathrm{~N}_{2}$ & $\mathrm{HF}$ & \\
\hline 1.000 & 30.24 & 36.54 & 144.27 & 418.95 & 44.35 \\
\hline 2.280 & 48.26 & 58.31 & 230.22 & 293.95 & 55.51 \\
\hline 1.410 & 37.49 & 45.3 & 178.85 & 368.36 & 49.41 \\
\hline 1.778 & 42.65 & 51.54 & 203.48 & 332.33 & 52.50 \\
\hline 1.598 & 40.26 & 48.65 & 192.07 & 349.03 & 51.12 \\
\hline 1.660 & 41.11 & 49.67 & 196.12 & 343.09 & 51.62 \\
\hline 1.651 & 40.99 & 49.53 & 195.54 & 343.94 & 51.55 \\
\hline 1.656 & 41.06 & 49.61 & 195.87 & 343.47 & 51.59 \\
\hline 1.653 & 41.01 & 49.56 & 196.67 & 343.75 & 51.56 \\
\hline 1.655 & 41.04 & 49.59 & 195.80 & 343.56 & 51.58 \\
\hline
\end{tabular}

\section{DISCUSSION}

The measurements of the "cold pressures" and the vapor compositions of cylinders $4 G 115688$ and 4 G127985 when evaluated in light of the known properties of the interactive components, $\mathrm{HF}$ and $\mathrm{UF}_{6}$, lead to the conclusion that an HF-rich solution is probably present in the case of cylinder $4 G 115688$ that is not present in cylinder $4 G 127985$. The data obtained after the removal of $8 \mathrm{lb}$ of vapor from cylinder 4G115688 indicate that this operation was successful in removing the liquid phase from this cylinder. The case for the existence of the solution is strong and is supported by other observations such as the size of the pressure changes from early morning to mid-day. However, the lack of any temperature measurements on either the solid $\mathrm{UF}_{6}$ or the vapor space prevents one from being absolutely certain. In estimating the quantities of 
$U_{6}$ that have been either hydrolyzed or reduced to $U_{4}$ it will be assumed that a liquid phase was in cylinder $4 \mathrm{G} 115688$.

The solubility data for $\mathrm{HF}$ in solld $\mathrm{UF}_{6}$ must also be employed in any estimation of the quantity of $\mathrm{UF}_{6}$ reacted. The only data avallable are the estimates of the solubility at saturation pressures by Barber, ${ }^{2}$ which are presented in Fig. B2-3. For pressures other than saturation pressures, an additional assumption is necessary. Because $U F_{6}(s)$ is a molecular solid, the solubility of vapors in it may be assumed to obey Henry's law, which permits the estimation of the soluhility of $\mathrm{HF}$ in $\mathrm{UF}_{6}(\mathrm{~s})$ at partial pressures of $\mathrm{HF}$ below the saturation value.

\section{QUANTTTIES OF UF 6 HYDROLYZED TO PRODUCE THE HF FOUND INSIDE CYLINDERS}

Table B2-8 gives the estimated quantities of HF in the vapor space and in the solid $\mathrm{UF}_{6}$ phase for both of the cylinders with holes and a normal product cylinder. If, as shown in Appendix $\mathrm{D}, \mathrm{UF}_{6}$ is converted to $\mathrm{FeF}_{3} * 3 \mathrm{H}_{2} \mathrm{O}, \mathrm{Fe}_{2} \mathrm{~F}_{5} * 7 \mathrm{H}_{2} \mathrm{O}, \mathrm{UF}_{4} * 2.5 \mathrm{H}_{2} \mathrm{O}, \mathrm{UF}_{4} * 1.5 \mathrm{H}_{2} \mathrm{O}$, and $\mathrm{UF}_{4} * 0.75 \mathrm{H}_{2} \mathrm{O}$, all the contained fluorine in the $\mathrm{UF}_{6}$ is utilized in the reaction so that none of the $\mathrm{UF}_{6}$, which is reduced to $\mathrm{UF}_{4}$, is involved in the production of the $\mathrm{HF}$ found in the ullage of the cylinders and in the solid $\mathrm{UF}_{6}$. The $\mathrm{HF}$ in the cylinder and any that escapes from the cylinder as liquid or vapor must be formed by reaction of additional $\mathrm{UF}_{6}$ to form $\left[\mathrm{H}_{3} \mathrm{O}\right]_{2}\left[\mathrm{U}(\mathrm{OH})_{4} \mathrm{~F}_{4}\right]$, as suggested by the phase diagram of Buslaev et al., ${ }^{7}$ and other hydrolysis products such as $\mathrm{UO}_{2} \mathrm{~F}_{2}$ and $\mathrm{U}_{2} \mathrm{O}_{3} \mathrm{~F}_{6}$. The latter, orange-colored product was observed as a thin layer between the yellow layer of hydrolyzed product and the $\mathrm{UF}_{6}(\mathrm{~s})$ in the experiments reported by Mallett ${ }^{24}$ and was observed on what had been such a surface during the inspection of the plugging material in the interior of cylinder $4 G 127985$ by Dorning. ${ }^{2}$ Since the ratio of F-atoms to U-atoms in the yellow layer is found to be 3.05 (ref. 8), the composition of the yellow layer will be taken as a 50:50 mole $\%$ mixture of $\left[\mathrm{H}_{3} \mathrm{O}\right]_{2}\left[\mathrm{U}(\mathrm{OH})_{4} \mathrm{~F}_{4}\right]$ and $\mathrm{UO}_{2} \mathrm{~F}_{2}$. The yield of $\mathrm{HF}$ is thus 3 moles per mole of additional $\mathrm{UF}_{6}$ hydrolyzed as illustrated below:

$$
\begin{aligned}
& U F_{6}(s)+6 \mathrm{H}_{2} \mathrm{O}(l)=\left[\mathrm{H}_{3} \mathrm{O}\right]_{2}\left[U(\mathrm{OH})_{4} F_{1}\right](s)+2 H F(l) \\
& U F_{6}(s)+2 \mathrm{H}_{2} \mathrm{O}(l)=U \mathrm{O}_{2} \mathrm{~F}_{2}(s)+4 \mathrm{HF}(l) \\
& \hline U F_{6}(s)+4 \mathrm{H}_{2} \mathrm{O}(\mathrm{l})=0.5\left[\mathrm{H}_{3} \mathrm{O}\right]_{2}\left[U(\mathrm{OH})_{4} F_{4}\right](s)+0.5 U \mathrm{O}_{2} F_{2}(s)+3 H F(l)
\end{aligned}
$$

The quantity of HF in the $8 \mathrm{lb}$ of vapor removed from cylinder $4 \mathrm{G} 115688$ was estimated using the calculated composition of the vapor space at a solid $\mathrm{UF}_{6}$ temperature of $55^{\circ} \mathrm{F}$ given in Table B2-6. The data at this particular temperature were employed because all phases were at the same temperature. On this basis, the $8 \mathrm{lb}$ of vapor removed were about $62 \%$ by weight HF.

As shown by the data in Table B2-8, the quantities of $\mathrm{UF}_{6}$ required to supply the HF in the solid $\mathrm{UF}_{6}$ and the ullage of the cylinders are significantly larger than the quantities of corrosion deposits recovered outside the cylinders. This means that a substantial amount of at least partially hydrolyzed $\mathrm{UF}_{6}$ is inside the cylinder surrounding the layer of $\mathrm{UF}_{4}$ hydrate inside the cylinder next to the hole. The chemical reactions involved in the scenario, which explains the origin of the products found both outside and inside the cylinders, are developed in Appendix B, Part 3, and are given below in Eqs. (B2-23)-(B2-27) for convenient reference. If it is assumed that most of the iron reacts as in Eq. (B2-25), the overall reaction is given by Eq. (B2-28). As written, the equations show the products developed outside the holes. The products inside involve the use of less water as the number of waters of hydration are reduced. The UFF hydrate deposits found 
Table B2-8. Estimates of the quantities of HF found in the ullage and solid UF 6 in cylindors 4G127985 and 4G115688 and normal cylinders and estimates of the quantities of $\mathrm{UF}_{6}$ required to produce them ${ }^{a}$

\begin{tabular}{|c|c|c|c|}
\hline Quantity & Cyl. 4G127985 & Cyl. 4G115688 & Normal cyl. \\
\hline Cyl. volume, $\mathrm{L}$ & 3940 & 3940 & 3940 \\
\hline $\mathrm{UF}_{6}$ mass, $\mathrm{kg}$ & 12701 & 12701 & 12701 \\
\hline Vol. UFF $(\mathrm{s}), \mathrm{L}$ & $2499^{b}$ & $2490^{C}$ & 2510 \\
\hline Ullage, L & 1441 & 1451 & 1430 \\
\hline Mass $\mathrm{HF}$ vapor, $\mathrm{g}$ & 303 & 3263 & 29 \\
\hline Mass HF liquid, $\mathbf{g}$ & 0 & 2264 & 0 \\
\hline $\begin{array}{l}\text { Sat. vapor comp, } \\
y(H F \text {, sat })\end{array}$ & 0.968 & 0.977 & - \\
\hline Solid comp, z(HF, sat) & $0.0027^{d}$ & $0.0023^{d}$ & - \\
\hline Mole frac. $\mathrm{HF}$ in $\mathrm{UF}_{6}(\mathrm{~s})$ & $0.00071^{e}$ & 0.0023 & $0.00014^{d}$ \\
\hline $\mathrm{HF}$ in $\mathrm{UF}_{6}(\mathrm{~s}), \mathrm{g}$ & 512 & 1660 & 102 \\
\hline Total HF in cyl., $g$ & 815 & 7186 & 131 \\
\hline $\begin{array}{l}\text { Wt } \mathrm{UF}_{6} \text { to produce } \mathrm{HF} \\
\text { in the cylinder, } \mathrm{kg}^{a}\end{array}$ & 4.8 & 42.2 & 0.8 \\
\hline $\begin{array}{l}\text { Mass corrosion deposit } \\
\text { outside cylinder, } \mathrm{kg}\end{array}$ & 0.45 & 6.8 & - \\
\hline $\begin{array}{l}\text { Est. } \mathrm{UF}_{6} \text { to produce } \\
\text { outside deposit, } \mathrm{kg}\end{array}$ & 0.32 & 4.9 & - \\
\hline
\end{tabular}

${ }^{a}$ Based on the production of a 50:50 molar mixture of $\left(\mathrm{H}_{3} \mathrm{O}\right)_{2}\left[\mathrm{U}(\mathrm{OH})_{4} \mathrm{~F}_{4}\right]$ and $\mathrm{UO}_{2} \mathrm{~F}_{2}$

$b_{\text {At }} 85^{\circ} \mathrm{F}$ ambient temperature; $70.8^{\circ} \mathrm{F}$ solid $\mathrm{UF}_{6}$ temperature, $106^{\circ} \mathrm{F}$ vapor.

${ }^{c}$ At $47^{\circ} \mathrm{F}$ ambient temperature; $55^{\circ} \mathrm{F}$ inside cylinder, all phases.

$d_{\text {Estimated from the work of Barber. }}{ }^{2}$

$e$ Value obtained by application of Henry's law.

inside the cylinder are $\mathrm{UF}_{4} * 1.5 \mathrm{H}_{2} \mathrm{O}$ and $\mathrm{UF}_{4} * 0.75 \mathrm{H}_{2} \mathrm{O}$. It is also likely that the water content of the hexavalent uranium oxyfluoride decreases as one goes deeper into the deposit, as evident from the orange color of the surface of the deposit originally in direct contact with the UF. The phase diagram of Buslaev et al. $^{7}$ also shows that, if the HF becomes too dilute, the $\left(\mathrm{H}_{3} \mathrm{O}\right)_{2}\left[\mathrm{U}(\mathrm{OH})_{4} \mathrm{~F}_{4}\right]$ becomes unstable with respect to $\mathrm{UO}_{2} \mathrm{~F}_{2} * 2 \mathrm{H}_{2} \mathrm{O}$ and releases additional $\mathrm{HF}$. 


$$
\begin{aligned}
& U F_{6}(s)+H_{2} O(l)=\left[H U F_{6}(O H)\right\rfloor(s)=\left[H O U F_{s}\right](s)+H F(a q), \\
& {\left[\mathrm{HOUF}_{s}\right](s)+5 \mathrm{H}_{2} \mathrm{O}(l)=\left[\mathrm{H}_{3} \mathrm{O}_{2} l U(\mathrm{OH})_{4} F_{4}\right](s)+\mathrm{HF}(\mathrm{aq}) \text {, }} \\
& 3\left[\mathrm{H}_{3} \mathrm{Ol}_{2} \mathrm{lU}(\mathrm{OH})_{4} \mathrm{~F}_{4} /(s)+6 \mathrm{HF}(\mathrm{aq})+2 \mathrm{Fe}(s)=3 U \mathrm{~F}_{1} * 2.5 \mathrm{H}_{2} \mathrm{O}(\mathrm{s})+2 \mathrm{FeF}_{3} * 3 \mathrm{H}_{2} \mathrm{O}(\mathrm{s})+4.5 \mathrm{H}_{2} \mathrm{O}(\mathrm{aq})\right. \text {, }
\end{aligned}
$$

or

$$
\left[\mathrm{H}_{3} \mathrm{O}\right]_{2}\left[U(\mathrm{OH})_{4} \mathrm{~F}_{4}\right](s)+2 \mathrm{HF}(a q)+\mathrm{Fe}(s)+0.5 \mathrm{H}_{2} \mathrm{O}(l)=U F_{1} * 2.5 \mathrm{H}_{2} \mathrm{O}(s)+F e F_{2} * 4 \mathrm{H}_{2} \mathrm{O}(s)
$$

Adding Eq. (B2-25) and two times Eq. (B2-26) gives:

$5 / \mathrm{H}_{3} \mathrm{O} \mathrm{J}_{2} \mathrm{l}\left(\mathrm{O}(\mathrm{OH}) \mathrm{F}_{4}(\mathrm{~s})+10 \mathrm{HF}(\mathrm{aq})+4 \mathrm{Fe}(s)=2 \mathrm{Fe}_{2} \mathrm{~F}_{3} * 7 \mathrm{H}_{2} \mathrm{O}(\mathrm{s})+5 U \mathrm{~F}_{4} * 2.5 \mathrm{H}_{2} \mathrm{O}(s)+3.5 \mathrm{H}_{2} \mathrm{O}(\mathrm{l})\right.$.

Similarly, adding three times Eqs. (B2-23) and (B2-24) to Eq. (B2-25) gives the principal reaction:

$$
3 U F_{6}(s)+13.5 \mathrm{H}_{2} \mathrm{O}(l)+2 \mathrm{Fe}(s)=2 \mathrm{FeF}_{3} * 3 \mathrm{H}_{2} \mathrm{O}(s)+3 U \mathrm{~F}_{4} * 2.5 \mathrm{H}_{2} \mathrm{O}(s) .
$$

Because the stoichiometry developed from the chemistry in Appendix B, Part 3, and shown above requires the use of all six fluorides in $U_{F}$ in the redox reaction with $F e$ to form $U F_{4}$ and iron fluorides, the accumulation of HF within the cylinder indicates that some of the uranium in the overall corrosion deposit must be in the hexavalent state. It is likely that most of this $U^{+6}$ hydrolysis product should be inside the cylinder. Evidence of this has been obtained from recent examination of the reaction products in the large hole in cylinder $4 \mathrm{G} 115688$ from which a sufficient amount of the soft and weak $\mathrm{UF}_{4} * \mathrm{xH}_{2} \mathrm{O}(\mathrm{s})$ deposit sloughed off to reveal a deep layer of fluorescent yellow, hexavalent uranium oxyfluorides. The detection of uranium in a soil grab sample, taken where the rainwater drains from the edge of the concrete pad on which the cylinder sits, is further evidence of the presence of a leachable, hexavalent uranium salt in the reaction products in the hole in cylinder $4 \mathrm{G} 115688$. It should be noted that, while $U \mathrm{~F}_{4} * 2.5 \mathrm{H}_{2} \mathrm{O}$ is the hydrate obtained in the redox reaction outside the cylinder, the two lower hydrates of $\mathrm{UF}_{4}$ are what are obtained inside the cylinder where the water concentration is lower.

\section{QUANTTTY OF UF, REDUCED TO UF, HYDRATE BY IRON}

A crude estimate of the mass of iron reacted in each of the cylinders can be made from the dimensions of the holes and estimates of the quantities reacted from the lugs adjacent to the holes. Such an cstimate for cylinder $4 \mathrm{G} 127985$ gives about $160 \mathrm{~g}$ Fe reacted. This would yield about $2.0 \mathrm{~kg}$ of reaction product based on reaction (B2-28) and suggests that some of the UF reduction product is inside the cylinder. This is true based on the color of the surface of the material plugging the hole in cylinder 4G127985 at the time the adjacent cylinder was removed. It is also true for cylinder $4 \mathrm{G} 115688$ from which a part of this $\mathrm{UF}_{4}$ deposit has only recently fallen off. Indeed, attempted core sampling suggests this material may extend about 4 in. into the cylinder, while the hexavalent material between it and the $\mathrm{UF}_{6}$ extends more than an additional 8 in. into the cylinder. ${ }^{6}$ 
The mass of iron reacted from cylinder $4 G 115688$ is estimated to be about $3.6 \mathrm{~kg}$ from the size of the hole and the dimensions of the thinned area. The mass of the $\mathrm{UF}_{6}$ reduced is estimated to be $34 \mathrm{~kg}$ assuming the reduction produces mostly $\mathrm{FeF}_{3}$ according to $\mathrm{Eq}$. (B2-28). Since $U F_{4}$ deposits are essentially insoluble and only $15 \mathrm{lb}(6.8 \mathrm{~kg})$ of corrosion product were recovered in June 1990 , much of the $U_{4}$ that had been produced was still attached to the reaction deposit at that time. As noted before, in October 1990, enough of this soft, weak material sloughed off at the center of the hole to reveal the deen, underlying layer of fluorescent yellow, hexavalent uranium oxyfluorides. The plug formed in the cylinder by the UF, and these materials (which are solvates) is an effective barrier against the escape of $\mathrm{UF}_{6}$ per se from the cylinder. A slow loss of HF from the hole, as a vapor, occurs during the summer, as is indicated by its detection in environmental samples taken over the cylinder by industrial hygiene personnel at PORTS and as noted by Investigating Committee personnel during an inspection in August 1990. No vapor-borne uranium was detected at any time.

\section{TOTAL QUANTITY OF UF, HYDROLYZED AND REDUCED AND THE ESCAPING HF}

On the basis of core sampling, the reduced $\mathrm{UF}_{4}$ hydrate material extended 4 in. into cylinder 4G115688, and the hydrolyzed material behind it extended to more than 12 in. into the cylinder. ${ }^{6}$ Based on observations of the shape of the plugging deposit in cylinder $4 \mathrm{G} 127985$ (ref. 12), the roughly hemispheroidal shape of the deposit requires that the total volume of the deposit be more than 27 times the volume of the $\mathrm{UF}_{4}$ hydrate. Since the densities of $\mathrm{UF}_{6}, \mathrm{UF}_{4}$ hydrate, and the hydrolysis product are similar, the mass of the $\mathrm{UF}_{6}$ to produce the total deposit is similarly related to the mass ${ } \mathrm{C}_{\mathrm{S}} \mathrm{F}_{6}$ reduced to form the $\mathrm{UF}_{4}$ hydrate. Thus, $916 \mathrm{~kg}$ of $\mathrm{UF}_{6}$ have been hydrolyzed; $34 \mathrm{~kg}$ of this is reduced to $\mathrm{UF}_{4}$, and the HF produced by $42 \mathrm{~kg}$ of it is retained in the cylinder. The HF produced by an additional $840 \mathrm{~kg} \mathrm{UF}_{6}$, or about $143 \mathrm{~kg}$ of $\mathrm{HF}$, is estimated to have escaped from the cylinder as solution or vapor over the 13-year storage period.

The $916 \mathrm{~kg}$ of $\mathrm{UF}_{6}$ will occupy $181 \mathrm{~L}\left(6.39 \mathrm{ft}^{3}\right)$ at $77^{\circ} \mathrm{F}$. If, as a crude approximation, one assumes that this volume occupies a hemisphere, the radius of the sphere would be $17.4 \mathrm{in}$. Since there is a small volume expansion in producing both $\mathrm{UF}_{4}$ hydrate and $\mathrm{UO}_{2} \mathrm{~F}_{2}$ hydrates from $\mathrm{UF}_{6}$, this quantity of hydrolyzed $\mathrm{UF}_{6}$ does indicate that the hydrolyzed material could extend more than 12 in. into the cylinder.

\section{ESTIMATION OF RATE OF ESCAPE OF HF FROM CYLINDERS}

If it is assumed that the rate of escape of $\mathrm{HF}$ is proportional to the open area of the hole in the cylinders and that the rate of increase of the radius of the hole is linear with time, the rate of escape of HF from the cylinder can be estimated at any time from the estimate of the total amount of HF that has escaped and the effective hole radius. For the cylinder 4G115688, the open area of the hole is estimated to be $472 \mathrm{~cm}^{2}$. The effective radius then is $12.3 \mathrm{~cm}$ and the rate of radius enlargement is $1.08 \times 10^{-4} \mathrm{~cm} / \mathrm{hr}$. Thus, the radius at any time, $t$, is $1.08 \times 10^{-4} \mathrm{t}$ and the effective area, $A$, at time, $t$, is

$$
A=\pi\left(1.08 \times 10^{-4} t\right)^{2}
$$

If the loss rate, $k$, is proportional to area, then the total loss, $Q$, is given by 


$$
Q=\int_{0}^{1} \pi\left(1.08 \times 10^{-4} t\right)^{2} k d t=(\pi / 3)\left(1.08 \times 10^{-4}\right)^{2} t^{3} k .
$$

Since $Q$ may be as much as $143,000 \mathrm{~g} \mathrm{HF}$ over 13 ycars or $114,000 \mathrm{~h}$, the corresponding value of $k$ is $7.91 \times 10^{-3} \mathrm{~g} /\left(\mathrm{cm}^{2}-\mathrm{h}\right)$. Using this value, the rate of loss of $\mathrm{HF}$ from the hole after 13 years is $3.73 \mathrm{~g} / \mathrm{h}$ of $\mathrm{HF}$. However, part of this HF is consumed in the reaction with iron and some is lost as solution, so that the loss rate as vapor is less. The loss rate of HF from the large hole at the end of an additional year is predicted to be $4.37 \mathrm{~g} / \mathrm{h}$ of HF. The HF lost during the 14 th year would amount to about $35.6 \mathrm{~kg} \mathrm{HF}$, which corresponds to the hydrolysis of an additional $209 \mathrm{~kg}$ of $\mathrm{UF}_{6}$. To hydrolyze all the $\mathrm{UF}_{6}$ in the cylinder at the $k$ value above, using the loss of 3 moles of HF per $U_{6}$ hydrolyzed, would take about 30 years and the hole would be about 12 in. in radius for an effective diameter of $24 \mathrm{in.}$ The indicated increase in the effective diameter of the hole is 0.75 in. per year.

For cylinder $4 \mathrm{G} 127985$ with a 4-year-old hole, these relations predict a hole of about $3.0 \mathrm{in}$. in diameter with a loss rate of $0.356 \mathrm{~g} / \mathrm{h}$ of $\mathrm{HF}$. The actual hole is about $33 \%$ smaller in diameter than this estimate and would suggest an HF loss rate of $0.16 \mathrm{~g} / \mathrm{h}$. This also suggests that the time required to penetrate the wall thickness and begin to enlarge the hole at an essentially constant rate is on the order of 1 year. The actual loss rate of HF might be still lower because the combination of the adjacent lug and the stiffening ring locations and the corrosion products forces a longer diffusion path as noted in Appendix B, Part 3. The actual loss rate for HF as vapor is also lower than this estimate for the same reasons as given for the large hole. Using the value for $k$ developed above for the large hole, the estimated quantity of HF lost from the cylinder over the period needed ( 2.7 years) to produce a 2 -in.-diam hole is $1.26 \mathrm{~kg} \mathrm{HF}$, which would require on the order of $7.4 \mathrm{~kg}$ of $\mathrm{UF}_{6}$ to produce. Adding the estimated quantity of $\mathrm{UF}_{6}$ to produce the $\mathrm{HF}$ in the cylinder (Table B2-8) and the quantity of $\mathrm{UF}_{6}$ to produce the HF lost from the cylinder to the quantity $\left(1.5 \mathrm{~kg}\right.$ ) reduced by iron, one obtains a total of $13.7 \mathrm{~kg} \mathrm{(30} \mathrm{lb)} \mathrm{of} \mathrm{UF}_{6}$ that may have been reacted. This quantity is $51 \mathrm{lb}$ less than the $81 \mathrm{lb}$ of residue left in the cylinder after the $\mathrm{UF}_{6}$ removal. The $13.7 \mathrm{~kg}$ of $\mathrm{UF}_{6}$ would occupy a hemispheric volume of 4.3 -in. radius, which is somewhat larger than the estimate of the plug size made by Dorning ${ }^{12}$ from the video inspection and radiography of the plug. This is in agreement with the expectation noted above that the losses of HF from the system are lower than predicted. The results of estimates made using this very simple model are shown in Table B2-9. The estimates suggest that more HF would be released during a 5 th year of exposure than during the previous 4 years, but this quantity is unimportant with respect to potential HF release during a 14 th year of exposure. Still, nearly all of the $\mathrm{UF}_{6}$ hydrolyzed is retained within the cylinder or is reduced and retained either within the cylinder or outside (on it and the cylinder below). In Appendix B, Part 1, it is shown, using the weight changes and this model, that within the estimated errors no loss of uranium-bearing material occurred from the vicinity of the cylinder with the small hole during its 4-year life, while between 11.5 and $73.7 \mathrm{~kg}$ of uranium were lost from the vicinity of the cylinder with the large hole, mostly after the first 5 years.

\section{CORROSION OF CYLINDER BELOW THE HOLE IN CYLINDER 4G115688}

The Buslaev et al. ${ }^{7}$ phase diagram (Appendix B, Part 3) indicates that the hydrolysis of solid $\mathrm{UF}_{6}$ with limited amounts of water produces a complex, sol:d oxyfluorouranic acid and HF solution in which the complex acid has but limited solubility. As the water content of the HF solution is increased, the solubility of the complex acid increases. When the dilution with water reduces the HF concentration below a certain value, the decomposition of the complex acid to 
Table B2-9. Estimated quantities of $\mathrm{UF}_{6}$ hydrolyzed and $\mathrm{HF}$ released, hole growth rates, and other model parameters

\begin{tabular}{|c|c|c|}
\hline Quantity estimated & Cyl. 4G127985 & Cyl. 4G115688 \\
\hline Mass of irou cxidized (fluorinated), $\mathrm{kg}$ & 0.16 & 3.6 \\
\hline Mass of $\mathrm{UF}_{6}$ reduced, $\mathrm{kg}$ & 1.5 & 34.0 \\
\hline Mass of $\mathrm{UF}_{6}$ to produce recovered deposits, $\mathrm{kg}$ & 0.32 & 4.9 \\
\hline Mass of $\mathrm{UF}_{6}$ hydrolyzed and reduced in cyl., $\mathrm{kg}$ & 1.2 & 29.1 \\
\hline Total mass of $\mathrm{UF}_{6}$ hydrolyzed, $\mathrm{kg}$ & 13.7 & 916. \\
\hline Mass of $\mathrm{UF}_{6}$ producing $\mathrm{HF}$ retained in cyl., $\mathrm{kg}$ & 4.8 & 42. \\
\hline Mass of $\mathrm{UF}_{6}$ producing escaping $\mathrm{HF}, \mathrm{kg}$ & 7.4 & 840. \\
\hline Total mass of $\mathrm{HF}$ that escaped hole, $\mathrm{kg}$ & 1.26 & 143. \\
\hline Predicted HF escaping in 5th and 14th years, resp., kg & 1.99 & 35.6 \\
\hline Predicted mass of $\mathrm{UF}_{6}$ hydrolyzed next year, $\mathrm{kg}$ & 11.7 & 209. \\
\hline Est. rate of HF esiape at discovery, $g / h$ & 0.16 & 3.73 \\
\hline Steady-state rate of esisape of $\mathrm{HF}, \mathrm{g} / \mathrm{sq} \mathrm{cm} / \mathrm{h}$ & $7.91 \times 10^{-3}$ & $7.91 \times 10^{-3}$ \\
\hline Rate of hole radium enlargement, $\mathrm{cm} / \mathrm{h}$ & $1.08 \times 10^{-4}$ & $1.08 \times 10^{-4}$ \\
\hline Est. time to steady-state rate, year & 1 & \\
\hline Est. time to hydrolyze all $\mathrm{UF}_{6}$ in cyl., year & & 32 \\
\hline Est. diameter of hole for above, in. & & 24 \\
\hline
\end{tabular}

$\mathrm{UO}_{2} \mathrm{~F}_{2} * 2 \mathrm{H}_{2} \mathrm{O}$ and more $\mathrm{HF}$ begins. There is some analytical evidence that this is occurring at the $\mathrm{UF}_{4}$ hydrate-uranium oxylfingride salt or acid interface. The result is that a strongly acidic hydrofluoric acid solution containing limited amounts of a hexavalent uranium oxyfluoride salt is oozing from the UF 4 hydrate deposits to the outside of the cylinder, running down from the hole onto the stiffening ring, and thence onto the cylinder below. The acid attacks the steel, which reduces the hexavalent uranium oxyfluoride ion to the insoluble $\mathrm{UF}_{4}$ hydrate, thus coating the solution path with this salt and hydrated iron fluorides. Because the acid solution tends to collect into rivulets and the rivulets into streams, the path where the most acid flows is attacked most severely. The tendency of the rivulets to run together is favored by flow where the surface of the steel approaches the vertical position and continues on below. Over the 13 years this process has been operating, deep grooves have been etched for long distances in the surface of the cylinder below the cylinder with the large hole. Even in the case of the small hole, the presence of the oozing solution is indicated by the shape of the hole in the cylinder itself. 


\section{SUMMARY}

Hydrogen fluoride tends to accumulate in the vapor space of the cylinders. So much had accumulated in the cylinder with the 13-year-old hole that explanation of the cold pressure and composition data is best accomplished by the assumption of the presence of an HF solution in the cylinder at the time of its discovery. The removal of $8 \mathrm{lb}$ of vapor removed this liquid layer. The pressure data are significant in that they prove that there was no connection between the atmosphere external to the cylinders and the vapor space in these cylinders. Further, once the liquid phase appears in the cylinder, the addition of more HF will simply increase the amount of liquid, and there will be no further increase in the pressure of the cylinder. The total pressure of the vapor space is limited to the sum of the pressures of the inert gases originally present and vapor pressure of the solution at the temperature of the solid $\mathrm{UF}_{6}$ in the cylinder.

Hydrogen fluoride is escaping from the large hole at a measurable rate estimated to have been about $3.7 \mathrm{~g} / \mathrm{h}$ at the time of discovery. If the escape rate from the small hole is the same per unit area as from the large hole, the loss of HF from the small hole was about $0.16 \mathrm{~g} / \mathrm{h}$. The hydrolysis rate for $\mathrm{UF}_{6}$ in the cylinder with the large hole greatly exceeds the rate of reduction to $\mathrm{UF}_{4}$. The hydrolysis rate and the reduction rate are somewhat more similar in the cylinder with the small hole, probably because the hole was not directly open to the atmosphere. The rate of enlargement of the hole diameter caused by the reduction of $U^{+6}$ to $U^{+4}$ by iron is similar for the two cylinders. There is a period of about a year before a steady-state rate of hole enlargement is reached.

The loss of HF solution from the cylinder with the large hole, in agreement with the phase diagram of Buslaev et al., ${ }^{7}$ is evident from the sh spe of the hole, from the pattern of the deposits on the cylinder below the one with this hole, and in the deep groove etched in the surface of this cylinder. This is also evident from the shape of the small hole and the etch pattern on the lifting lug of the adjacent cylinder. 
APPENDIX B, PART 3 (B3)

CHEMICAL ASPECTS OF CYLINDER CORROSION AND A SCENARIO FOR HOLE FORMATION 


\section{CORROSION OF UNBREACHED CYLINDERS}

\section{Internal Corrosion}

The reaction that occurs within cylinders is normally a general corrosion involving the reaction summarized by Eq. (B3-1).

$$
2 U F_{\sigma}(g)+F e(s)=F c F_{\gamma}(s)+U_{j} F_{g}(s) .
$$

The $\mathrm{FeF}_{3}$ and the $\mathrm{U}_{2} \mathrm{~F}_{9}$ form a mixed film thin has a volume 18 times the volume of iron oxidized. While this film is not very protective to the underlying steel, the overall attack rate of the cylinder steels by $\mathrm{UF}_{6}$ at cylinder storage temperatures is negligibly small. Equations that may be used to quantitatively relate the reaction of $\mathrm{UF}_{6}$ with this class of steels as functions of time and temperature are given below:

$$
d\left[U F_{6}\right] / d t=\exp (34.6476-12380 / T), m g U /(s q \text { ft-day }),
$$

where $t$ is the time in days and $T$ is the temperature in Kelvin. At any given $T, d\left[U F_{6} / d t\right.$ is essentially independent of $t$.

At a steady temperate of $140^{\circ} \mathrm{F}(333.15 \mathrm{~K})$, a $5 / 16$-in.-thick steel plate with a roughness factor of 2.5 would be predicted to be corroded through in about one million years. Since the temperature would be that high for only a fraction of the total time, normal internal corrosion by $\mathrm{UF}_{6}$ could not have been the cause of the condition being investigated.

\section{Effect of $\mathrm{HF}$ in the $\mathrm{UF}_{6}$}

Any increase in the corrosion due to the presence of $\mathrm{HF}$ in the $\mathrm{UF}_{6}$ should be insignificant for two reasons. Firstly, cylinders collecting the low-assay stream from the gaseous diffusion cascades should be relatively free of $\mathrm{HF}$, since this gas goes rapidly to the top of the diffusion cascades and should only be present in this low-assay $\mathrm{UF}_{6}$ to the extent that traces of residual water remain in the receiving cylinder. Secondly, even if present in modest amounts, anhydrous $\mathrm{HF}$ does not pose a serious corrosion threat to the cylinder, since mild steel cylinders are used commercially for shipping and handling this gas. It is aqueous HF that is capable of corroding iron. The $\mathrm{UF}_{6}$ is an excellent desiccant converting water to uranium oxyfluorides and HF.

\section{Effect of Stress in the Metal on Internal and External Corrosion}

The corrosion of most metals by $\mathrm{UF}_{6}$ is known to be accelerated by the introduction of stress into the metal. Thus, the denting of cylinder walls may result in somewhat higher rates of corrosion due to $\mathrm{UF}_{6}$, but no failures, to date, have been attributed to enhanced internal corrosion at such sites. One should also note that external corrosion is also enhanced by stress. Such an attack from the outside is electrochemical in nature, and the attack can be quite site specific, whereas the internal attack due to $\mathrm{UF}_{6}$ is not electrochemical in nature and is, in general, not site specific. To be certain that electrochemical corrosion does not occur from the outside, the cylinder would require storage under conditions which ensure that the relative humidity remains below $60 \%$ if the surface is free of rust and below $40 \%$ if the surface is already rusty. 


\section{External Corrosion}

External corrosion of the cylinder is much more significant than internal corrosion but is unlikely to have caused the initial cylinder wall penetration in the subject cylinders. The results of technical studies ${ }^{16}$ have indicated that general corrosion of cylinders in long-term storage initially proceeds at a rate of 1 to 2 mils per year (mpy) but soon slows to a rate of 1 mpy or less. At this rate it would take about 300 years to penetrate the cylinder wall. A higher atmospheric corrosion rate $\left(2.6 \mathrm{mpy}\right.$ ) was estimated ${ }^{3}$ for piping in a hypothetical abandoned plant in a nonindustrial environment. Even at this rate, cylinder wall penetration would require 120 years. It follows that general atmospheric corrosion could not have been the root cause of the cylinder wall failures. Localized rusting (e.g., crevice and pitting corrosion) can penetrate faster than normal rusting, but the most severe cases ${ }^{17}$ have only produced wall thinning to slightly under the onequarter-inch minimum required for heated cylinders. Thus, external corrosion can easily be ruled out as the root cause of these cylinder failures.

\section{CHEMICAL CORROSION AT BREACH IN CYLINDER WALL}

Because of the poor impact resistance in the trans rolling direction of the thin-wall cylinder steels, fractures have been encountered due to accidental impact of the lifting lugs of an adjacent cylinder near welds and stiffening rings during handling. ${ }^{4}$ These failures were mechanical, not chemical, in origin. However, fractures of this type, if undetected, can result in the initiation of the chemical reactions which, over time, will produce holes such as those found in the two tails cylinders at PORTS. While external electrochemical crevice corrosion at a crack that only partially penetrates the wall is capable of completing the penetration, it is not believed that this was necessary in the two cases under investigation; i.e., the cracks from the impacts completely penetrated the wall at the time of stacking.

\section{Postulated Corrosion Mechanism}

The position of the crack relative to the position of the solid cake of $\mathrm{UF}_{6}$ in the cylinder is believed to be important to the course of the reaction. In the cases under investigation, the impacts were both in places where solid $\mathrm{UF}_{6}$ remained continuously in contact with the wall and would prevent any air flow through the crack to the vapor space of the cylinder. The proof for this is that one cylinder maintained a partial vacuum in the vapor space, whereas the other, even with an 8- by 16-in. hole, maintained a pressure as high as 11 psig in the vapor space of the cylinder. The data on the composition of the vapor in the two cylinders show that the pressure difference is entirely due to differing amounts of HF (see Appendix B, Part 2).

The course of the reactions that occur between $\mathrm{H}_{2} \mathrm{O}$ and $\mathrm{UF}_{6}$ is very dependent upon the state of the reactants. It is therefore necessary to note whether one is reacting (1) $\mathrm{H}_{2} \mathrm{O}$ vapor with $\mathrm{UF}_{6}$ vapor, (2) $\mathrm{H}_{2} \mathrm{O}$ vapor with $\mathrm{UF}_{6}$ solid, (3) $\mathrm{H}_{2} \mathrm{O}$ liquid with $\mathrm{UF}_{6}$ solid, or (4) $\mathrm{H}_{2} \mathrm{O}$ liquid with $\mathrm{UF}_{6}$ vapor an 1 whether or not these reactions are occurring in the presence of reducing agents under condi ions which permit reduction to take place. In the case of a crack in a cylinder sitting on a pad in ar open field, all of these possibilities will be present at some time, and it becomes necessary to choose the one or ones most important to the overall process.

Observations and analyses on the reaction products, on and in the cylinder, led to the conclusion that th important long-range reactions of greatest significance are produced by 
possibility (3), both in the presence and absence of a reducing agent. Data that may be related to these conditions were obtained by A. J. Mallett. ${ }^{24}$ In the most pertinent, but unplanned, examination of possibility (1), there was long-term flow of a dilute stream of $\mathrm{UF}_{6}$ in dry air, through small holes, into ambient air inside an unheated building. This resulted in the growth of hollow stalactites or tubules of uranyl fluoride hydrates that were several feet in length. The presence of rain and possibly dew, on an intermittent basis, would have altered this outcome by dissolving the uranyl fluoride and providing the solution needed for the reduction of the $\mathrm{UO}^{+2}$ ion to $\mathrm{UF}_{4}$ by iron in a redox reaction. In this case, the actual outcome would not differ much from that occurring with possibility (3). When the effects of the hydrogen bonding between $\mathrm{H}_{2} \mathrm{O}$ vapor and the product $\mathrm{HF}$ to produce a liquid condensate are considered, it is evident that the end consequences of possibility (2) primarily would be different from those of possibility (3) in quantity, rather than in kind.

Possibility (4), which leads to acidic (HF) uranyl fluoride solution formation, would not be pertinent long because the presence of the iron cylinder wall would lead to the production of $U_{4}$. D. M. Manuta has discussed, in terms of standard electrode potentials, the electrochemistry involved in the reduction of $\mathrm{U}^{+6}$ to $\mathrm{U}^{+4}$ by iron. ${ }^{26}$ The conducting hydrofluoric acid film serves as a salt bridge between the iron electrode and the solid hydrolysis product suggested by the phase work of Buslaev et al. ${ }^{7}$ to be $\left[\mathrm{H}_{3} \mathrm{O}\right]_{2}\left[\mathrm{U}(\mathrm{OH})_{4} \mathrm{~F}_{4}\right]$, which may serve as the second electrode. The conversion of the $\mathrm{U}^{+6}$ to $\mathrm{UF}_{4}$ inside the cylinder is believed to occur primarily at the surface of this electrode.

The phase diagram of Buslaev et al., ${ }^{7}$ given in Fig. B3.1, also shows that an HF-rich liquid phase saturated with a small amount of $\left[\mathrm{H}_{3} \mathrm{O}\right]_{2}\left[\mathrm{U}(\mathrm{OH})_{4} \mathrm{~F}_{4}\right]$ exists in equilibrium with the latter solid. This solution would be slowly squeezed out of the solid to react with the outside surfaces of the cylinder or cylinders with which it comes into contact. This is seen in the attack between the stiffening ring of cylinder 4G127985 and the adjacent lifting lug of cylinder 4G127902 resting against cylinder 4 G127985 at the bottom of the small hole (see Fig. B1.5). It is also to be seen from the shapes of both holes and the extensive etching of grooves into the wall of the cylinder directly below the large hole in cylinder 4G115688 [see Figs. B1.6 (Appendix B1) and 6 (main text)].

Because the vapor pressure of solid $\mathrm{UF}_{6}$, at a given temperature, is several times the vapor pressure of water in the air, the hydrolysis of $\mathrm{UF}_{6}$ initially will tend to occur near the external exit of the crack. When the crack is small, the air will be hard to displace from the crack, so that hydrolysis of $\mathrm{UF}_{6}$ will occur continuously at the crack exit, forming HF that condenses with water vapor to give an aqueous hydrofluoric acid surface film in contact with both the steel and a solvated uranyl fluoride salt. "This conductive, hydrofluoric acid surface film permits the cylinder oxidation of the iron at the crack edge on the outside to form a dense, iron fluoride hydrate and

\footnotetext{
"The term "solvated $\mathrm{UO}_{2} \mathrm{~F}_{2}$ " or " $\mathrm{UO}_{2} \mathrm{~F}_{2}$ solvate" indicates a chemical composition that can be described by the general formula, $\mathrm{UO}_{2} \mathrm{~F}_{2} * \mathrm{xH}_{2} \mathrm{O} * \mathrm{yHF}$. The water and $\mathrm{HF}$ are chemically bound but not necessarily, as such, to the uranium. If only water is bound, the material is more precisely described as "hydrated $\mathrm{UO}_{2} \mathrm{~F}_{2}$ " or " $\mathrm{UO}_{2} \mathrm{~F}_{2}$ hydrate," which specifies that the bound solvent is water. Examples of "solvated $\mathrm{UO}_{2} \mathrm{~F}_{2}$ " are $\mathrm{U}(\mathrm{OH})_{4} \mathrm{~F}_{2}$ or $\mathrm{UO}_{2} \mathrm{~F}_{2} * 2 \mathrm{H}_{2} \mathrm{O}, \mathrm{H}\left[\mathrm{U}(\mathrm{OH})_{4} \mathrm{~F}_{3}\right]$ or $\mathrm{UO}_{2} \mathrm{~F}_{2} * 2 \mathrm{H}_{2} \mathrm{O} * \mathrm{HF}$, and $\left[\mathrm{H} 3 \mathrm{O}_{2}\left[\mathrm{U}(\mathrm{OH})_{4} \mathrm{~F}_{4}\right]\right.$ or $\mathrm{UO}_{2} \mathrm{~F}_{2} * 4 \mathrm{H}_{2} \mathrm{O} * 2 \mathrm{HF}$.
} 

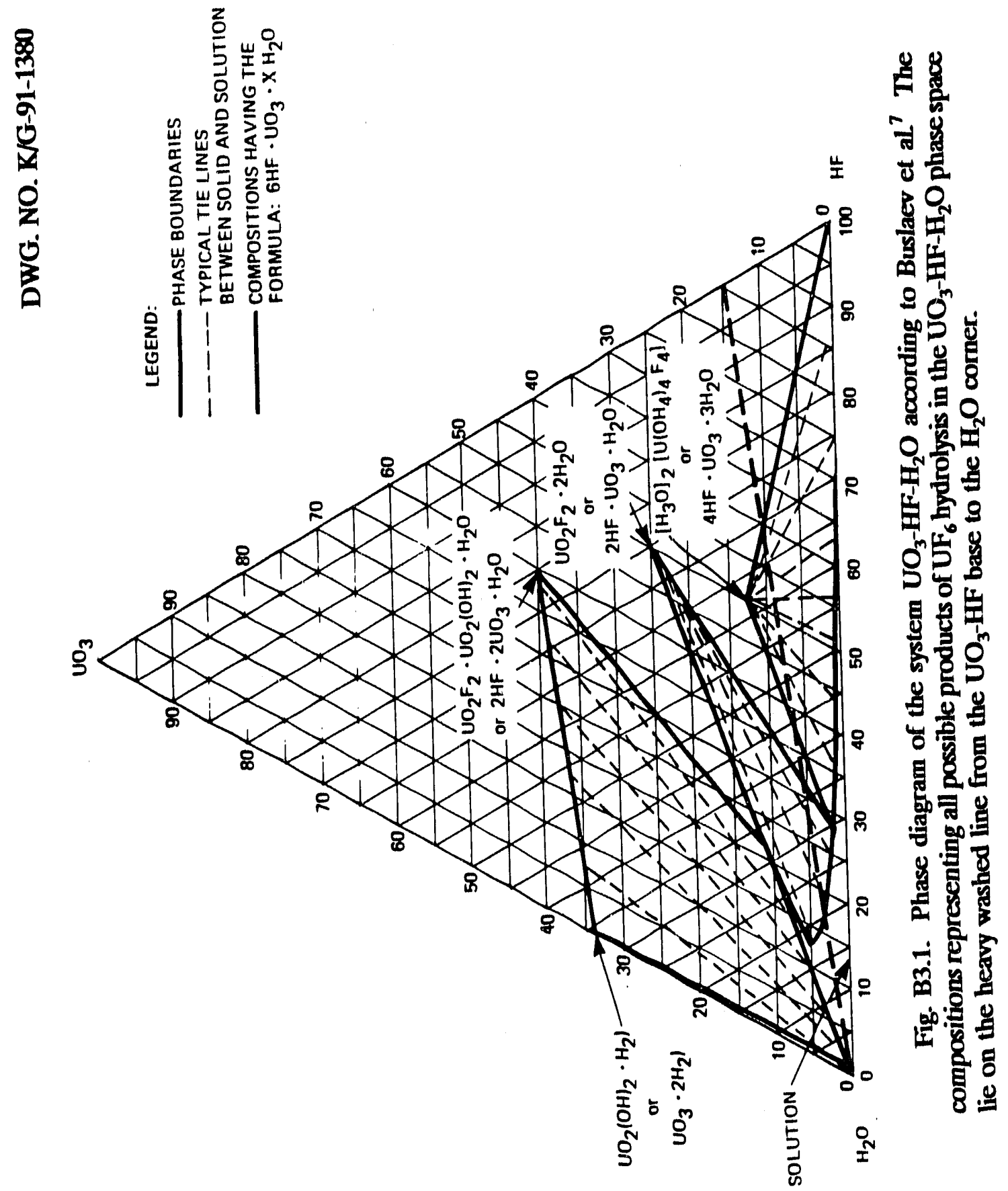
the reduction of uranyl ion to precipitate a loose UF, hydrate in the void of the crack. By this mechanism, the crack is slowly enlarged from the outside. In fact, the bevel of the edges of the 2 -in. hole in cylinder $4 \mathrm{G} 127985$ clearly indicated that the enlargement of the hole was continuing to occur from the outside even after 4 years of activity. The soft, porous, green $\mathrm{UF}_{4}$ hydrate was clearly seen in the hole in cylinder $4 G 127985$ when cylinder $4 G 127902$ was pulled away from cylinder 4G127985.

The data obtained on the thickness of the steel wall in the vicinity of the hole in cylinder 4G115688 indicate that the wall of this cylinder was being attacked from the inside and that, as a result, the wall surrounding the hole had been thinned for about 5 in. beyond the apparent edge of the hole. Color photographs of the hole, taken at the time of discovery (see Fig. 3, main text), show that essentially all the surface of the hole deposit was covered by a layer of the insoluble, green $\mathrm{UF}_{4}$ hydrates. Recently, a significant portion of this $\mathrm{UF}_{4}$ hydrate layer has sloughed off the center of the hole revealing a deep layer of a fluorescent yellow compound believed to be a $\mathrm{UO}_{2} \mathrm{~F}_{2}$ solvate. ${ }^{44}$ The existence of this material was predictable from the dependence of the "cold pressure" data of cylinder 4G115688 on temperature, as discussed in Appendix $\mathrm{C}$, and might also have been expected from the work of Mallett. ${ }^{24}$

As the corrosion slowly continues, a layered cake of corrosion products, which are not very water soluble, tends to build up on the outside of the cylinder. However, this material (particularly the UF, hydrate which tends to be in the middle of the hole) is porous, and the same reactions within the cylinder can continue to enlarge the crack. The deposit pattern of the hydrates of ferrous and ferric fluorides and $\mathrm{UF}_{4}$ below the hole between the stiffening ring of cylinder 4G127985 and the impacting lug of the adjacent cylinder 4G127985 would result from the expected flow pattern for a solution containing some hexavalent uranium slowly oozing from the hole. Since the surface of iron available for the redox reaction is large relative to the oozing flow, only the barest trace of corrosion product has fallen to the pad. The flow pattern for rainwater from the cylinder is not marked on the concrete pad by deposits of iron compounds as was the case for cylinder $4 \mathrm{G} 115688$. The $454 \mathrm{~g}$ of corrosion product was well retained by the lug of cylinder $4 \mathrm{G} 127902$ and the stiffening ring on cylinder $4 \mathrm{G} 127985$. Just when a significant amount of corrosion product would have begun to spall off this cylinder is a matter for speculation.

As noted earlier in Appendix B, Parts 1 and 2, the cylinder with the large hole (4G115688) already has had significant amounts of these insoluble salts spall off and, as noted, just recently an additional quantity of the $U_{4}$ salt sloughed off the deposit at the center of the hole revealing the underlying deep deposit of a uranyl fluoride solvate. The reaction products inside the cylinder are thus layered with the $\mathrm{UF}_{4}$ hydrates on the outside and the hexavalent hydrolysis products on the inside next to the $\mathrm{UF}_{6}$. The iron fluoride hydrates are formed next to the steel surface. Since the $\mathrm{UF}_{4}$ hydrate layer appears to be somewhat porous and uranyl salts are more soluble than $\mathrm{UF}_{4}$ salts, slow leaching at the $\mathrm{UF}_{4}$ hydrate $-\mathrm{UO}_{2} \mathrm{~F}_{2}$ solvate interface is possible and may result in the sloughing of the $\mathrm{UF}_{4}$ hydrate layer as observed.

There is no reason to expect the corrosion to stop under the present circumstances. The uranium salts making up the outermost surface of the corrosion deposit are all hydrated, soft, somewhat porous, and insoluble. The high relative humidity, the almost nightly dew, and the rains would ensure the presence of plenty of moisture to maintain the state of hydration of the reaction products and to cause the hydrolysis and reduction of the $\mathrm{UF}_{6}$ to continue, although the latter 
may become increasingly more difficult as the distance from the center of the hole to the edge increases. The actual nature of the attack on the iron to enlarge the hole should remain unchanged regardless of hole size, since the reduction of the hexavalent uranium and the oxidation of the iron are believed to result from transfer processes in acidic solution that do not require immediate contact.

Five features of the chemical attack of the cylinder are significant. First, the overall reaction is very slow, but the accumulation of reaction products does not prevent the reaction continuing. Second, the hydrolysis occurring close to the surface of solid UFF $\mathrm{U}_{6}$ ultimately results in the retention of most of the uranium as complex uranium oxyfluoride solvates of limited solubility in the conductive solution of nearly anhydrous HF also produced there. Third, this conducting solution permits the coating of the hydrolyzed hexavalent uranium salt by a thickening, more protective layer of $U F_{4}$ hydrate. In this process, the iron is oxidized to an insoluble iron fluoride hydrate that is retained at the iron surface while the $U^{+6}$ material in the solution and at the surface is reduced to produce the insoluble $U^{+4}$ compounds. Fourth, all the solid products deposited as the outer coating layer are not very soluble in water and tend not to migrate far, limiting the environmental impact of these materials to the immediate vicinity of the cylinder. Fifth, when the hole becomes large, there will be enough of the strongly acidic HF solution produced that some will ooze out of the plugging materials and attack the cylinder wall below the hole and even the surface of the cylinder below, producing groovelike etching of these cylinders. The corrosion deposits on the adjacent lifting lug and stiffening ring just below the small hole in cylinder 4G127985 are believed to have been produced by this mechanism. This condition may be aggravated by rain, since more hexavalent uranium is dissolved in more dilute HF solutions (see Fig. B3.2). The shape of the holes in the cylinders $4 G 127985$ and $4 G 115688$ and the grooves: in the wall of the cylinder below the one with the large hole are also proof of the operation of this mechanism. The finding of a high concentration of uranium in a gr ts sample of the soil at the edge of the concrete pad where the rain falling on cylinder $4 \mathrm{G} 115688$ drained off is supporting evidence.

\section{Discussion of Specific Chemical Reactions Occurring at Penetrating Cracks Below the Level of Solid UF6}

Room-temperature hydrolysis of $\mathrm{UF}_{6}$ by water has been reported to occur preferentially on surfaces. This means that the initial reaction will be the same, whether the surface itself is $U_{6}$ or the $\mathrm{UF}_{6}$ is sorbed from the vapor phase. Thereafter, the nature of the surface becomes important. When that surface is an active metal, like iron, an immediate reduction of the hydrolyzed $\mathrm{UF}_{6}$ to $\mathrm{UF}_{4}$ takes place. Considering that the water is already there (at least at night), the probable initial reactions on solid $\mathrm{UF}_{6}$, based on the products shown in the $\mathrm{UO}_{3}-\mathrm{HF}-\mathrm{H}_{2} \mathrm{O}$ phase diagram of Buslaev et al. ${ }^{3}$ (Fig. B3.1), are given by Eqs. (B3-1) and (B3-2).

$$
\begin{gathered}
U F_{6}(s)+\mathrm{H}_{2} \mathrm{O}(l)=\left[\mathrm{HUF}_{6}(\mathrm{OH})\right](s)=\left[\mathrm{HOUF}_{s}\right](s)+\mathrm{HF}(a q), \\
{\left[\mathrm{HOUF} F_{s}\right](s)+5 \mathrm{H}_{2} \mathrm{O}(\mathrm{l})=\left[\mathrm{H}_{3} \mathrm{O}\right]_{2}\left[U(\mathrm{OH})_{4} F_{4}\right](s)+H F(a q) .}
\end{gathered}
$$

With a limited amount of water and in the absence of a reducing metal, the $\left[\mathrm{H}_{3} \mathrm{O}\right]_{2}\left[\mathrm{U}(\mathrm{OH})_{4} \mathrm{~F}_{4}\right](\mathrm{s})$ is the expected product. This material has limited solubility in strong $\mathrm{HF}$

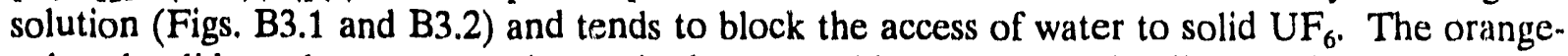
colored solid products expected to exist between this material and solid $\mathrm{UF}_{6}$ have been seen 


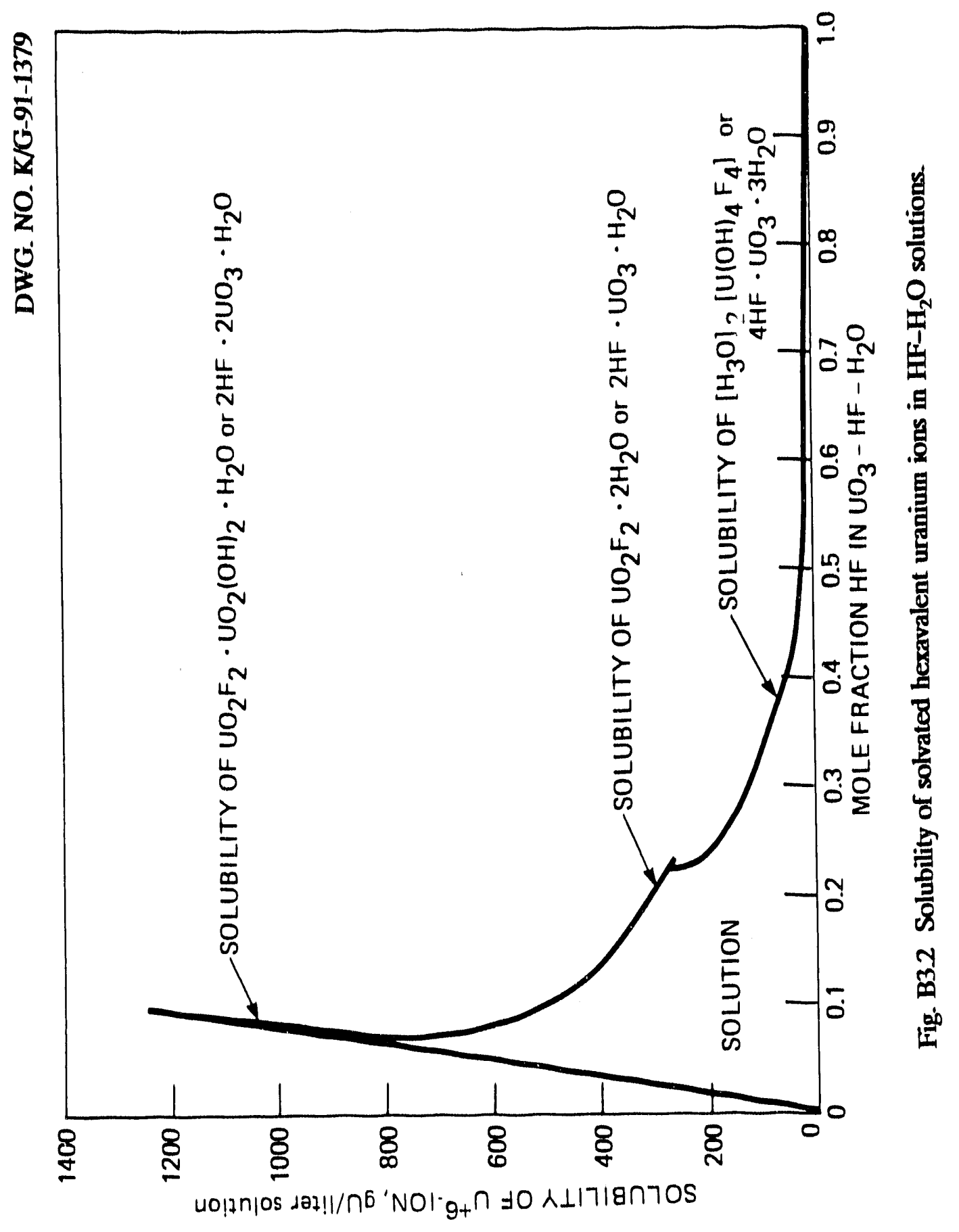


during video inspection of the backside of the deposits in the small hole with a fiber optics boroscope. While X-ray patterns have not been determined for $\left[\mathrm{H}_{3} \mathrm{O}\right]_{2}\left[\mathrm{U}(\mathrm{OH})_{4} \mathrm{~F}_{4}\right](\mathrm{s})$, which may be written as $\mathrm{UO}_{2} \mathrm{~F}_{2} * 4 \mathrm{H}_{2} \mathrm{O} * 2 \mathrm{HF}$, these do exist for a related material, $\mathrm{UO}_{2} \mathrm{~F}_{2} * 2 \mathrm{H}_{2} \mathrm{O} * \mathrm{HF}$, which is formed when $\mathrm{UF}_{6}$ vapor undergoes reaction with water vapor at low partial pressures. ${ }^{34}$

As D. M. Manuta ${ }^{26}$ has shown, acidic, hexavalent uranium fluoride solutions in contact with iron are reduced to $\mathrm{UF}_{4}$, and the iron is oxidized to either the ferrous or ferric state. These reactions are shown in Eqs. (B3-3) and (B3-4) under conditions existing outside the holes.

$3\left[\mathrm{H}_{3} \mathrm{O}\right]_{2}\left[\mathrm{U}(\mathrm{OH})_{4} \mathrm{~F}_{4}\right](s)+6 \mathrm{HF}(\mathrm{aq})+2 \mathrm{Fe}(s)=3 U \mathrm{~F}_{1} * 2.5 \mathrm{H}_{2} \mathrm{O}(s)+2 \mathrm{FeF}_{3} * 3 \mathrm{H}_{2} \mathrm{O}(s)+4.5 \mathrm{H}_{2} \mathrm{O}(\mathrm{aq})$

or

$\left[\mathrm{H}_{3} \mathrm{O}\right]_{2}\left[U(\mathrm{OH})_{4} \mathrm{~F}_{1}\right](s)+2 \mathrm{HF}(\mathrm{aq})+\mathrm{Fe}(s)+1.5 \mathrm{H}_{2} \mathrm{O}(l)=U \mathrm{~F}_{1} * 2.5 \mathrm{H}_{2} \mathrm{O}(s)+\mathrm{FeF}_{2} * 4 \mathrm{H}_{2} \mathrm{O}(s)$.

Adding Eq. (B3-3) and two times Eq. (B3-4) gives

$5\left[\mathrm{H}_{3} \mathrm{O}\right]_{2}\left[U(\mathrm{OH})_{4} \mathrm{~F}_{4}\right](s)+10 \mathrm{HF}(\mathrm{aq})+4 \mathrm{Fe}(s)=2 \mathrm{Fe}_{2} \mathrm{~F}_{5} * 7 \mathrm{H}_{2} \mathrm{O}(s)+5 U \mathrm{~F}_{1} * 2.5 \mathrm{H}_{2} \mathrm{O}(s)+1.5 \mathrm{H}_{2} \mathrm{O}(l)$

The $\mathrm{HF}, \mathrm{UF}_{4} * 2.5 \mathrm{H}_{2} \mathrm{O}, \mathrm{FeF}_{3} * 3 \mathrm{H}_{2} \mathrm{O}$, and $\mathrm{Fe}_{2} \mathrm{~F}_{5} * 7 \mathrm{H}_{2} \mathrm{O}$ have been identified in the products exterior to the holes. The $\mathrm{UF}_{4}$ found in deposits inside the cylinder contains fewer waters of hydration (namely, $\mathrm{UF}_{4} * 1.5 \mathrm{H}_{2} \mathrm{O}$ and $\mathrm{UF}_{4} * 0.75 \mathrm{H}_{2} \mathrm{O}$ ). Analysis of the fluorescent yellow layer within cylinder $4 \mathrm{G} 115688$ indicates that the mean composition corresponds closely to that of 50:50 mole \% mixture of $\mathrm{UO}_{2} \mathrm{~F}_{2}(\mathrm{~s})$ and $\left[\mathrm{H}_{3} \mathrm{O}\right]_{2}\left[\mathrm{U}(\mathrm{OH})_{4} \mathrm{~F}_{4}\right]$. The yellow layer contains some $\mathrm{UO}_{2} \mathrm{~F}_{2} * n \mathrm{H}_{2} \mathrm{Os}$ next to the $\mathrm{UF}_{4}$ hydrate layer and grades into $\mathrm{U}_{2} \mathrm{O}_{3} \mathrm{~F}_{6}$ (orange band) next to the $\mathrm{UF}_{6}$. All these observations suggest a decreasing concentration of water as one passes through the plug toward the $\mathrm{UF}_{6}$ solid. $\mathrm{No}_{\mathrm{FeF}} * 4 \mathrm{H}_{2} \mathrm{O}$ is found as a separate product, probably because $\mathrm{Fe}^{+2}$ is so readily oxidized to $\mathrm{Fe}^{+3}$ and the mixed fluoride is stable. Still, it is interesting that sufficient water might not be available to form it according to Eq. (B3-4). For the other two ironfluoride hydrate reactions, according to the reactions as written, water is left after the reactions for additional hydrolysis of $\mathrm{UF}_{6}$.

Because the redox reactions involved are electron transfer processes, the reactions can occur very fast and with a high degree of separation of reaction products. In this case, the iron fluorides were found immediately in contact with the iron, while the $\mathrm{UF}_{4}$ hydrates were not in direct contact with the walls but had a layer of iron fluorides between them and the steel surfaces.

Another feature of the oxidation-reduction reaction is that all the fluorine atoms on each $\mathrm{UF}_{6}$ reduced to $\mathrm{UF}_{4}$ are used in the production of iron fluoride and $U F_{4}$, leaving none for $\mathrm{HF}$ formation (see Appendix B, Part 2). Since HF is found, additional $\mathrm{UF}_{6}$ must also be hydrolyzed, and the resulting hydrolysis product must be present as a layer beneath the $\mathrm{UF}_{4}$ layer. Direct evidence of this truth was found when part of the $\mathrm{UF}_{4}$ layer sloughed off the deposit in the large hole, revealing the deep layer of fluorescent yellow compound.

Reactions in Eqs. (B3-1) and (B3-2) and the subsequent speculation of other partial hydrolysis products between Buslaev et al. ${ }^{7}$ complex oxyfluorouranic acid and solid UF 6 suggest 
a high concentration of HF may exist at the hydrolysis product-solid $U F_{6}$ interface. This would account for the increase in partial pressure of HF in the vapor space of cylinder 4G127.985 from a probable value of 20 to 40 torr initially to 200 torr. Hydrogen lluoride is reasonably soluble in solid $\mathrm{UF}_{6}$ and could thus diffuse from the point of high concentration to the vapor space surface of the $U_{6}$, where it would escape to the vapor cavity raising the pressure there. As shown in Appendix B, Part 2, this continuous accumulation of HF in the vapor cavity of cylinder 4G115688 had resulted in the accumulation of about $2.3 \mathrm{~L}$ of liquid $\mathrm{HF}$ solution there.

From these considerations, the quantities of $\mathrm{UF}_{6}$ reacted must be the sum of quantity required to react with the iron and the quantity required to produce the HF, both that found in the cylinders and that which oozed or diffused out. These values have been quantified to the degree possible in Appendix B, Part 2.

\section{Reaction at Cracks Above the Level of Solid $\mathrm{UF}_{6}$ in the Cylinder}

If the crack were to be nade above the level of solid $\mathrm{UF}_{6}$ in the cylinder, which was not the case in either of the cylinders discussed here, the reaction might be similar to the one described above if the crack were in a position in which the thin coating of solid $\mathrm{UF}_{6}$ was continuously present on the inside surface of the cylinder. As far as is presently known, this is a possibility with the bottom layer of cylinders; however, in view of the surface temperatures reached on the top part of the upper layer of cylinders, it is considered unlikely that this condition would persist there. In that case, the vapor space in the cylinder might become open to the atmosphere, and hydrolysis can occur at the inside opening of the crack during the nighttime hours and at the outside opening of the crack during the daylight hours. Since the nighttime reactions in the crack would be like those already discussed, at least a short-term plugging should occur, which will greatly limit the reaction rate; however, this plug will not stop the slow persistent corrosion of the crack to a hole. It is entirely possible that the plug, which is unsupported except for its contact area with the cylinder wall, will become dislodged and, subsequently, a much larger release rate of $\mathrm{UF}_{6}$ hydrolysis products wil! be experienced including uranyl fluoride aerosols that are not expected to be significant for cracks below the level of the solid UF .

Since the actual sequence of events for a crack in the top of a cylinder is presently a matter of speculation, a study should be performed to establish an actual sequence. For filled cylinders that have been stacked for the first time, the chances of finding a crack in the top part of the top layer of cylinders are minimal. Such assurance cannot be given for restacked cylinders.

\section{A SCENARIO FOR HOLE AND PLUG DEVELOPMENT}

The observations, measurements, analyses, and deductions arrived at in the main text and in the appendices, including this one, can be summarized by the following scenario which traces the development of holes through four phases by means of illustrative sketches. Figure B.3.3 shows the coding used in Figs. B3.5 through B3.12.

\section{Phase 1 - Wall Fracture (Fig. B3.3)}

The duration of this phase is on the order of milliseconds. The sharp corner of a lifting lug of one cylinder strikes or is struck by another cylinder near a stiffening ring below the surface of 


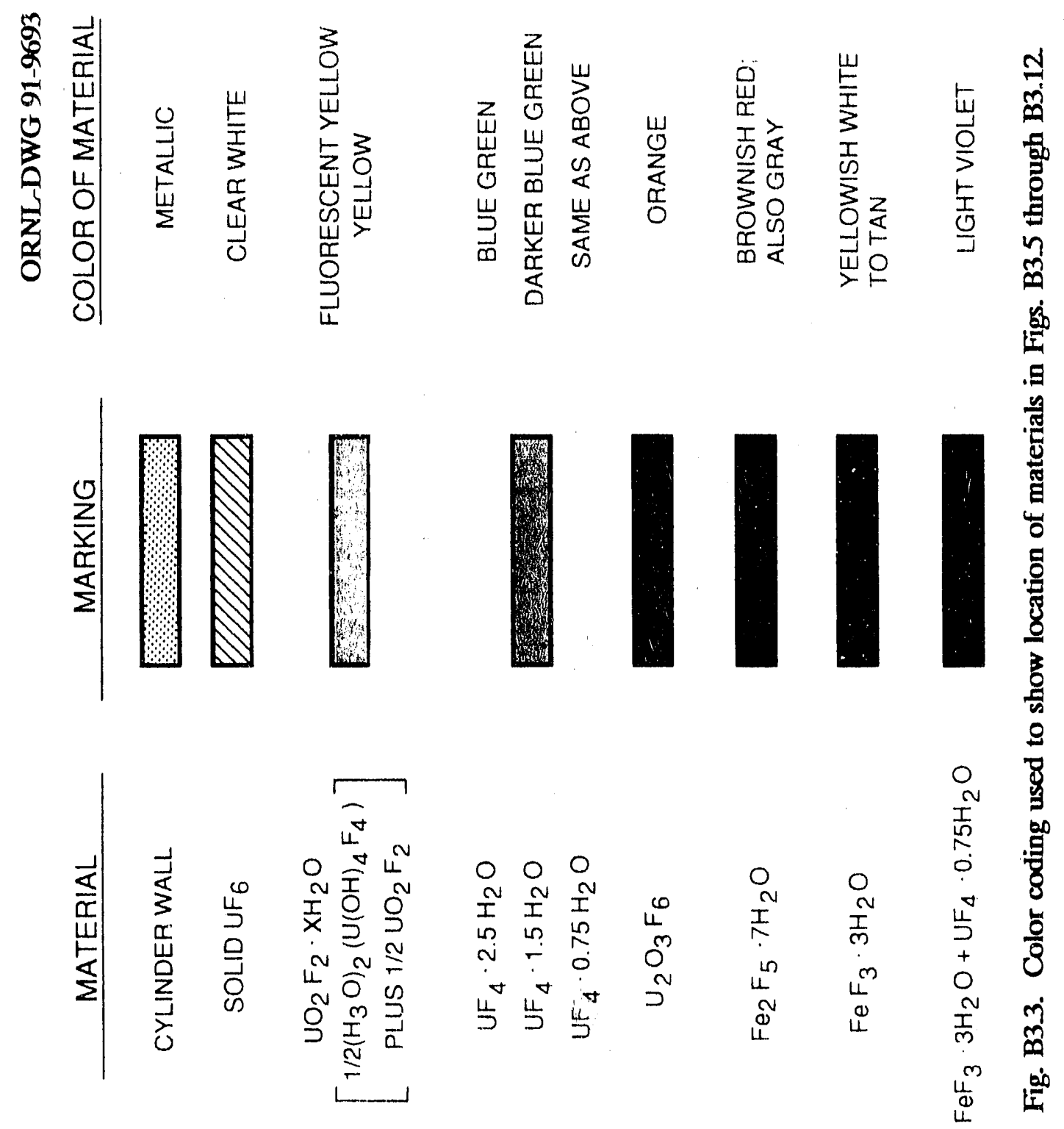


the solid $\mathrm{UF}_{6}$ in the cylinder, as shown. The impact problem is the same whether the lifting lug involved is on the moving or stationary cylinder. On rare occasions ( 2 in more than 40,000 ), the result of the impact is a fracture which extends completely through the wall of the cylinder. In the case of the A285 steel cylinders, the failure may be by brittle or ductile fracture, depending on the temperature at the time of impact. With the A516 steel cylinders, failure is by a combination of brittle fracture and ductile tearing termed "lamellar tearing" and is more apt to occur with sulfur contents near the upper specification limit. (This is a result of sulfide lamination in the plate rolling direction and has been corrected by using lower sulfur content heats for the cylinder material.)

Almost immediate detection may or may not be possible as discussed under phase 2.

\section{Phase 2 - Initial Plugging of the Fracture (Figs. B3.4 through B3.6)}

The next phase is the development of a plug in the fracture produced in phase 1 . The time frame for this phase is hours, and the plug will be developed fully in about $24 \mathrm{~h}$. Figure B3.5 shows a very early stage in the plug development. The chemical attack begins in the fracture, at or near the external surface of the cylinder wall. It must be here because the sublination pressure of $\mathrm{UF}_{6}$ is approximately four times the vapor pressure of water, and two moles of water are required for each mole of $\mathrm{UF}_{6}$ converted to $\mathrm{UO}_{2} \mathrm{~F}_{2}$. This deduction also is confirmed by crude computer simulation using reasonable values for the diffusion coefficients of water vapor and $\mathrm{UF}_{6}$ vapor in air." Only at the exterior surface is sufficient water vapor available to produce $\mathrm{HF}-\mathrm{H}_{2} \mathrm{O}$ fog and some condensate on the steel surface. The $\mathrm{UO}_{2} \mathrm{~F}_{2}$ produced is largely retained in the fracture which, with the passage of time, produces a plug that slows the diffusion of $\mathrm{UF}_{6}$ to the surface. If the fracture is not detected before this plug develops, it is not likely to be detected until some time after the completion of phase 3. Gas phase diffusion is the controlling factor in phase 2.

The initial fracture may or may not be immediately detectable depending upon the conditions. Detection is dependent upon seeing the $\mathrm{HF}-\mathrm{H}_{2} \mathrm{O}$ fog formed upon the hydrolysis of $\mathrm{UF}_{6}$ with water vapor. Conditions in winter are less favorable to the fog formation because the stored $\mathrm{UF}_{6}$ is colder, the rates of reaction slower, and the concentrations of the reactants lower. Storing cylinders longer before stacking also lowers the probability of detection. For some combination of these reasons, the fractures in cylinders $4 \mathrm{G} 127985$ and $4 \mathrm{G} 115688$ went undetected during this phase.

Figure B3.6 illustrates the conditions existing in the fracture, just before final closure of the fracture by hydrolysis products makes another change in the time frame for reaction. The reactions at this point in the process are the same as in Fig. B3.4, except for being slower.

\section{Phase 3 - Corrosion of the Walls of the Fracture (Figs. B3.7 through B3.10)}

When the diffusion of the $\mathrm{UF}_{6}$ to the surface is reduced sufficiently that water vapor is in excess at the fracture exit, aqueous $\mathrm{HF}$ is produced which dissolves some of the $\mathrm{UO}_{2} \mathrm{~F}_{2}$. This is a conducting acidic solution which attacks the iron-producing green $\mathrm{UF}_{4}$ hydrate and an ironfluoride hydrate. At the steel surface, a very thin layer of $\mathrm{FeF}_{2}$ is probable. (It is not visible.)

"The computer simulation was performed by L. D. Trowbridge of the PLRTS Department, Enrichment Technical Operations Division. 

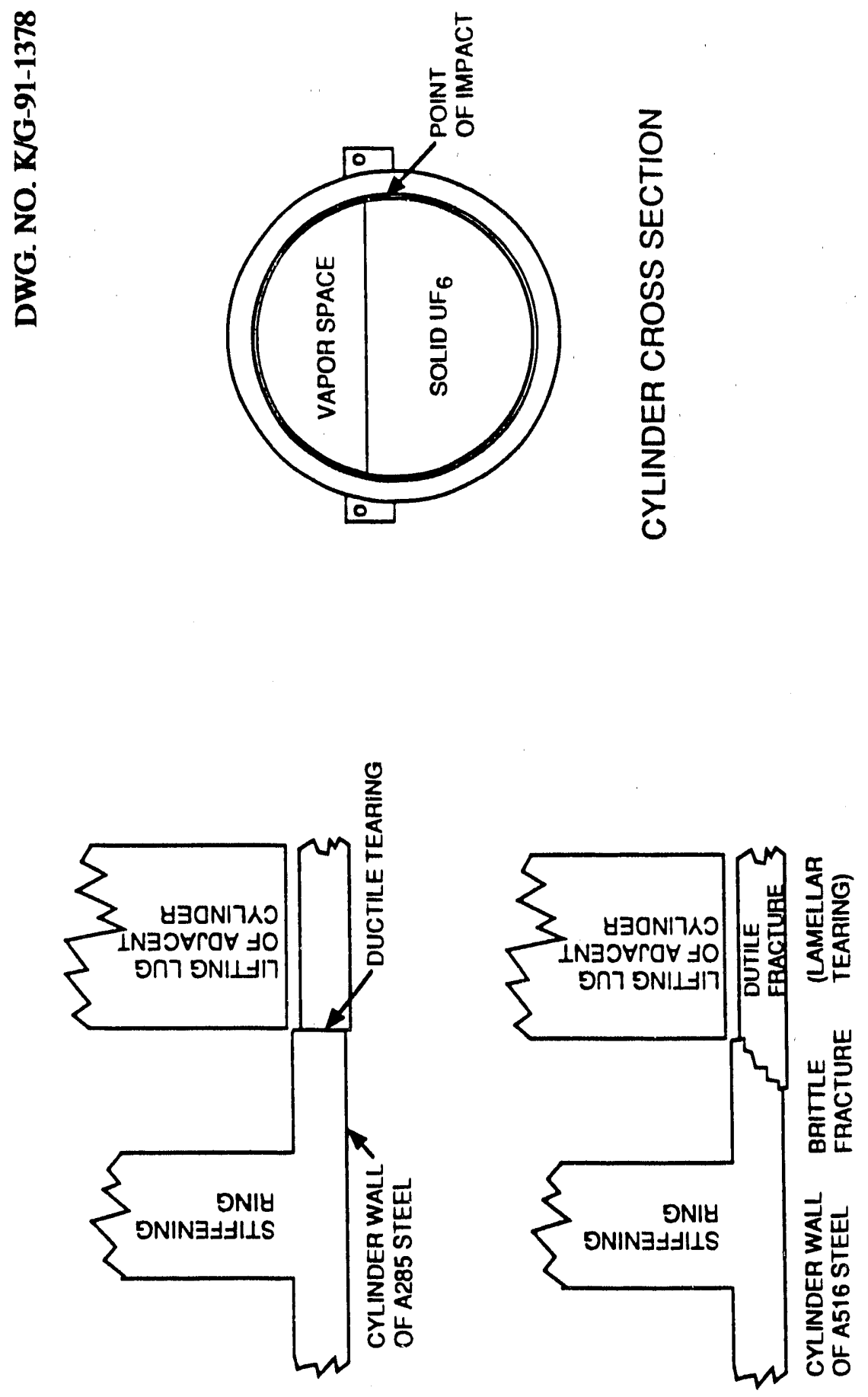


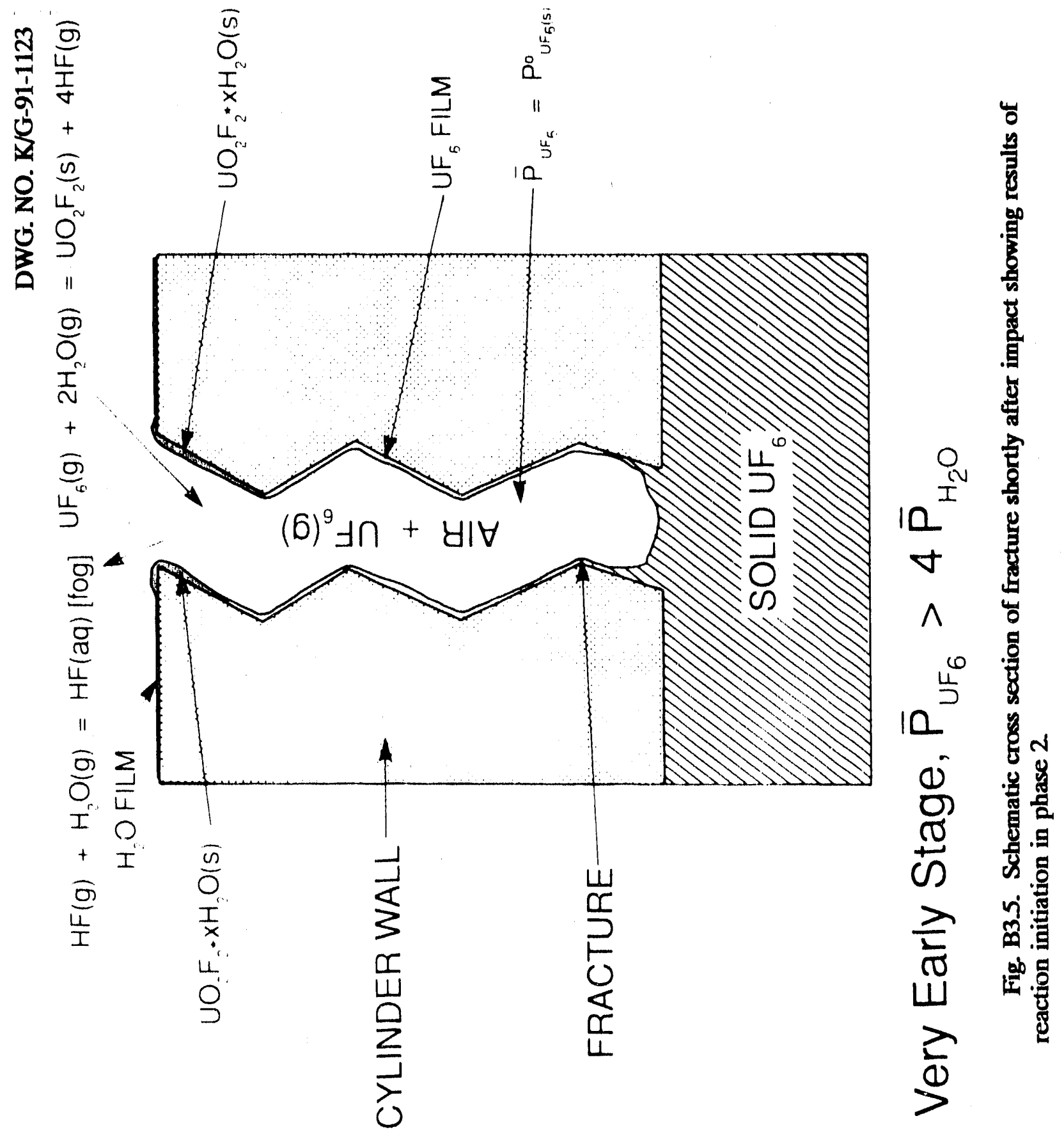




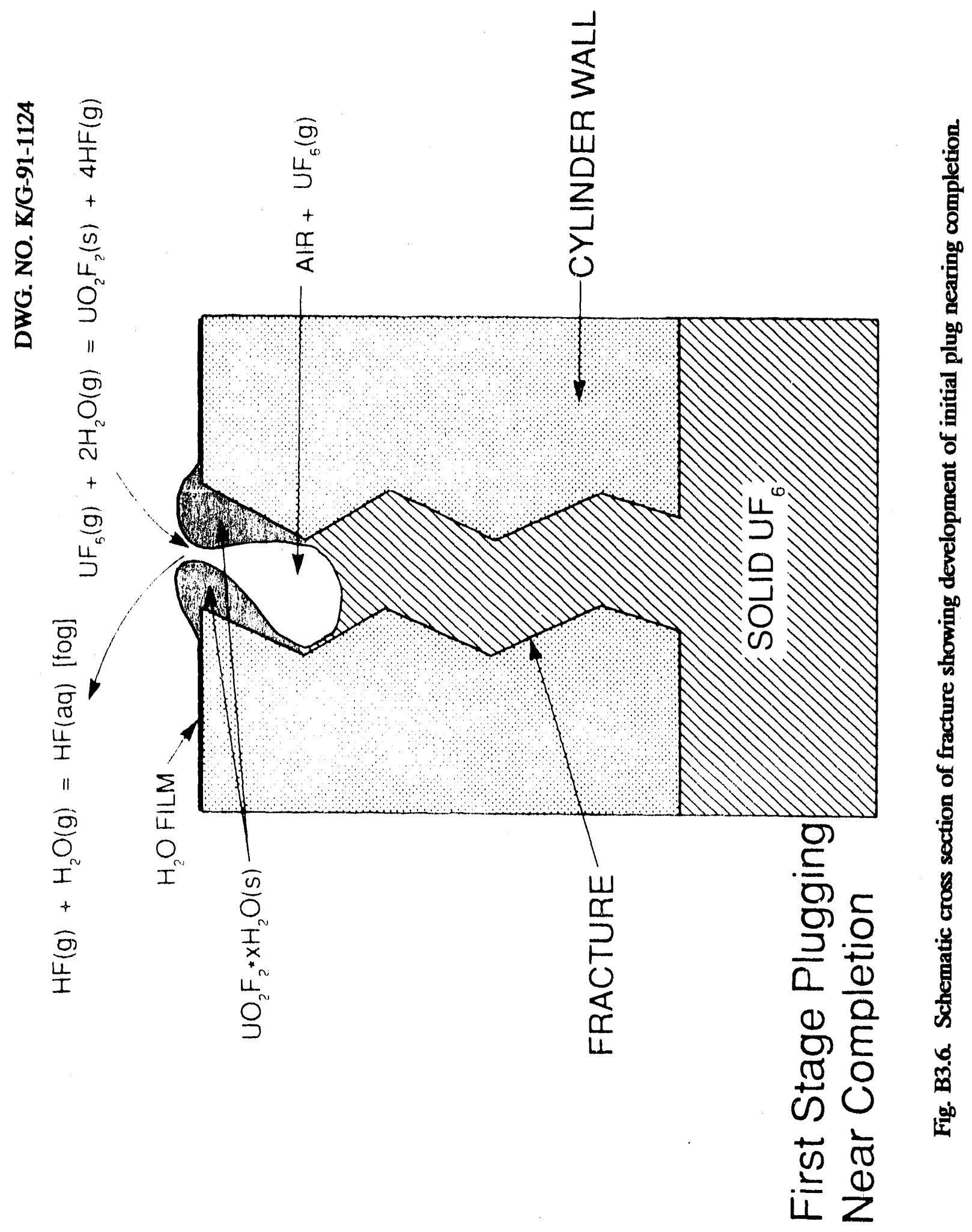




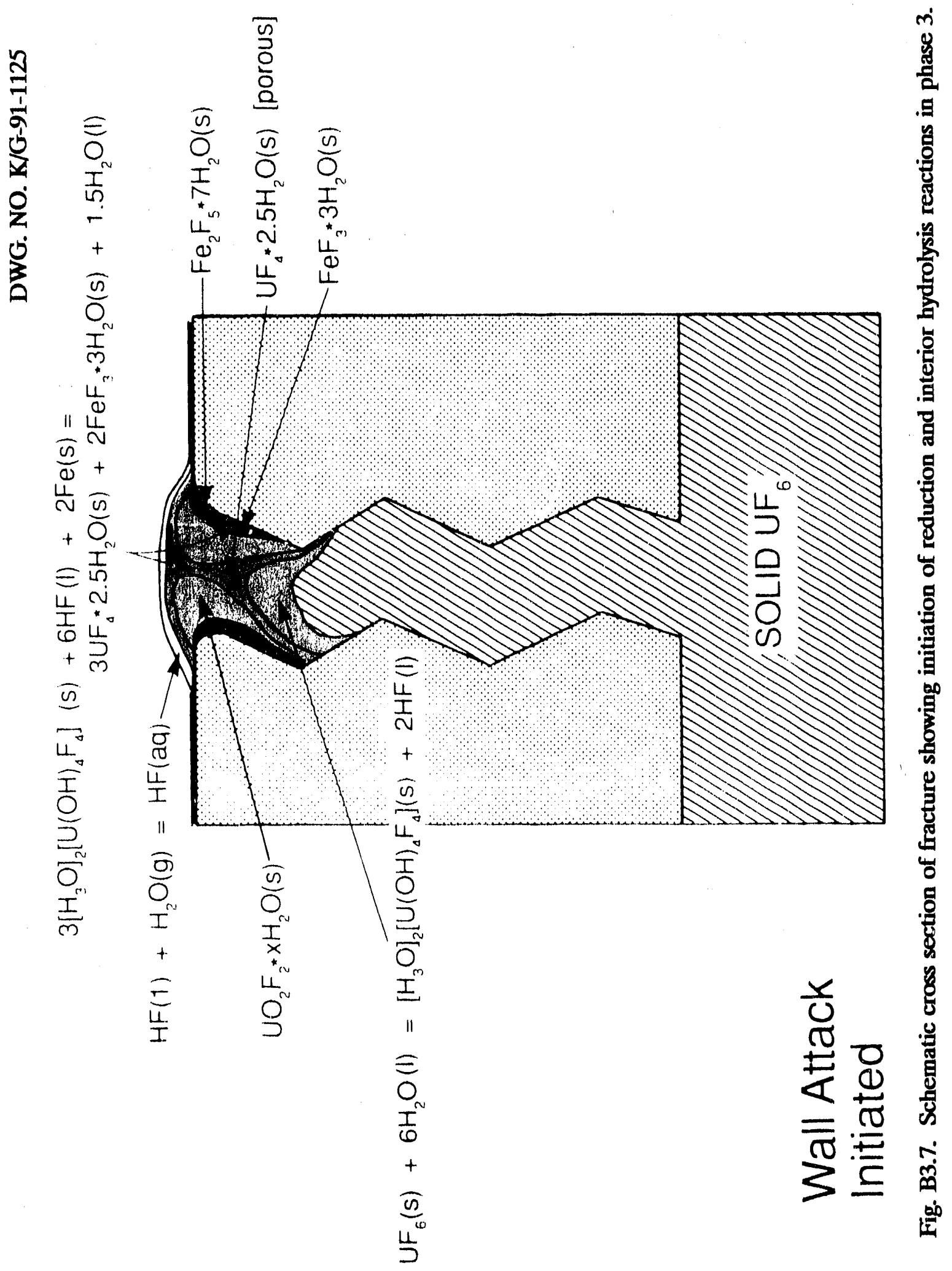




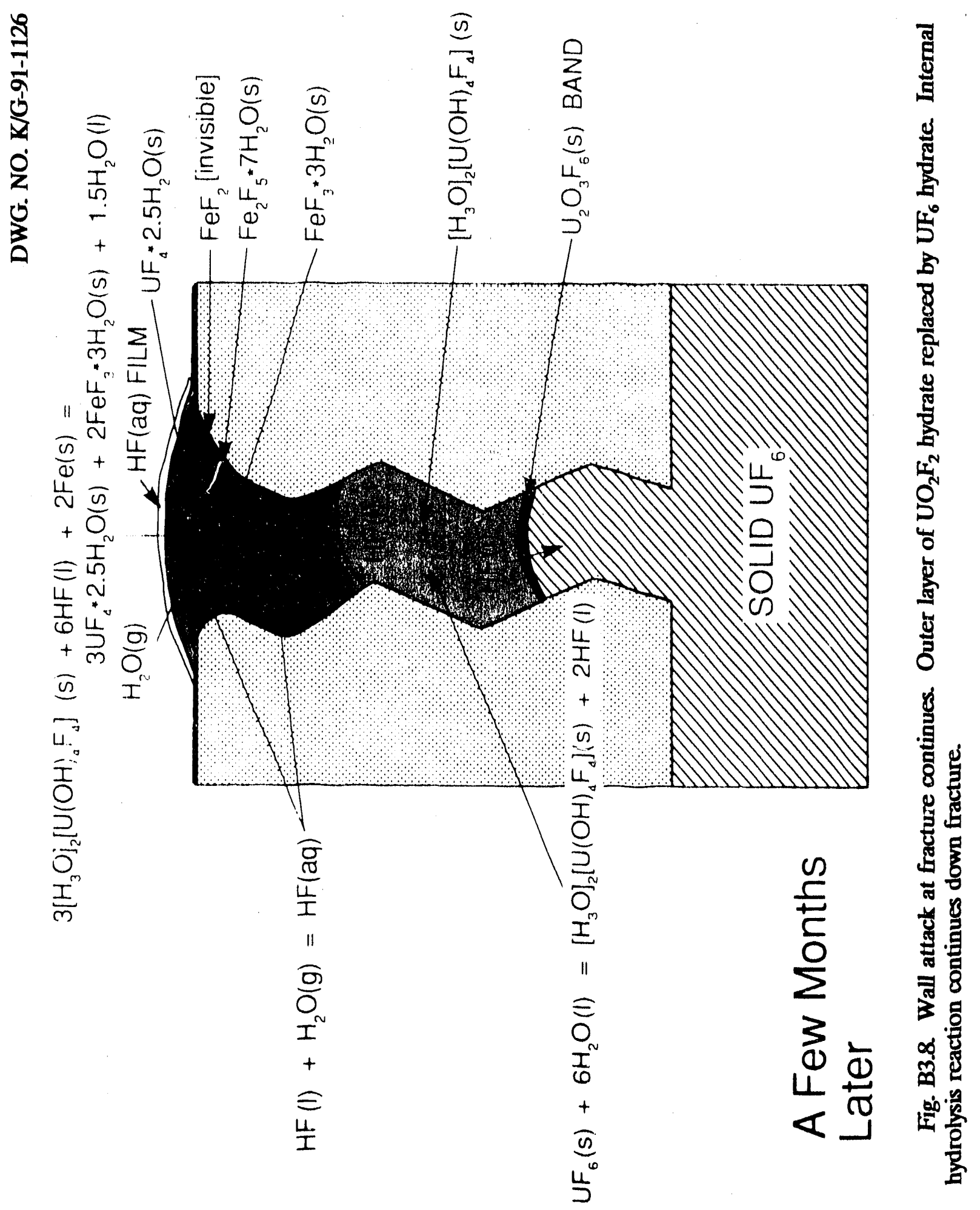




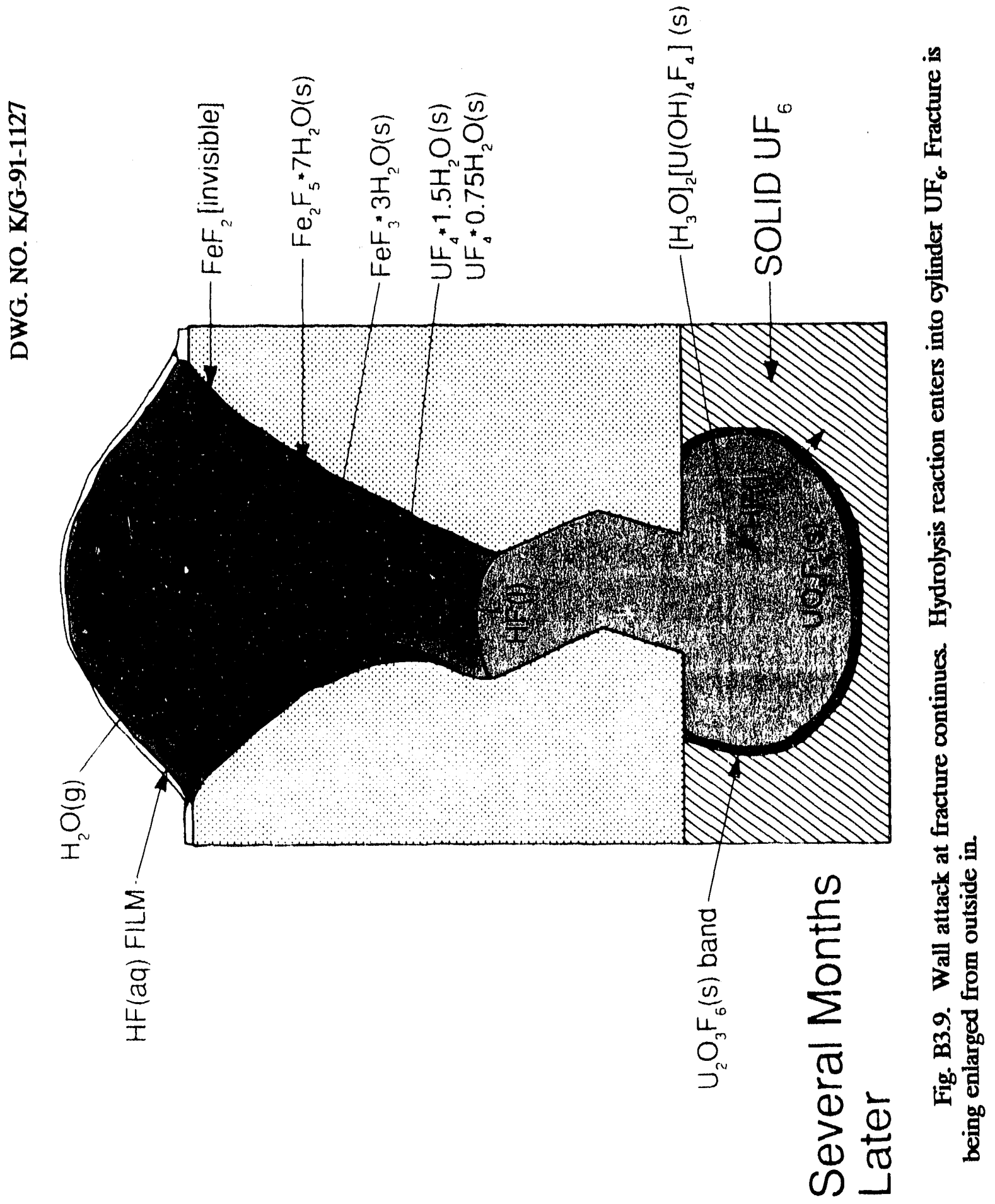




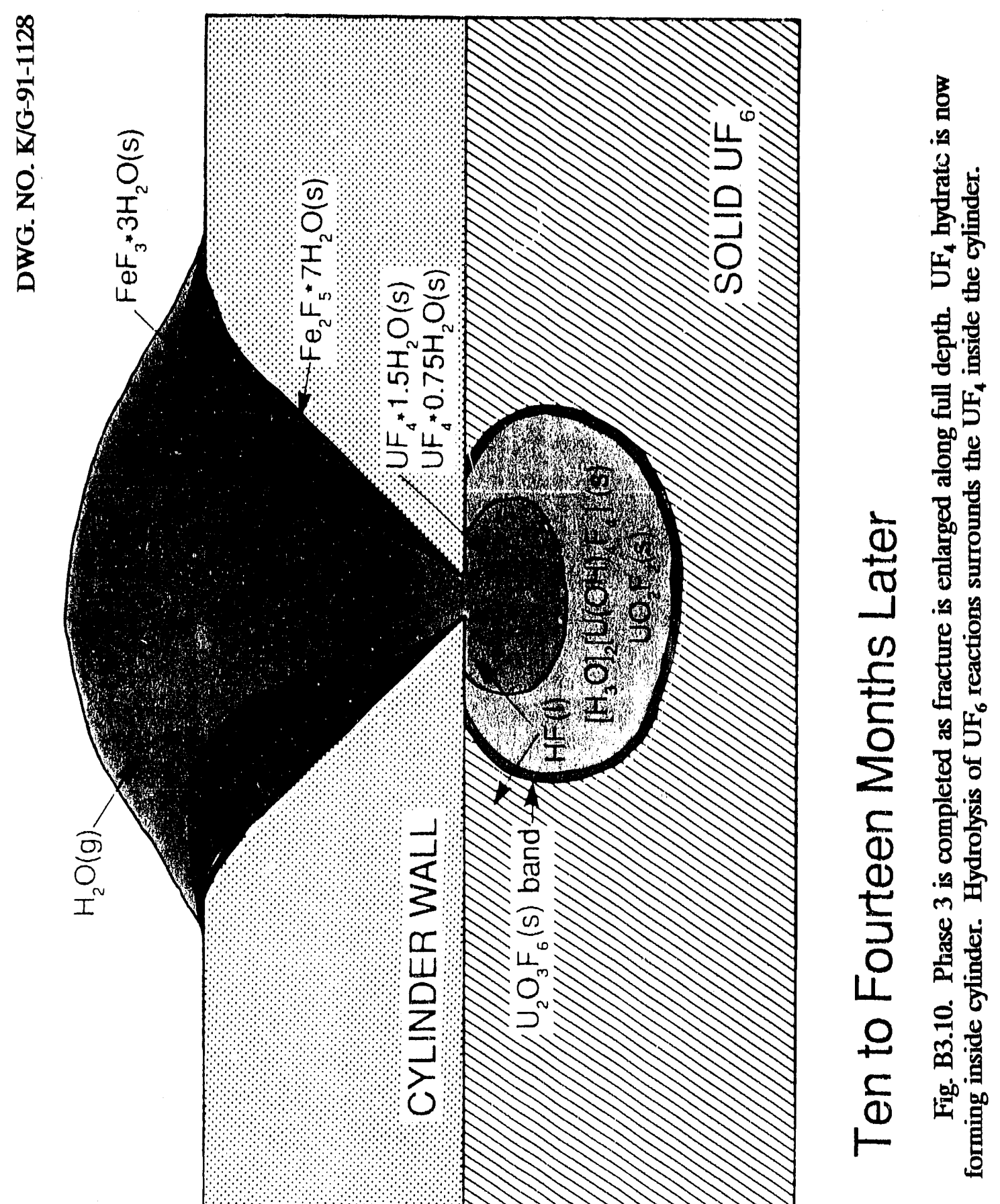


On top of this, a layer of brick-brown or gray $\mathrm{Fe}_{2} \mathrm{~F}_{5}$ hydrate is found. Next to this is a layer of greenish-white $\mathrm{FeF}_{3}$ hydrate, which becomes tan on exposure to air. The $\mathrm{UF}_{4}$ hydrate is at the center of the fracture and is somewhat porous. This $\mathrm{UF}_{4}$ hydrate contains very little iron. There is always $\mathrm{UO}_{2} \mathrm{~F}_{2}$ solvate between the $\mathrm{UF}_{4}$ hydrate layer and the $\mathrm{UF}_{6}(\mathrm{~s})$. In fact, based on the earlier observations of Mallett and the results of the inspection of the backside of the plug in cylinder 4G127985, the composition changes in something like the following sequence:

$$
\begin{aligned}
& \mathrm{UF}_{4}{ }^{*} 0.75 \mathrm{H}_{2} \mathrm{O}:: \mathrm{UO}_{2} \mathrm{~F}_{2}{ }^{*} \mathrm{nH}_{2} \mathrm{O}::\left[\mathrm{H}_{3} \mathrm{O}_{2}\left[\mathrm{U}(\mathrm{OH})_{4} \mathrm{~F}_{4}\right]:: \mathrm{UO}_{2} \mathrm{~F}_{2}:: \mathrm{U}_{2} \mathrm{O}_{3} \mathrm{~F}_{6}:: \mathrm{UOF}_{4}:: \mathrm{UF}_{6}\right. \\
& \text { green yellow yellow yellow orange orange clear }
\end{aligned}
$$

Mallett's evidence ${ }^{24}$ is the existence of an orange band well below the surface of the $\mathrm{UO}_{2} \mathrm{~F}_{2}$ that defined the extent to which at least partial hydrolysis had proceeded. The backside of the deposit in cylinder $4 \mathrm{G} 127985$ was orange. Since both $\mathrm{U}_{2} \mathrm{O}_{3} \mathrm{~F}_{6}(\mathrm{~s})$ and $\alpha-\mathrm{UOF}_{4}$ are orange, it is not known whether only one or both are present. In the drawings only the $\mathrm{U}_{2} \mathrm{O}_{3} \mathrm{~F}_{6}$ is shown. The time frame for the corrosion illustrated in the figures is on the order of months.

In Fig. B3.7 the initiation of the chemical attack of the wall is illustrated. The reaction of the $\mathrm{UF}_{6}(\mathrm{~s})$ with $\mathrm{H}_{2} \mathrm{O}$ within the fracture is given by the following relation which is the sum of reactions (B3-1) and (B3-2):

$$
U F_{6}(s)+6 \mathrm{H}_{2} \mathrm{O}(l)=\left[\mathrm{H}_{3} \mathrm{O}\right]_{2}\left[U(\mathrm{OH})_{4} F_{4}\right](s)+2 \mathrm{HF}(l) .
$$

The principal reaction, which is initiated at the exterior surface of this material and at the iron surface, may be summarized by

$$
\begin{aligned}
& 3\left[\mathrm{H}_{3} \mathrm{O}\right]_{2}\left[U(\mathrm{OH})_{4} \mathrm{~F}_{4}\right](s)+6 \mathrm{HF}(\mathrm{l})+2 \mathrm{Fe}(s)= \\
& 3 \mathrm{UF}_{4} * 1.5 \mathrm{H}_{2} \mathrm{O}(\mathrm{s})+2 \mathrm{FeF}_{3} * 3 \mathrm{H}_{2} \mathrm{O}(\mathrm{s})+4.5 \mathrm{H}_{2} \mathrm{O}(\mathrm{l})
\end{aligned}
$$

Nearer the exit of the fracture, the reaction of the $\mathrm{HF}(\mathrm{l})$ with the $\mathrm{H}_{2} \mathrm{O}$ vapor produces aqueous $\mathrm{HF}$, which dissolves the previously produced $\mathrm{UO}_{2} \mathrm{~F}_{2}$ hydrate, so the redox reaction given by the following equation may be considered representative since similar equations may be written for the $\mathrm{Fe}$ to $\mathrm{Fe}^{+2}$ and $\mathrm{Fe}^{+2}$ to $\mathrm{Fe}^{+3}$ reactions:

$$
\begin{aligned}
& 3 U \mathrm{O}_{2}{ }^{+2}(a q)+6 \mathrm{~F}^{-1}(a q)+12 \mathrm{HF}(a q)+7.5 \mathrm{H}_{2} \mathrm{O}(a q)+2 \mathrm{Fe}(s)= \\
& 3 U \mathrm{~F}_{4} * 2.5 \mathrm{H}_{2} \mathrm{O}(s)+2 \mathrm{FeF}_{3} * 3 \mathrm{H}_{2} \mathrm{O}(s) .
\end{aligned}
$$

These reactions require strongly acidic solutions, and if the acid content were to be reduced too much by dilution with rainwater, the escape of uranium as soluble uranyl ion in the form of $\mathrm{UO}_{2} \mathrm{~F}_{2}$ becomes possible.

Figure B3-8 represents the condition existing in the fracture a few months later. The original plug of $\mathrm{UO}_{2} \mathrm{~F}_{2}$ hydrate is entirely converted to $\mathrm{UF}_{4}$ hydrate, and both the hydrolysis of the $\mathrm{UF}_{6}$ and the conversion of the hydrolysis product to a $\mathrm{UF}_{4}$ hydrate have proceeded deeper into the cylinder wall. The overall layering pattern of the products is established and perhaps includes, as shown, the development of the orange-colored layer. The rate of reaction is expected to be increasing as the fraction of the fracture surface attacked increases. 
The next Fig. (B3.9), which represents the conditions in the fracture several months later, shows the hydrolytic attack of the $\mathrm{UF}_{6}(\mathrm{~s})$ has proceeded into the $\mathrm{UF}_{6}$ inside the cylinder itself. The same redox reactions continue to deepen the $\mathrm{UF}_{4}$ hydrate layer, and the area of the fracture surface attacked continues to enlarge. The degree of hydration of the UF ${ }_{4}$ changes in the same direction as one would logically expect the concentration of $\mathrm{H}_{2} \mathrm{O}$ to change (namely, to decrease as one proceeded ever deeply into the plugging material). The overall rate of attack of the steel surface is increasing. Note that the ordered layering of the reaction products continues.

Phase 3 comes to completion when the attack of the iron is occurring over the full depth of the fracture as is illustrated in Fig. B3.10. The attack of the steel is proceeding from the outside in and is producing a hole with the bevel facing the outside. Once the bevel reaches through the wall thickness, the rate of attack will increase as the circumference of the crack increases, but the rate of attack per unit length of the circumference will remain practically constant. Ten to 14 months will have elapsed since the impact when this coccurs. As shown, $\mathrm{UF}_{4} * 1.5 \mathrm{H}_{2} \mathrm{O}$ and $\mathrm{UF}_{4} 40.75 \mathrm{H}_{2} \mathrm{O}$ will have begun to be produced inside the cylinder with a major yellow layer between it and the $\mathrm{UF}_{6}(\mathrm{~s})$. Later measurements led to the expectation that the average composition of the yellow layer will correspond closely to a 50:50 mole \% mixture of $\mathrm{UO}_{2} \mathrm{~F}_{2}$ and $\left[\mathrm{H}_{3} \mathrm{O}\right]_{2}\left[\mathrm{U}(\mathrm{OH})_{4} \mathrm{~F}_{4}\right](\mathrm{s})$ with some $\mathrm{HF}(\mathrm{l})$ formed and squeezed out. Production of $\mathrm{UF}_{4}$ hydrate exterior to the hole can only begin when the flow of the HF fluid from the yellow layer is more than is required to maintain the saturation of the $\mathrm{UF}_{4}$ and iron fluoride hydrates and to supply the acid requirements of the redox reactions producing additional $\mathrm{UF}_{4}$ hydrate. This will not happen until the attack enters phase 4. Layering of the reaction products is maintained.

Phase 4 - Enlargement of the Hole and Production of External Products (Figs. B3.11 and B3.12)

The last or fourth phase of hole development is entered when the fracture begins to increase in size. It begins about 1 year after the initiating impact and ends when all the $\mathrm{UF}_{6}$ in the cylinder has been hydrolyzed, perhaps as much as 30 years later. Thus, the time frame for this process is years. In this scenario, the enlargement of the effective hole diameter is assumed to occur at a relatively constant rate when viewed over a sufficiently long period of time. At some stage in the growth of the hole, attack of the iron cylinder wall on the inside surface at the hole edge becomes significant, and wall thinning from the inside occurs by the same mechanism as it initially began from the outside. In fact, the wall thinning extended on the inside beyond the hole by 5 in. or more in the case of cylinder 4 G115688 (see Fig. B3.12).

Figure B3.11 is a schematic, cross-sectional drawing illustrating the distribution of reaction products in the hole in cylinder $4 \mathrm{G} 127985$ and on the lifting lug of the adjacent cylinder 4G127902 after a 4-year exposure. The layered isolation of products is seen, except that directly over the hole where no iron remains, the different layers are mixed on a macroscopic basis with retention of identity. The pattern of the attack of the cylinder wall below the hole and on the top and sides of the lifting lug toward the cylinder and the stiffening ring provides evidence of the acidic, hexavalent uranium-bearing solution, which has oozed from the hydrolysis products

"The hole development being described here is for the presence of solid $\mathrm{UF}_{6}$ at the bottom of the fracture. If the fracture is in the top of the cylinder, the scenario being preseriied is not necessarily correct for long, once the hole growth enters the fourth phase. 
DWG. NO. K/G-91-11'29

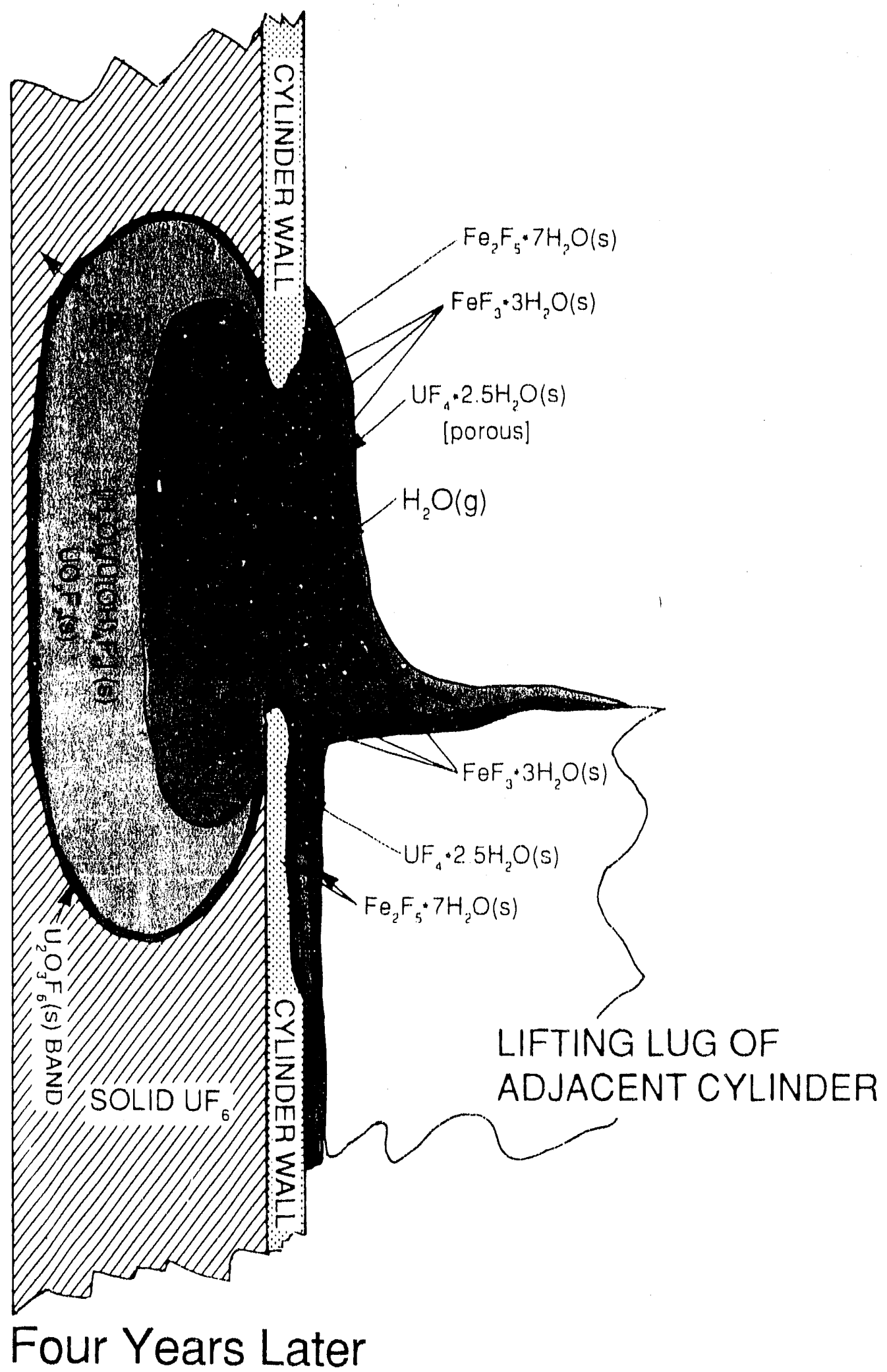

Fig. B3.11. The main reactions continue to be hydrolysis of $\mathrm{UF}_{6}$ inside and reduction to $\mathrm{UF}_{4}$ inside and outside the cylinder. The fracture has become a small hole after 4 years. 


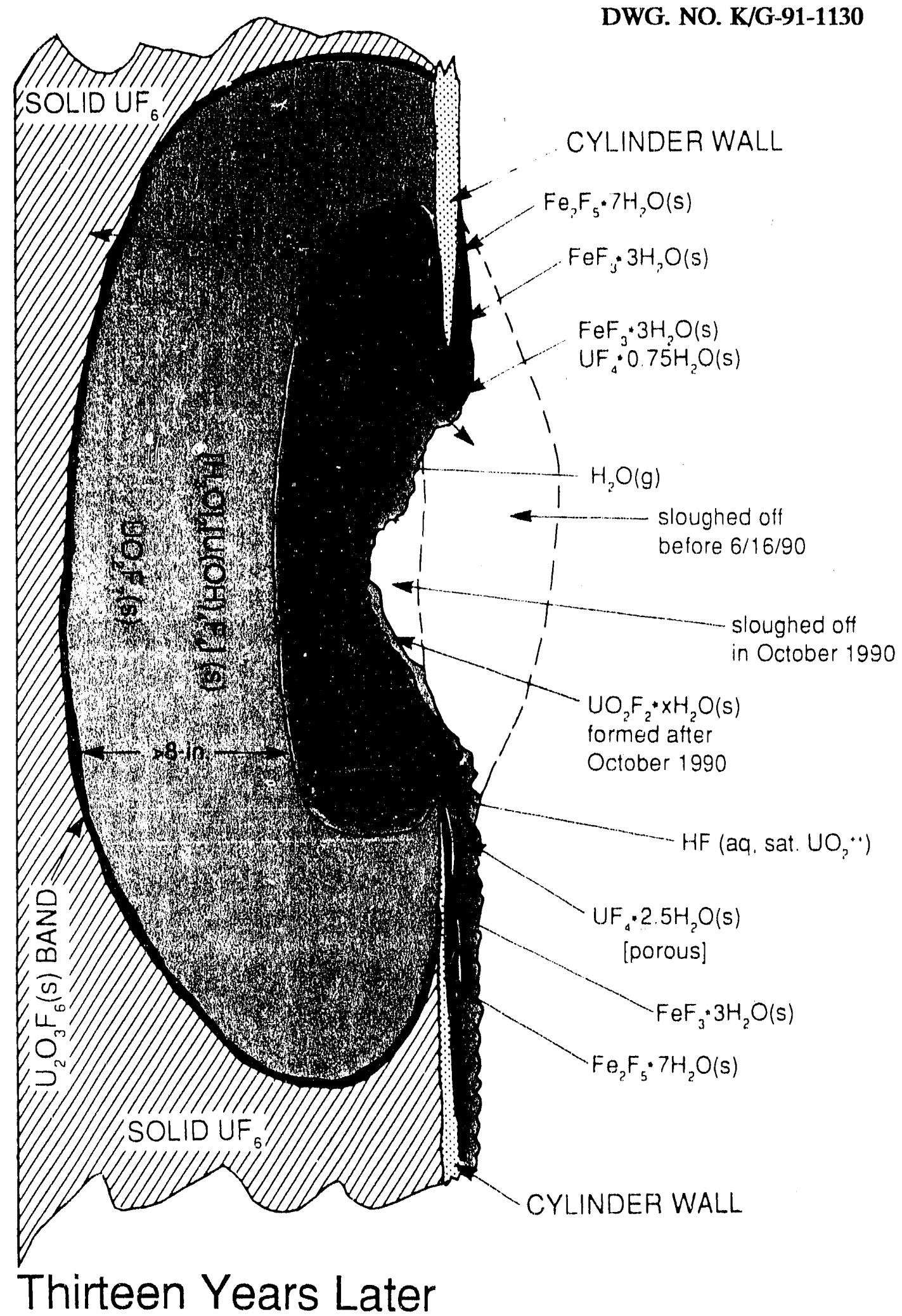

Fig. B3.12. The hydrolysis and reduction reactions continue. Deposits outside the cylinder slough off. The HF escapes both as vapor and liquid solution. A small amount of hexavalent uranium in solution not reduced to $\mathrm{UF}_{4}$ hydrate escapes as $\mathrm{UO}_{2}{ }^{++}$from the vicinity of the cylinder. Condition shown is for 1.3 years after initial impact. The hole is now large, greater than 8 in. 
being produced in the hole. At this stage of hole development, it appears that essentially all of the hexavalent uranium being so transported from the cylinder is reduced to the insoluble $\mathrm{UF}_{4}$ hydrate by the iron and retained at the reduction site.

The redox reaction occurring externally to the cylinder hole between hexavalent uranium and iron to deposit insoluble $\mathrm{UF}_{4}$ and iron fluoride hydrates also ties up large amounts of $\mathrm{F}^{-1}$-ion from the oozing acid as suggested by Eq. (B3-9).

Additionally, dilute aqueous HF slowly aitacks iron to form iron fluoride hydrates and hydrogen gas. For these reasons, the loss by evaporation of $\mathrm{HF}$ vapor from the hole at this stage of development would be expected to be quite limited. In fact, if any HF vapor is escaping, the quantity is so small that it does not produce a detectable concentration in the atmosphere in the immediate vicinity of the hole. The predicted maximum rate of escape of $\mathrm{HF}$ at the time of discovery, as estimated in Appendix B, Part 2, is $0.16 \mathrm{~g} / \mathrm{h}$ of HF.

It is thought that an additional 9 years of exposure (13 years after impact) will produce the effects shown schematically in Fig. B3.12. A portion of the green $\mathrm{UF}_{4}$ hydrate layer sloughed off the center of the hole between the time of discovery in June 1990 and October 1990. This revealed the presence of the deep, yellow layer of hydrolysis products behind the $\mathrm{UF}_{4}$ hydrate layer inside the cylinder. This yellow layer extended more than $12 \mathrm{in.} \mathrm{into} \mathrm{the} \mathrm{cylinder,} \mathrm{indicating}$ the hydrolysis of a significant fraction of the $\mathrm{UF}_{6}$ in the cylinder had occurred. Some slow drainage of the acidic solution from the hydrolysis zone occurred in the area where the $U_{4}$ hydrate sloughed off. Vaporization of this oozing solution left the yellow deposit over the green $\mathrm{UF}_{4}$ hydrate layer, as shown.

All the reactions, which were going on earlier inside the cylinder, are continuing at a rate which probably is increasing at least as fast as the area of the hole is increasing. Thus, the quantity of acidic solution produced gradually increases until the wettable iron surface on the cylinder with the hole will no longer reduce all the contained hexavalent uranium to $\mathrm{UF}_{4}$. When this happens, the solution will slowly trickle down the cylinder wall and stiffening ring, etching them while producing the layered $\mathrm{UF}_{4}$ and iron fluoride hydrates. When the solution reaches the cylinder below the hole, it spreads out and etches this cylinder, forming shallow rivulets in the steel surface. These coalesce into grooves and finally into a single, deep groove as the pitch of the cylinder surface passes vertical. These are filled with the layers of iron fluoride hydrates which, in turn, are covered with a layer of $U_{4}$ hydrate. This condition, after removal of the reaction products, is illustrated in Fig. 5 in the main text.

As is suggested above, when a hole becomes this large, there will be loss of HF vapor by vaporization of the cozing liquid. This loss has been quantified in Appendix B, Part 2, which indicates that the rate of loss of HF at the time of discovery might have been as large as $3.7 \mathrm{~g} / \mathrm{h}$ of HF; however, not all of this quantity would have had to have been as vapor. No environmental samples taken in the vicinity of the cylinder with this large hole indicated a concentration of HF above the PEL (permissible exposure limit for $8 \mathrm{~h}$ ) of $2.5 \mathrm{mg} \mathrm{HF} / \mathrm{M}^{3}$

The etch pattern on the cylinder below the one with the large hole suggests that not all the hexavalent uranium in the strongly acidic solution was reduced to $\mathrm{UF}_{4}$ hydrate. The missing mass of $17 \mathrm{lb}$, which the chemistry indicates might be equivalent to the loss of about $109 \mathrm{lb}$ of $\mathrm{UF}_{6}$ as 
uranyl fluoride solution, is sirongly supportive of this observation. Failure to find any general soil contamination at the edge of the pad where the rainwater drained from cylinder $4 \mathrm{G} 115688$ is not counter indicative because uranyl ion is not retained very well in soil, except under reducing conditions.

The four-phase scenario presented allows for the explanation of the observations made to date. It provides a simple model that can be used to estimate the seriousness of the effects of hole development in a cylinder impacted below the level of the solid UF 6 for a longer time than 13 years (see Appendix B, Part 2). It also appears to be applicable for a period of 1 to possibly 2 years to an impact fracture above the solid $\mathrm{UF}_{6}$ level. It is not applicable to a large hole, such as might be introduced above the solid $\mathrm{UF}_{6}$ level by a projectile. 


\section{APPENDIX B, Part 4 (B4)}

\section{A LIST OF REPORTS}

(An alphabetical listing by principal author of the available reports and references used in the preparation of this report is included in this part of Appendix B. The document numbers referenced in Appendix B are keyed to this listing. The reference numbers in the text of the main body refer to the list at the end of that portion of the document. Those documents are included in this listing but with different numbers. The numbers used in the list at the close of the main body of the report are given in square brackets at the close of the reference in this listing.) 


\section{LIST OF REPORTS}

1. C. R. Barlow et al., Cylinder Yard Inspections and Corrective Actions, K/SS-546, Martin Marietta Energy Systems, Inc., Oak Ridge Gaseous Diffusion Plant, Oak Ridge, Tenn., July 1990. [4]

2. E. J. Barber, Relationships of the UF6-HF Phase Equilibria to the Operating Conditions for Compression-Liquefaction Product Withdrawal and the Freezer-Sublimer Systems (U), an UNCLASSIFIED report in preparation in support of the Safety Analysis Reports. Projected completion date is third quarter of calendar year 1991. First draft of section referenced can be made available from the author upon request.

3. E. J. Barber, Pefforation of Steel in an Abandoned Plant (U), K/ET-459, Union Carbide Corp.-Nuclear Div., Oak Ridge Gaseous Diffusion Plant, Oak Ridge, Tenn., March 11, 1980.

4. S. C. Blue, "Fracture Control of Steel UF 6 Cylinders," in Uranium Hexafluoride-Safe Handiiivis Processing and Transporting--Conference Proceedings, CONF-880558, Martin Marietta Energy Systems, Inc., Oak Ridge Gaseous Diffusion Plant, Oak Ridge, Tenn., May 1988. [6]

5. R. A. Boelens, Martin Marietta Energy Systems, Inc., Portsmouth Gaseous Diffusion Plant, Piketon, Ohio, Weighing Analysis of 4G115688, 829-9119, letter to J. H. DeVan, Martin Marietta Energy Systems, Inc., Oak Ridge Natl. Lab., Oak Ridge, Tenn., Jan. 9, 1991.

6. D. E. Boyd, Martin Marietta Energy Systems, Inc., Portsmouth Gaseous Diffusion Plant, Piketon, Ohio, personal communication to E. I. Barber, Martin Marietta Energy Systems, Inc., Oak Ridge Gaseous Diffusion Plant, Oak Ridge, Tenn., during discussion of attempted and partially successful core sampling of plug in cylinder 4G115688.

7. Yu. A. Buslaev, N. S. Nikolaev, and I. V. Tananaev, "On the Solubility and Composition of the Solid Phases in the System HF-UO ${ }_{3}-\mathrm{H}_{2} \mathrm{O},{ }^{n}$ Akademy of Sciences, USSR 148, 832-34 (1963). [8]

8. A. L. Cardenas, Analysis of a Core Sample for Uranium and for Fluoride, POEF-523-91-34, Martin Marietta Energy Systems, Inc., Portsmouth Gaseous Diffusion Plant, Piketon, Ohio, Feb. 5, 1991.

9. J. H. DeVan, Martin Marietta Energy Systems, Inc., Oak Ridge Natl. Lab., Oak Ridge, Tenn., Committee Recommendations Relating to PORTS Tails Cylinders, 0709/01/90, letter to D. L. Mason, Martin Marietta Energy Systems, Inc., Downtown Concourse, Oak Ridge, Tenn., July 9, 1990. [9] 
10. J. H. DeVan, Martin Marietta Energy Systems, Inc., Oak Ridge Natl. Lab., Oak Ridge, Tenn., Recommendations for Breached Cylinders Investigation, letter to R. A. Boelens, Martin Marietta Energy Systems, Inc., Portsmouth Gaseous Diffusion Plant, Piketon, Ohio, Oct. 30, 1990.

11. J. H. DeVan, Martin Marietta Energy Systems, Inc., Oak Ridge Natl. Lab., Oak Ridge, Tenn., Planning Actions for Empty Cylinder 127985 Evaluation, letter to J. E. Shoemaker, Martin Marietta Energy Systems, Inc., Portsmouth Gaseous Diffusion Plant, Piketon, Chio, Aug. 20, 1990.

12. R. E. Dorning, Martin Marietta Energy Systems, Inc., Portsmouth Gaseous Diffusion Plant, Piketon, Ohio, personal communication to E. J. Barber, Martin Marietta Energy Systems, Inc., Oak Ridge Gaseous Diffusion Plant, Oak Ridge, Tenn., during inspection of the inside of cylinder 4G127985 using a fiber optics video probe.

13. R. E. Dorning, Martin Marietta Energy Systems, Inc., Portsmouth Gaseous Diffusion Plant, Piketon, Ohio, personal communication to E. J. Barber, Martin Marietta Energy Systems, Inc., Oak Ridge Gaseous Diffusion Plant, Oak Ridge, Tenn., on observations made while patching the hole in cylinder $4 \mathrm{G} 115688$ the first time.

14. R. E. Dorning, Status of Support to Breached Tails Cylinder Investigation, POEF-522-90-539, Martin Marietta Energy Systems, Inc., Portsmouth Gaseous Diffusion Plant, Piketon, Ohio, Aug. 1, 1990.

15. R. E. Dorning, Core Sampling of Cylinder \#4G115688, POEF-522-90-767, Martin Marietta Energy Systems, Inc., Portsmouth Gaseous Diffusion Plant, Piketon, Ohio, Nov. 8, 1990.

16. M. L. Glenn, Uranium Hexafluoride Tails Storage Cylinders, KY-657, Union Carbide Corp.Nuclear Div., Paducah Gaseous Diffusion Plant, Paducah, Ky., June 1974. [3]

17. H. M. Henson et al., Monitoring of Corrosion in ORGDP Cylinder Yards, CONF-890601-1, Martin Marietta Energy Systems, Inc., Oak Ridge Natl. Lab., Oak Ridge, Tenn., December 1989. [2]

18. J. H. Hildebrand and R. L. Scott, The Solubility of Nonelectrolytes, Third Edition, Reinhold Publishing Company, New York, 1950.

19. W. E. Hobbs, E. J. Barber, and C. G. Jones, Cold Trapping of Uranium Hexafluoride Containing Hydrogen Fluoride (U), K/ET-501, Union Carbide Corp.-Nuclear Div., Oak Ridge Gaseous Diffusion Plant, Oak Ridge, Tenn., May 23, 1980, CONFIDENTIAL.

20. R. L. Jarry and W. Davis, Jr., The Vapor Pressure, Association and Heat of Vaporization of Hydrogen Fluoride, K-968, Union Carbide Corp.-Nuclear Div., Oak Ridge Gaseous Diffusion Plant, Oak Ridge, Tenn., November 15, 1982. [See also same authors, J. Phys. Chem. 57, 600 (1953).] 
21. R. L. Jarry, F. D. Rosen, C. F. Hale, and W. Davis, Jr., Liquid-Vapor Equilibrium in the System Uranium Hexafluoride-Hydrogen Fluoride $(U)$, K-872, Union Carbide Corp.-Nuclear Div., Oak Ridge Gaseous Diffusion Plant, Oak Ridge, Tenn., March 10, 1952, DECLASSIFIED. [See same authors, J. Phys. Chem. 57, 905 (1953).]

22. T. R. Lemons et al., The Ultimate Disposition of Depleted Uranium, K/ETO-44, Martin Marietta Energy Systems, Inc., Oak Ridge Gaseous Diffusion Plant, Oak Ridge, Tenn., December 1990. [1]

23. R. W. Long, J. H. Hildebrand, and W. E. Morrell, J. Am. Chem. Soc. 69, 1273 (1947).

24. A. J. Mallett, Water Immersion Tests of UF ${ }_{6}$ Cylinders with Simulated Damage, K-D-1987, Union Carbide Corp.-Nuclear Div., Oak Ridge Gaseous Diffusion Plant, Oak Ridge, Tenn., Nov. 7, 1967. [7]

25. D. M. Manuta, Ga, Analysis of Tails Cylinder \#4G115688, POEF-522-90-866, Martin Marietta Energy Systems, Inc., Portsmouth Gaseous Diffusion Plant, Piketon, Ohio, Dec. 18, 1990.

26. D. M. Manuta, Electrochemical and Thermodynamic Analyses of Breached Tails Cylinder Reaction Products, POEF-522-90-541, Martin Marietta Energy Systerns, Inc., Portsmouth Gaseous Diffusion Plant, Piketon, Ohio, Aug. 2, 1990.

27. D. M. Manuta, Analysis of Deposits from Tails Cylinders: An Interpretation of the Additional Data on Unidentified $U$ and Fe Compounds, POEF-522-90-658, Martin Marietta Energy Systems, Inc., Portsmouth Gaseous Diffusion Plant, Piketon, Ohio, Oct. 17, 1990.

28. W. H. McCulla, Determination of the Rate of HF Hydration and the Effects of HF on Moisture Condensation, K/PS-155, Union Carbide Corp.-Nuclear Div., Oak Ridge Gaseous Diffusion Plant, Oak Ridge, Tenn., Apr. 30, 1982.

29. G. D. Oliver, H. T. Milton, and J. W. Grisard, "The Vapor Pressure and Critical Constants of Uranium Hexafluoride," J. Am. Chem. Soc. 75, 2827 (1953).

30. ORGDP Tails Cylinder Overpressure. Data supplied by H. M. Henson and J. K. Keith, Martin Marietta Energy Systems, Inc., Oak Ridge Gaseous Diffusion Plant, Oak Ridge, Tenn.

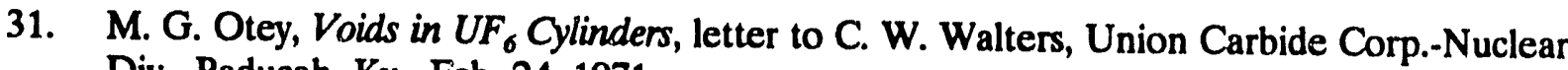
Div., Paducah, Ky., Feb. 24, 1971.

32. M. G. Otey and R. A. LeDoux, "A New Compound in the U-O-F System," J. Inorg. Nucl. Chem. 29, $2249-56$ (1967).

33. PGDP Tails Cylinder Overpressure. Data supplied by R. B. Gross, Martin Marietta Energy Systems, Inc., Paducah Gaseous Diffusion Plant, Paducah, Ky. 
34. P. W. Pickrell, Characterization of the Solid, Airborne Materials Created by the Interaction

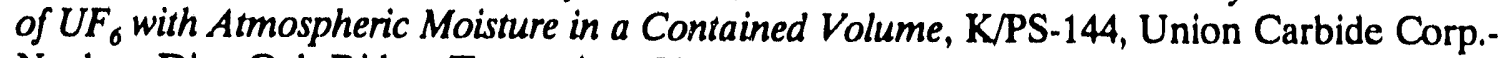
Nuclear Div., Oak Ridge, Tenn., Apr. 30, 1982, p. 13.

35. PORTS Tails Cylinder Overpressure. Data supplied by R. A. Boelens, Martin Marietta Energy Systems, Inc., Portsmouth Gaseous Diffusion Plant, Piketon, Ohio.

36. G. P. Rutledge, R. L. Jarry, and W. Davis, Jr., Freezing Point Diagram and Liquid-Liquid Solubilities in the System Uranium Hexafluoride-Hydrogen Fluoride, K-845, Union Carbide Corp.-Nuclear Div., Oak Ridge Gaseous Diffusion Plant, Oak Ridge, Tenn., Dec. 28, 1951, DECLASSIFIED. [See also same authors, J. Phys. Chem. 57, 541 (1953).]

37. R. J. Schwab, Gas Analysis of Tails Cylinder \#4G127985, POEF-522-90-500, iviartin Marietta Energy Systems, Inc., Portsmouth Gaseous Diffusion Plant, Piketon, Ohio, July 10, 1990.

38. R. J. Schwab, Gas Analysis of Tails Cylinder \#4G115688, POEF-522-90-604, Martin Marietta Energy Systems, Inc., Portsmouth Gaseous Diffusion Plant, Piketon, Ohio, Sept. 12, 1990.

39. W. Schotte, "Fog Formation of Hydrogen Fluoride in Air," Ind. Eng. Chem. Res. 26, 300-306 (1987).

40. D. L. Scott and K. Ralston, Deposits From Tails Cylinders 4G115688, 4G127985, and 4G127902, POEF-522-90-531, Martin Marietta Energy Systems, Inc., Portsmouth Gaseous Diffusion Plant, Piketon, Ohio, July 31, 1990.

41. D. L. Scott and K. Ralston, Core Samples from Breached Cylinder 4G115688, POEF-522-91-9, Martin Marietta Energy Systems, Inc., Portsmouth Gaseous Diffusion Plant, Piketon, Ohio, Jan. 8, 1991.

42. D. L. Scott, Deposits from Tails Cylinders: Additional Data on Unidentified $U$ and Fe Compounds, POEF-522-90-585, Martin Marietta Energy Systems, Inc., Portsmouth Gaseous Diffusion Plant, Piketon, Ohio, Sept. 4, 1990.

43. D. L. Scott, Materials from Breached Cylinder 4G115688, Located at " $C^{m}$ Lot, POEF-522-90-766, Martin Marietta Energy Systems, Inc., Portsmouth Gaseous Diffusion Plant, Piketon, Ohio, Nov. 8, 1990.

44. D. L. Scott, "Core" Samples from Breached Tails Cylinder 4G115688, POEF-522-90-834, Martin Marietta Energy Systems, Inc., Portsmouth Gaseous Diffusion Plant, Piketon, Ohio, Dec. 6, 1990.

45. K. W. Sommerfeld, Martin Marietta Energy Systems, Inc., Uranium Enrichment Central Management, Y-12 Plant, Oak Ridge, Tenn., Tails Cylinder Integrity, letter to Mr. Joe W. Parks, Enriching Operations Division, Department of Energy, DOE Field Office, Oak Ridge, Tenn., June 18, 1990. [5] 
134

46. K. W. Sommerfeld, Martin Marietta Energy Systems, Inc., Uranium Enrichment Central Management, Y-12 Plant, Oak Ridge, Tenn., Activities of the Team to Investigate Tails Cylinder Breaches, letter to Mr. Joe W. Parks, Enriching Operations Division, Department of Energy, DOE Field Office, Oak Ridge, Tenn., July 23, 1990.

47. W. E. Sykes, Martin Marietta Energy Systems, Inc., Paducah Gaseous Diffusion Plant, Paducah, Ky., Response to Recommendations Relating to Failure of PORTS Tails Cylinders, letter to J. H. BeVan, Martin Marietta Energy Systems, Inc., Oak Ridge Natl. Lab., Oak Ridge, Tenn., Dec. 21, 1990. [10]

48. P. W. Wilson, "The Preparation and Properties of Uranium Oxide Tetrafluoride", J. Inorg. Null. Chem. 36, 303-305 (1974). 
APPENDIX C

ACTION PLANS 


\section{ACTION PLAN FOR CYLINDER 4G115688}

Previous action plans have covered the unstacking of cylinders to acces 4 G115688 with the large corrosion hole and preliminary field evaluations prior to unstacking. These evaluations have determined that the adjacent cylinder (4G113241) ear was not in constant contact with the damaged area of $4 \mathrm{G} 115688$, and that the cold pressure of $4 \mathrm{G} 115688$ is above atmospheric pressure at 8.5 psig. A sample of the gas phase has been taken for analysis.

1. Bleed pressure from $4 \mathrm{G} 115688$ through a portable sample buggy with chemical traps to empty cylinders or trapping system depending on results of gas phase analysis to reduce consequences should the corrosion area be bumped during adjacent cylinder unstacking.

2. Unstack adjacent cylinder $4 \mathrm{G} 113241$ being careful not to bump the corrosion area of 4G115688. Emergency response personnel will be on standby to assist in emergency actions if necessary.

3. Conduct ultrasonic thickness measurements on $4 \mathrm{G} 115688$ to determine the overall strength of the cylinder.

4. Determine method of patching the corrosion area and any other devices needed to provide structure to $4 \mathrm{G} 115688$ for unstacking. A permanent patching method may be necessary after unstacking.

5. Apply patch and unstack 4G115688. Provide photographs and video recording as possible.

6. Weigh cylinder with patch and other structural devices still applied.

7. Remove contents from cylinder by feeding, hydı ;zation and other methods as verbally agreeable by the investigating committee.

Revision of the actions above may be necessary as situations are encountered and evaluated. Situations which would effect the corrosion area will be agreed upon at least verbally by the investigating committee.

\begin{tabular}{l} 
Approved $\quad \begin{array}{l}\text { (signature on file) } \\
\text { J. H. DeVan }\end{array}$ \\
Approved $\frac{\text { (signature on file) }}{\text { W. E. Sykes }}$ \\
Approved $\quad$ (signature on file) \\
\hline J. E. Shoemaker, Jr.
\end{tabular}




\section{ACTION PLAN FOR EXAMINATIOI OF TAILS CYLINDER 4G127985}

\section{Introduction}

This 14-ton 5/16-inch walled cylinder was manufactured in 1982 by United Fabricators. The cylinder was constructed of 516 steel. The cylinder was filled in June 1986 and stacked in 1986 in C-Lot where it presently resides on the bottom of row 13, position 44 of Section 3. Approximately 200 cylinders will be unstacked and moved to access this cylinder. An inspection of this cylinder on June 19, 1990, indicated that the cylinder had been damaged in stacking (i.e., dented) with a resulting loss of containment as noted by a minor buildup of uranium-containing salts adjacent to the valve and stiffening ring. The objective of this Action Plan is to provide the foundation for safely and effectively emptying this cylinder. Worker safety will be paramount; health physics personnel will be present at all movement activities.

\section{Action Plan}

1. All of the approximately 200 cylinders will be visually and ultrasonically inspected prior to moving. Approximately 25 ultrasound positions will be mapped on each cylinder to determine overall cylinder integrity.

2. Line management shall verify that approved procedures are available and used in all operations covered by this plan. Also, appropriate training shall be completed and documented.

3. Personnel assigned to field cylinder inspection and moving will have radio communication available for immediate use in the event of need to report a problem or summon help.

4. Code Inspection will approve each cylinder for lifting prior to moving. Any problem beyond the scope of Code Inspection will be referred to the $\mathrm{UF}_{6}$ Safety Handling Committee for resolution. Every cylinder will have an inspection sheet of the cylinder including the cylinder lug orientation and the location of any apparent damage will be noted; particular notations will be made of any lifting lugs in contact with adjacent cylinders. The inspection report will include additional information noted in Appendix $\mathrm{A}$.

5. In the course of the inspections, damaged cylinders (e.g., cylinders with dents) will be noted and photographed, and cylinders will be segregated as to damaged or non-damaged when moved. Damaged cylinders will be stored to allow ready access for non-destructive examination. Damaged cylinders will undergo complete ultrasonic inspections and, where feasible, dye checking of the localized damaged areas.

6. Cylinders will be moved as necessary to provide complete access to cylinder 4G127985 with the exception of the adjacent cylinder (i.e., 4G127902 suspected of causing the damage). Cylinders 4 G127902 and 4 G127985 will not be moved at this time.

7. Photographs and inspections will be made of these two cylinders. The inspections will be made as directed by the Investigating Committee Chairman, Dr. Jack DeVan or his representative. 
8. Cylinder 4G127902 will be moved and photographs will be taken of the damaged cylinder; then, the cylinder and surrounding area will be decontaminated. Photographs will be taken of the decontaminated cylinder.

9. The damage to the cylinder will be examined and Engineering evaluations will be carried out specifying handling and repair procedures prior to proceeding.

Approved

Approved

Approved (signature on file)

J. H. DeVan

(signature on file)

W. E. Sykes

(signature on file)

J. E. Shoemaker, Jr. 


\section{ACTION PLAN FOR FIELD EVALUATION OF CYLINDER 4G127985}

Purpose: This plan outlines the actions to be taken after access to the damaged cylinder (4G127985) has been achieved. This plan is a tentative plan with some flexibility/alternatives to handle the more likely situations encountered. The overall intent of this plan is to preserve the evidence while maintaining personnel safety and minimizing the impact to the environment. This plan is an extension of the previously approved plan which permitted the removal of tails cylinders to gain access to the damaged cylinder (4G127985) and the adjacent cylinder (4G127902) suspected of inflicting the damage.

1. Obtain cold pressure measurement on the cylinder. Gas sample the cylinder for infrared and mass spectroscopy analyses, if possible. If pressure is above atmosphere, bleed down to atmosphere using chemical traps prior to moving adjacent cylinder.

2. The failure site will be documented (photographed) prior to moving the adjacent cylinder (4G127902) as to the relative location of the two cylinders, the extent of damage to cylinder $4 \mathrm{G127985}$, and the extent of deposits/reaction products visible. Samples of the deposits/reaction products will be obtained provided that only minimal disturbance to the failure site occurs.

3. After visual and ultrasonic inspection to determine cylinder integrity and following the precautions previously outlined, the adjacent cylinder (4G127902) will be relocated.

4. The removal of the adjacent cylinder and the failure will be photographed for documentation as well as being witnessed by the investigating committee.

5. The deposits/reaction products will be collected for analysis from the adjacent cylinder, ground, and the damaged cylinder, if applicable. The investigating committee will be at the site to oversee and direct this activity.

6. Visual and ultrasonic thickness measurements will be taken to determine the extent of damage as well as the patching requirements.

7. Patch the cylinder for movement/cold feeding. Depending upon the nature of the cylinder shell breach, the area will be prepared and patched. The preferred patch will consist of an oversized patch epoxy sealed to the cylinder. Every attempt will be made to exclude epoxy from contacting the failed surfaces. Dr. John Barber has suggested a teflon layer or possibly a teflon spray coating to be placed over the failed surfaces.

8. Material from the adjacent cylinder (4G127902) offending lifting lug will be obtained for metallurgical evaluation including compositional analysis and microstructural analysis.

Adjacent cylinder could not be moved. Cylinder 4G127985 will be moved to free it from adjacent cylinder. 
9. Cylinder 4G127985 will be prepared and emptied. The cylinder will either be transferred to another cylinder or fed to the cascade in accordance with approved special procedures depending upon the overall condition of the cylinder.

10. After emptying, the cylinder will be filled with dry air or nitrogen, the valve removed, and the cylinder inspected internally using the Welch-Allen video system. If possible, deposit/reaction product samples will be collected.

11. The cylinder will be cleaned and made available for destructive testing to aid in identifying the cause of failure.

Approved

(signature on file)

J. E. Shoemaker, Jr.

Approved

(signature on file)

J. H. DeVan

Approved

(signature on file)

W. E. Sykes 


\section{ACTION PLAN TO FEED CYLINDER 4G127985}

Concurrence is given to cold feed cylinder $4 G 127985$ to the Portsmouth cascade in accordance with the prepared Operational Change Memo (OCM) CN 9.5-7, Add 7, titled "Cold Feeding Tails Cylinder Material to the Cascade," dates 7/17/90.

In addition to the provisions of the OCM, the following two actions will be included:

1. Inspect the patch when recording cylinder weight in item 4 of the OCM.

2. Evaluate the feed rate and overall time to empty the cylinder versus alternative methods of cold feeding in an autoclave.

Approved (signature on file)

W. E. Sykes

Approved (signature on file)

J. H. DeVan

Approved (signature on file)

J. E. Shoemaker, Jr. 


\section{ACTION PLAN FOR CYLINDER 4G115688 FIELD EVALUATION}

In an effort to initiate the evaluation of cylinder $4 \mathrm{G} 115688$ in a timely fashion, field evaluation and material sampling of the adjacent cylinder will be conducted following Health Physics personnel protection requirements.

1. Preliminary measurements will be conducted to determine the location of the adjacent cylinder lifting lug in reference to the projected outer surface of cylinder $4 \mathrm{G} 115688$ shell.

2. Ultrasonic thickness measurements will be taken in the vicinity of the hole to map out the cylinder thinning to the extent possible prior to cylinder unstacking. More inclusive work will be performed after gaining access to the cylinder by removing surrounding cylinders.

3. Material for metallurgical analysis (less than 1-inch ${ }^{2}$ ) will be taken from the adjacent cylinder lifting lug to allow for determination of composition and microstructure. The failure site will not be disturbed during material removal.

4. Cylinder 4G115688 will be cold pressure checked and a gas sample collected, if possible.

5. The contents of the recovered material (approximately 17 pounds) will be sent to the laboratory for sampling and identification using X-ray techniques (diffraction and fluorescence). This material was initially collected in buckets at the failure site (from the cylinder surface, the cylinder beneath the failure location, and the ground) and later transferred to accountability containers in X-744G. The material will also be evaluated to determine the water solubility using rain water or distilled water if rain water is not available.

Approved (signature on file)

J. E. Shoemaker, Jr.

Approved (signature on file) W. E. Sykes

Approved (signature on file) J. H. DeVan 


\section{UNSTACKING ACTION PLAN FOR ACCESS TO 4G115688}

This action plan provides for the unstacking of approximately seventy cylinders in $745 \mathrm{C}$ section 01 , row 20 and 24 to gain access to cylinder $4 \mathrm{G} 115688$ with the large corroded opening. Cylinder 4G115688 resides in position 15 on the top shelf of row 20 from the south end of the row. The adjacent cylinder to the south, 4G113241 with the potential impacting lifting lug, will also remain in place for further evaluation. Unstacking operations will involve a mobile crane with special bellyhand lifting fixture.

1. Line management shall verify that all equipment and personnel involved in the unstacking operation are qualified. This includes certification of the mobile crane and lifting fixture as well as maintenance personnel.

2. Approximately 25 ultrasonic test readings will be performed on the cylinders to be unstacked by Code Inspection. Documentation of the measurements will be recorded.

3. Notations of lifting lugs in contact with adjacent cylinder walls will be noted on the ultrasonic thickness document.

4. Code Inspection will be present during $b$ unstacking operation to further verify or test cylinder integrity due to the age of these cy...ders.

5. Cylinders noted with any damage will be segregated for further ultrasonic thickness measurements and evaluation.

6. Adjacent cylinder 4G113241 will not be unstacked to gain access to $4 \mathrm{G} 115688$ at this time. The previous field evaluation action plan for $4 \mathrm{G} 115688$ involves measurements on the proximity of the ear and cylinder wall.

Approved

Approved

Approved (signature on file)

W. E. Sykes

(signature on file)

J. H. DeVan

(signature on file)

J. E. Shoemaker, Jr. 
POEF-2086

ORNL/TM-11988

\section{INTERNAL DISTRIBUTION}

1-2. Central Research Library

3. Document Reference Section

4-5. Laboratory Records Department

6. Laboratory Records, ORNL-RC

7. ORNL Patent Section

8-10. M\&C Records Office

11. J. H. Alderson

12. E. J. Barber

13. C. R. Barlow

14. G. A. Bazzell

15. G. C. Bell

16. M. E. Bennett

17. S. C. Biue

18. R. A. Boelens

19. D. E. Boyd

20. J. T. Bradbury

21. C. R. Brinkman

22. T. R. Butler

23. D. F. Craig

24. J. G. Crawford

25-29. J. H. DeVan

30. J. R. DiStefano

31. R. E. Dorning

32. R. H. Dyer

33. R. S. Eby

34. C. D. Ecklund

35. R. L. Faulkner

36. J. M. Googin

37. R. A. Green

38. V. M. Green

39. P. J. Gross

40. F. M. Haggag

41. J. C. Hall
42. H. M. Henson

43. J. Horak

44. P. S. Johnson

45. M. J. Kania

46. J. R. Keiser

47. G. W. Lamb

48. T. R. Lemons

49. D. L. Mason

50. R. D. McDermott

51. W. D. Netzer

52. V. S. Newman

53. W. W. Ogg

54. J. W. Parks

55. S. A. Polston

56. R. R. Rawl

57. J. D. Rothrock

58. J. E. Rushton

59-63. J. R. Russell

64. C. W. Sheward

65. J. E. Shoemaker, Jr.

66. G. M. Slaughter

67. K. W. Sommerfeld

68. R. V. Stachowick

69. J. J. Staley

70. W. E. Sykes

71-80. M. S. Taylor

81. D. A. Towne

82. J. P. Vournazos

83. S. J. Walker

84. C. W. Walter

85. D. L. Weishaar

86. D. F. Wilson 


\section{EXTERNAL DISTRIBUTION}

87. JOHN W. ARENDT ASSOCIATES, INC., 109 Caldwell Drive, Oak Ridge, TN 37830

J. W. Arendt

88. MIB TECHNICAL ASSOCIATES, 114 Regent Circle, Oak Ridge, TN 37830

K. T. Ziehlke

89. PAI CORPORATION, 116 Milan Way, Oak Ridge, TN 37830

W. A. Pryor

90-91. TECHNICAL LIBRARY, Portsmouth Gaseous Diffusion Plant,

P.O. Box 628, Piketon, OH 45661-1213

92-95. DOE, 19901 Germantown Rd., Germantown, MD 20874

R. W. Barber (EH-36)

C. A. Caves (NE-33)

P. G. Sewell (NE-30)

D. C. Thomas (NE-33)

96. DOE, 1000 Independence Ave., S.W. Washington, DC 20585

L. P. Duffy (EM-1)

97. DOE/PEO, Portsmouth Gaseous Diffusion Plant, P.O. Box 628,

Piketon, OH 45661-1213

E. W. Gillespie

98. DOE, OFFICE OF URANIUM ENRICHMENT, 19901 Germantown Rd., Germantown. MD 20874

J. W. Bennett (NE-33)

99-108. DOE, OFFICE OF SCIENTIFIC AND TECHNICAL INFORMATION, P.O. Box 62, Oak Ridge, TN 37831 

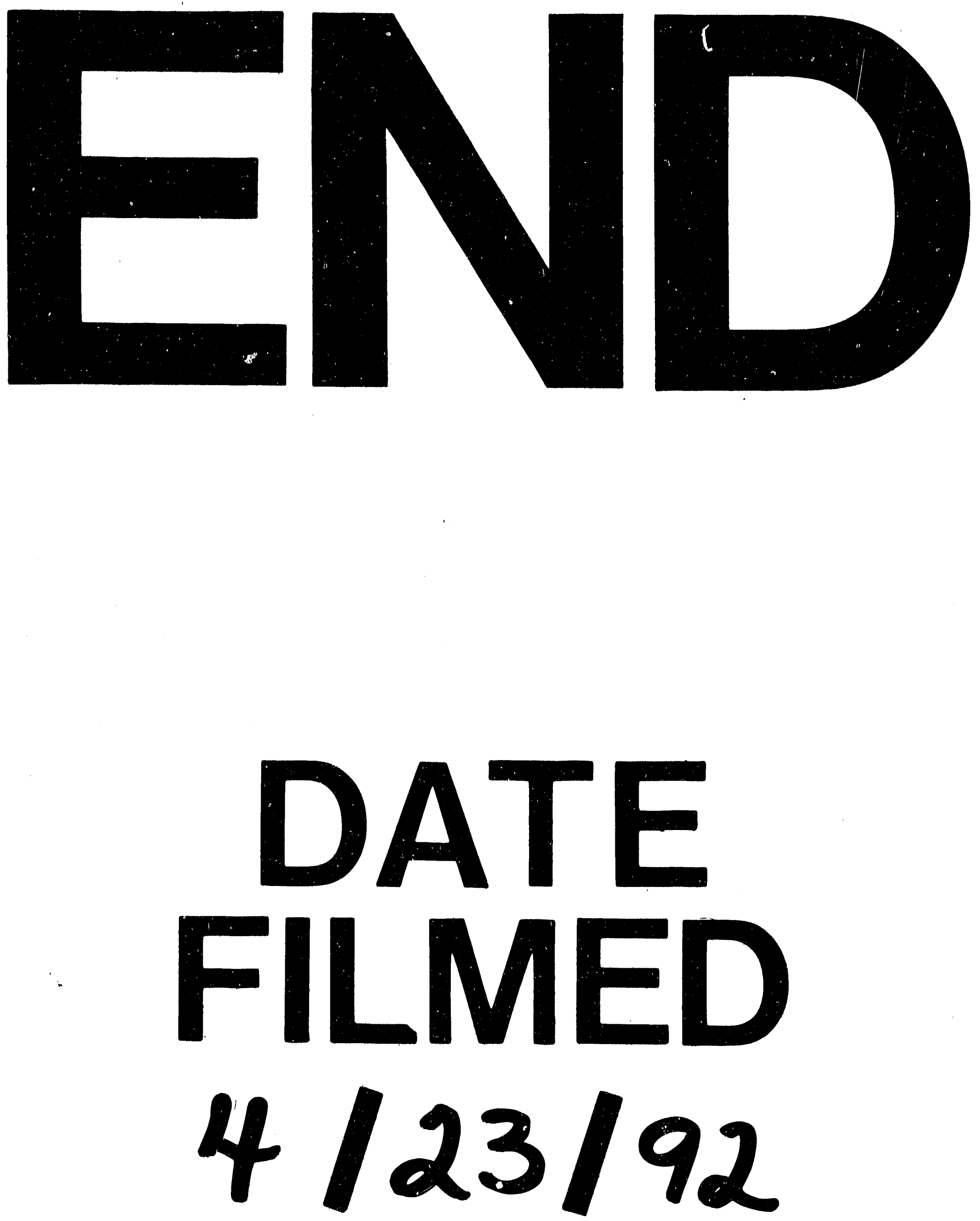
